University of Rhode Island

DigitalCommons@URI

Open Access Master's Theses

2013

\title{
Tuning Intermolecular Interactions to Enhance Solid-State Nanopore Force Spectroscopy
}

Elaine Foun

University of Rhode Island, lainyytf@yahoo.com

Follow this and additional works at: https://digitalcommons.uri.edu/theses

\section{Recommended Citation}

Foun, Elaine, "Tuning Intermolecular Interactions to Enhance Solid-State Nanopore Force Spectroscopy" (2013). Open Access Master's Theses. Paper 50.

https://digitalcommons.uri.edu/theses/50

This Thesis is brought to you for free and open access by DigitalCommons@URI. It has been accepted for inclusion in Open Access Master's Theses by an authorized administrator of DigitalCommons@URI. For more information, please contact digitalcommons-group@uri.edu. 
TUNING INTERMOLECULAR INTERACTIONS TO

ENHANCE SOLID-STATE NANOPORE FORCE

SPECTROSCOPY

BY

ELAINE FOUN

A THESIS SUBMITTED IN PARTIAL FULFILLMENT OF THE

REQUIREMENTS FOR THE DEGREE OF

MASTERS OF SCIENCE

IN

CHEMISTRY

UNIVERSITY OF RHODE ISLAND 


\title{
MASTER OF CHEMISTRY THESIS
}

OF

ELAINE FOUN

\section{APPROVED:}

Thesis Committee:

\author{
Major Professor Jason R. Dwyer \\ Radha Narayanan \\ Keunhan Park \\ Nasser H. Zawia \\ DEAN OF THE GRADUATE SCHOOL
}

\section{UNIVERSITY OF RHODE ISLAND}

2013 


\begin{abstract}
Nanopores, nanometer sized holes in membranes, have recently come into prominence as tools for single molecule sensing. A technique called nanopore force spectroscopy uses the nanopore to probe energy landscapes between molecules. With the development of this technique, it will be possible for molecular recognition in complex fluids, such as blood. However, before that can be possible, solid-state nanopores, commonly fabricated in silicon nitride membranes, and having very confined sizes and charged surfaces, need to be optimized to minimize unwanted interactions between solution-phase molecules and the surface. DNA, for example, a crucial part of nanopore force spectroscopy, frequently sticks to the nanopore surface. Surface functionalization techniques, both on the nanopore and molecular surface, were attempted in this thesis work. These surface functionalization methods aimed to reduce surface charge or alter molecular properties in order to minimize the unwanted surface interactions, and they include silane modification, fluid lipid bilayer coating, and surfactant self-assembly on the DNA phosphate backbone. Results from some of these methods yield insights to improve nanopore force spectroscopy performance that will minimize the unwanted surface interactions and deliver on the promise of nanopore sensing.
\end{abstract}




\section{ACKNOWLEDGMENTS}

Since the summer of 2010, Dr. Jason R. Dwyer has given me a wonderful opportunity to work in his group, and for all his patience and guidance, I would like to give a million thanks. Dr. Dwyer encourages his students to reach their full potential, not only in science, but in life as well, through interesting and amusing anecdotes.

I could not have done any of this without my fellow group members, who provided insight and discussion to the many challenges I was met with in the lab, as well as fabulous conversation, humor, and spontaneous singing and dancing. Thank you to Julie Whelan, Cameron Frament, Caitlin Ross, Daniel Wilson, Lucas Ginsberg, and Ian Thompkins. I hope the newer members of our group, Nuwan Bandara and Buddini Karawdeniya, will have a fulfilling time in the group. I would also like to acknowledge past members who have helped me as well, Brian Kite and Elsa Ortega.

Thank you to Dr. Radha Narayanan, Dr. Keunhan Park, and Dr. Aftab Ahmed for serving on my committee. I would like to express my gratitude to the individuals who have inspired my pursuit of science. Dr. Paul L. Dubin has given excellent guidance that led me to pursue research. Dr. Tan-yun Cheng has been a supportive mentor and role model, showing how a woman can be a great scientist.

Thank you to my parents, Danny and Shuming, and my sister, Amanda, as well as all of my extended family members for never failing to ask, "When will you be done?" This question was one of my biggest motivators.

Finally, I dedicate this to all the accountants who have ever wanted to be scientists. 


\section{TABLE OF CONTENTS}

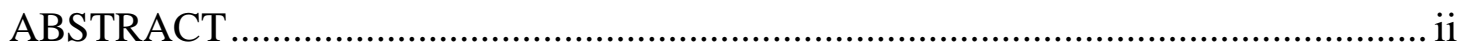

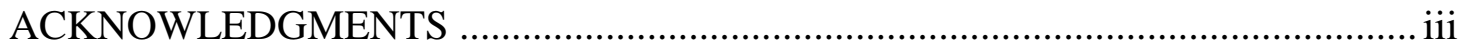

TABLE OF CONTENTS .......................................................................... iv

LIST OF TABLES …............................................................................. vi

LIST OF FIGURES .............................................................................. vii

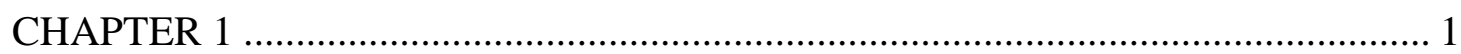

INTRODUCTION AND BACKGROUND ....................................................... 1

1.1. Single Molecule Sensing and the Promise of Nanopores................................ 1

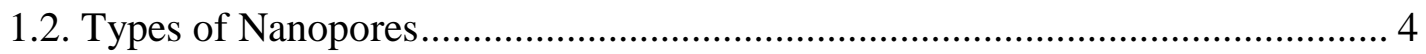

1.3 Solid-State Nanopore Fabrication ........................................................... 5

1.4 General Overview of Nanopore Sensing ................................................. 7

1.5. Nanopore Force Spectroscopy (NFS) ..................................................... 11

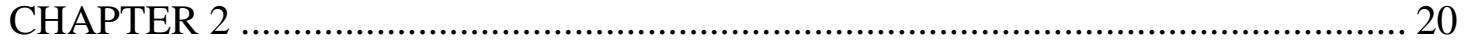

CHARACTERIZING NANOPORE SENSING PERFORMANCE ......................... 20

2.1. Preparation of a Nanopore and Laboratory Set Up ...................................... 20

2.2. Current Characterization of Nanopores ........................................................ 24

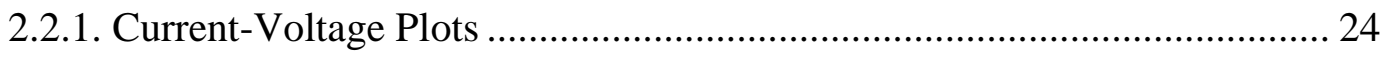

2.2.2. Current Trace Measurements ................................................................. 30

2.3. Detection of Molecules with Bare Silicon Nitride Pores ................................. 36

2.3.1. Detection of 5-(and-6)-Carboxyfluorescein Dye ...................................... 36

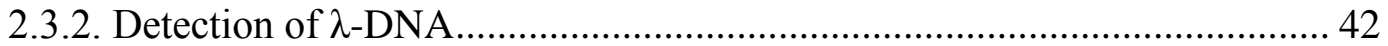

2.4. Clearing a Clogged Silicon Nitride Nanopore ............................................. 45

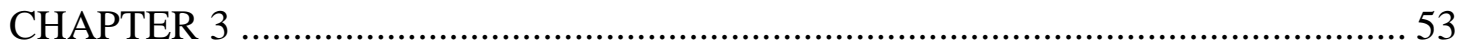

SURFACE FUNCTIONALIZATION OF A NANOPORE ...................................... 53

3.1. Nanopore Surface Functionalization with Silane ......................................... 53 
3.1.1. Silane Functionalization Methods ........................................................ 55

3.1.2. Probe DNA Construct Preparation ........................................................ 59

3.1.3. Characterization of Probe DNA Construct in the Silane-Coated Pore ....... 60

3.2. Nanopore Surface Functionalization with a Fluid Lipid Bilayer .................... 61

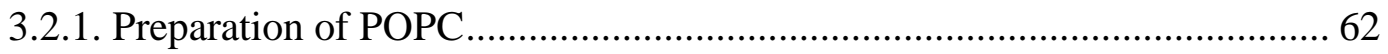

3.2.2. Formation of a Fluid Lipid Bilayer on the Nanopore .............................. 62

3.3. Formation of a Lipid Bilayer in a Solid-State Pore with the Nanion ................ 69

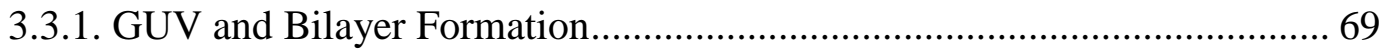

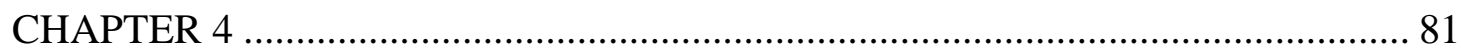

MOLECULAR SURFACE FUNCTIONALIZATION TO ENHANCE NFS

PERFORMANCE ............................................................................ 81

4.1. The Promise of Solving DNA Sticking with a Cationic Surfactant ................. 81

4.2. Preparation of the CTAB:DNA Complexes .................................................. 85

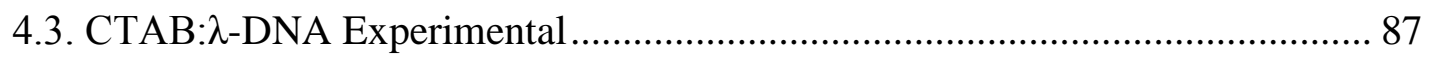

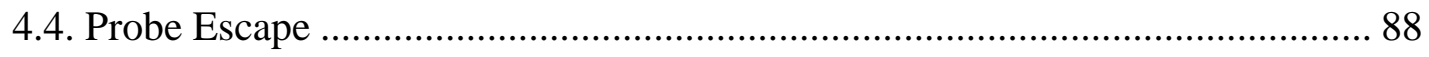

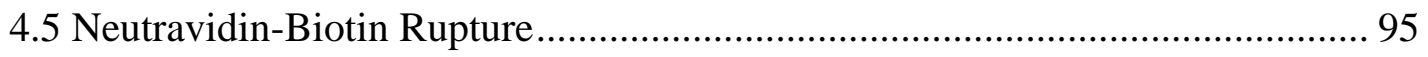

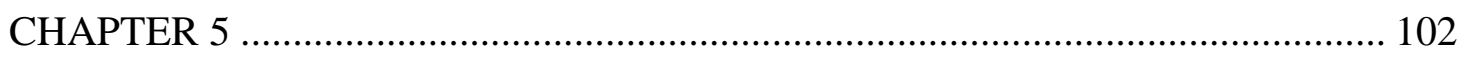

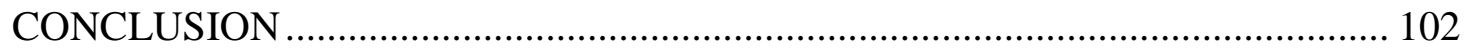

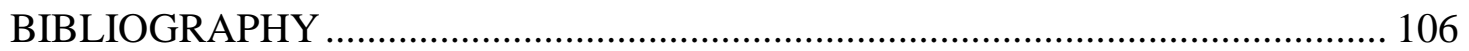




\section{LIST OF TABLES}

Table

Page

\section{Chapter 2}

Table 1. The relative rate of current drift $\left(\mathrm{I}_{\mathrm{t}}^{\mathrm{d}}\right)$ for scans of 30 minutes, calculated from

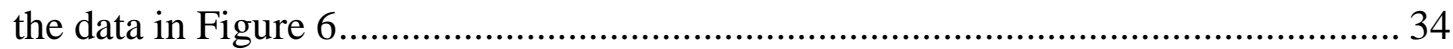

\section{Chapter 4}

Table 1. A table of the concentrations of CTAB used to make each ratio of number of CTAB molecules to the number of base pairs in $\lambda$-DNA for a $\lambda$-DNA concentration of

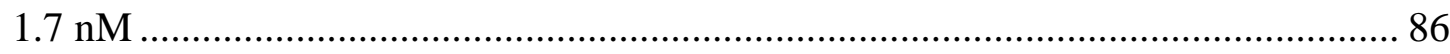




\section{LIST OF FIGURES}

Figure

Page

\section{Chapter 1}

Figure 1. A) Nanopores milled with a correctly configured electron beam typically have a conical-cylindrical profile and B) helium-ion-milled pores typically have a cylindrical pore shape..

Figure 2. The silicon nitride chip (1) is placed between two silicone elastomer gaskets (2), and placed between the two halves of an electrochemical cell (3) in the channel connecting the two liquid reservoirs (4). In the assembled electrochemical cell (5), the electrodes are placed in the liquid reservoirs that hold the electrolyte (6)................. 9 Figure 3. When a voltage is applied, a current passes through the pore (the open current.) When a molecule enters that pore, the current may decrease (the blockage.) In this case, a negative voltage $(-200 \mathrm{mV})$ is applied, so that the $170 \mathrm{~ms}$, about 1000 pA blockage is shown as a rise towards 0 pA.

Figure 4. The probe DNA construct (not drawn to scale), where an avidin molecule is linked to a biotinylated-DNA strand. The DNA strand has a spacer to prevent misfolding and contains a probe sequence at the end which is complementary to the analyte DNA sequence. 
Figure 5. A schematic depiction of nanopore force spectroscopy (not drawn to scale). From left to right, the avidin is attached to a long biotinylated-DNA strand. With an applied voltage the long strand is driven into the pore, and an analyte molecule attaches, once the applied voltage is reversed, the DNA and the analyte will dissociate from the DNA as it is driven back to its original side. 14

\section{Chapter 2}

Figure 1. The laboratory set-up of (A) the electrochemical cell (1) with $\mathrm{Ag} / \mathrm{AgCl}$ electrodes (2) on either side, which is placed in (B) a primary aluminum (3) and (C) secondary copper Faraday cage (4), and attached to a patch clamp amplifier (5) and placed on a vibration isolation table. 23

Figure 2. A representative current-voltage (IV) plot of a $4.5 \mathrm{~nm}$ pore in a $\mathrm{pH} 7$ aqueous solution of $1 \mathrm{M} \mathrm{KCl}$ and $10 \mathrm{mM}$ HEPES. From this plot, the slope will give the conductance. 25

Figure 3. The presence of charges on the nanopore surface has a profound influence on the distribution of ions in the nanopore. The consequence is that the ions can be categorized as being in either a "surface zone" near the surface, or in bulk solution. Ions in each zone have different conductivities as a result of their environment. ...... 26 
Figure 4. An IV curve can show contamination, any unwanted molecule, inside the pore. This is indicated by the asymmetrical nature of the curve. It is possible to distinguish which side of the nanopore is contaminated by looking at if the positive or negative voltage is asymmetrical. In this case, a $4.5 \mathrm{~nm}$ pore in a $\mathrm{pH} 7$ aqueous solution containing $1 \mathrm{M} \mathrm{KCl}$ and $10 \mathrm{mM}$ HEPES, both sides display a curvature, indicating that both sides are contaminated. 29

Figure 5. A current trace can reveal how stable the pore is. Here is a current sample from a conical-cylindrical shaped $4.4 \mathrm{~nm}$ sized pore in a $30 \mathrm{~nm}$ thick silicon nitride chip in an aqueous solution of $0.1 \mathrm{M} \mathrm{KCl}$ buffered to $\mathrm{pH} 7.4$ with $10 \mathrm{mM}$ HEPES with $-200 \mathrm{mV}$ applied voltage. It can be noted that there can be slight changes in the current due to noise or possible contaminants. A) The pore is clean and stable, while B) the fluctuation of current reveals that there is something in the pore. 
Figure 6. Data of the drifting tests were run in an $8 \mathrm{~nm}$ nanopore in a $\mathrm{pH} 7$ aqueous solution of $1 \mathrm{M} \mathrm{KCl}$ and $10 \mathrm{mM}$ HEPES. In A, the continuous $200 \mathrm{mV}$ (black line) was applied first and the 3 seconds of applied $200 \mathrm{mV}$ every minute (green circles) was done after. Both of these current traces were followed by a one minute current trace with $200 \mathrm{mV}$ applied voltage (red filled squares and blue triangles, respectively). In $\mathrm{B}$, the continuous $200 \mathrm{mV}$ (black line) was applied second and the 3 seconds of applied $200 \mathrm{mV}$ (green circles), which was fit with a Gaussian curvature to smooth the data (red line), was done first. Both of these current traces were followed by a one minute current trace with $200 \mathrm{mV}$ applied voltage (red filled squares and blue triangles, respectively). In $\mathrm{C}$, a one minute current trace was applied before (blue line) and after (red open squares) a 30 minute waiting period, where the electrodes sat in the electrochemical cell without any interference. All these indicate that drifting happens.

Figure 7. 5-carboxyfluorescein dye (left) and 6-carboxyfluorescein dye (right)....... 38 
Figure 8 . In an $11 \mathrm{~nm}$ pore with $100 \mu \mathrm{L}$ of $1 \times 10^{-8} \mathrm{M} 5$-(and-6)-carboxyfluorescein dye injected into one $0.5 \mathrm{~mL}$ well containing a $\mathrm{pH} 6.99$ aqueous solution of $0.1 \mathrm{M}$ $\mathrm{KCl}$, and $10 \mathrm{mM}$ HEPES at an applied voltage of $-500 \mathrm{mV}$, there were two types of blockages. The figures show the two types of current blockages characteristic of the detection signals; the event durations are not representative of each type but are drawn from broad event duration distributions. Figure A shows a two-step blockage. The deeper blockage at the end is a signature of 5-(and-6)-carboxyfluorescein dye in this pore, and could indicate that the molecule may stay around the entrance of the pore before inserting all the way. Figure B shows a one-step blockage with the typical blockage depth. 40

Figure 9. Histogram of the event blockage ratio and the event duration of a concentration of $1 \times 10^{-6} \mathrm{M}$ dye molecules through an $11 \mathrm{~nm}$ nanopore in a $\mathrm{pH} 6.99$ aqueous solution of $0.1 \mathrm{M} \mathrm{KCl}$ and $10 \mathrm{mM}$ HEPES run with an applied voltage of $-300 \mathrm{mV}$, where average $\mathrm{I} / \mathrm{I}_{0}$ is the depth of the blockage, where $\mathrm{I}$ is the blocked current and $\mathrm{I}_{0}$ is the open current. 41

Figure 10. A $\lambda$-DNA event at $+50 \mathrm{mV}$ applied voltage through a $25 \mathrm{~nm}$ pore with a $\mathrm{pH}$ 7 aqueous solution of $1 \mathrm{M} \mathrm{KCl}$ and $10 \mathrm{mM}$ HEPES in which $5 \mu \mathrm{L}$ of a diluted $\lambda$-DNA solution $\left(10 \mu \mathrm{L}\right.$ of $500 \frac{\mathrm{mg}}{\mathrm{mL}} \lambda$-DNA in $10 \mathrm{mM}$ Tris- $\mathrm{HCl}(\mathrm{pH} 8.0), 1 \mathrm{mM}$ EDTA into 10 $\mu \mathrm{L}$ of a pH 7 aqueous solution of $2 \mathrm{M} \mathrm{KCl}$ and $20 \mathrm{mM}$ HEPES and $80 \mu \mathrm{L}$ of a pH 7 aqueous solution of $1 \mathrm{M} \mathrm{KCl}$ and $10 \mathrm{mM}$ HEPES) was injected into both sides of the pore to give a concentration of $16.8 \mathrm{pM}$ in the well. 
Figure 11. A Teflon chip holder designed for Nanostrip solution cleaning to reduce handling damage. The Teflon is stable in the Nanostrip solution so it will not degrade. The silicon nitride chip is sandwiched between two Teflon pieces (A) and they are screwed together with Teflon screws (B). The holder with the chip is submerged into the Nanostrip solution.

\section{Chapter 3}

Figure 1. A) Methoxyethoxyundecyltrichlorosilane (1) was used in an effort to coat pores and is a B) polyethylene glycol (PEG) type molecule. 54

Figure 2. A) An ideal depiction of what a silane-coated nanopore will look like. B) A depiction of what could happen when $\mathbf{1}$ polymerizes the pore. 58

Figure 3. Before and after injection of $2 \mathrm{mM}$ POPC to one side of a well with a $\mathrm{pH} 7.0$ aqueous solution of $1.0 \mathrm{M} \mathrm{KCl}$ and $10 \mathrm{mM}$ HEPES. A) Before POPC the pore size is shown to be about $41 \mathrm{~nm}$, and the IV curve is very linear. B) After POPC, the pore size decreases to about $18 \mathrm{~nm}$, and the IV curve is bent indicating that something is in the pore. 64

Figure 4. An example of a current blockage of $33 \mathrm{pM}$ of $\lambda$-DNA in an $18 \mathrm{~nm}$ sized nanopore in an electrochemical cell with containing a $\mathrm{pH} 7$ aqueous solution of $1 \mathrm{M}$ $\mathrm{KCl}$ and $10 \mathrm{mM}$ HEPES. While this particular blockage duration was about 6 seconds, the mean blockage duration was about 1 second, which is longer than blockages of $\lambda$-DNA on bare silicon nitride pores. Even though the duration varied, the blockage depth for all the blockages remained essentially the same. 
Figure 5. Histogram of the event blockage depth and the event duration of a concentration of $33 \mathrm{pM}$ of $\lambda$-DNA through an $18 \mathrm{~nm}$ nanopore coated with a POPC lipid bilayer in a pH 7 aqueous solution of $1 \mathrm{M} \mathrm{KCl}$ and $10 \mathrm{mM}$ HEPES run with an applied voltage of $-200 \mathrm{mV}$, where average $\mathrm{I} / \mathrm{I}_{0}$ is the depth of the blockage, where $\mathrm{I}$ is the blocked current and $\mathrm{I}_{0}$ is the open current 68 Figure 6. The Nanion Vesticle Prep Pro an instrument that automates electroswelling process to make GUVs. The lipids and d-sorbitol are placed in an O-ring sandwiched between two conductive glass slides (1), where an alternating voltage of $\pm 3.0 \mathrm{~V}$ and frequency of $5.0 \mathrm{~Hz}$ applied over was applied for 2 hours at $36^{\circ} \mathrm{C}$ to create the GUVs.

Figure 7. The GUVs formed by the Nanion Vesticle Prep Pro are aggregated (A), when lipids clump together, or (B) "good”, single round GUVs. 72

Figure 8. The Nanion Port-a-Patch system for the systematic formation of lipid bilayers. The chip (1) with a 3-5 M $\Omega$ resistance micropore in the center, where electrolyte is placed, is screwed on so that the electrodes (2 and 3) will be touching solution on either side of the micropore. This system will apply a cross-pore pressure to help form the bilayer across the micropore. 74

Figure 9. An IV-curve of the glass micropore with a $\mathrm{pH}$ gradient from 7 on the top and 6 on the bottom in an aqueous solution of $0.1 \mathrm{M} \mathrm{KCl}$, and $10 \mathrm{mM}$ HEPES. The conductance, from the slope, is $205.04 \mathrm{nS}$. 75 
Figure 10. An IV-curve of the glass micropore with a $\mathrm{pH}$ gradient from 7 on the top and 6 on the bottom in an aqueous solution of $0.1 \mathrm{M} \mathrm{KCl}$, and $10 \mathrm{mM}$ HEPES after the formation of a bilayer displays an almost flat line, very close to $0 \mathrm{pA}$ at all applied voltages, indicating a bilayer. The red dots are the standard deviation. 76

\section{Chapter 4}

Figure 1. Cetyltrimethylammonium bromide (CTAB) may allow for charge neutralization on the DNA molecule as well as creating a more rigid structure affecting how the DNA molecule enters into the pore. Before DNA was a very flexible polymer, as shown on the left, but, as modeled on the right, the DNA becomes a more rigid structure once the CTAB is attached. Also, as the model shows, it is evident that the CTAB will also increase the diameter of the DNA molecule (diameter of DNA is about $2 \mathrm{~nm}^{73}$ and of CTAB is $2.2 \mathrm{~nm}^{77}$ ), allowing for size modification of a molecule. Not drawn to scale. 84

Figure 2. The probe-DNA construct on the left, as shown in Chapter 1 (Section 3.1.2 for details about sequence and preparation). An avidin molecule is linked to a biotinylated-DNA strand, which has a DNA spacer to prevent misfolding and contains a probe sequence at the end which is complementary to the analyte DNA sequence. On the right, a model of what the probe-DNA contract with CTAB attached might look like. Not drawn to scale. 90 
Figure 3. A schematic of probe escape. At 1, the probe is on one side of the pore and the capture voltage is applied to drive it into the pore. The probe molecule is not in the pore, as indicated by the open current. At 2, the probe has entered the pore, as indicated by a decrease in current, and from there the applied voltage is lowered to the hold voltage to allow the probe the escape the pore. At 3, the probe molecule escapes at the hold voltage, as indicated by the increase in current, at which point, the voltage is returned to the original capture voltage in order to capture another probe molecule.

92

Figure 4. A schematic of neutravidin-biotin bond rupture. At A, the probe DNA molecule, tethered to a neutravidin protein via a biotin linkage, is on one side of the pore and a voltage is applied, which will lead to $\mathrm{B}$, where the applied voltage has driven the probe DNA construct into the pore, thus decreasing the current. After a period of time, the applied force will break the neutravidin-biotin bond as shown in $\mathrm{C}$, and this will cause the pore to be clear again, leading to an open current once again at D. 97

Figure 5. One of the rupture events captured at an applied voltage of $-500 \mathrm{mV}$ with $100 \mathrm{nM}$ probe DNA in an electrochemical cell with a $\mathrm{pH} 7$ aqueous solution of $1 \mathrm{M}$ $\mathrm{KCl}$ and $10 \mathrm{mM}$ HEPES. 98

Figure 6. Distribution of the dissociation times at $500 \mathrm{mV}$ for probe DNA molecules with CTAB attached with the ratio of 30 CTAB to 94 bases at a concentration in the nanopore well of $100 \mathrm{nM}$ (Blue) compared to the values from the literature ${ }^{80}$ without CTAB (red) in a pH 7 aqueous solution of $1 \mathrm{M} \mathrm{KCl}$ and $10 \mathrm{mM}$ HEPES. 100 


\section{CHAPTER 1}

\section{INTRODUCTION AND BACKGROUND}

\subsection{Single Molecule Sensing and the Promise of Nanopores}

Understanding biological and chemical processes is fundamental to our understanding of how organisms function. This function, carried out through complex biochemical pathways, depends on the ability of molecules to interact in specific, reproducible, and well-defined ways. Molecular-level understanding of these complex biochemical processes can begin to be had through detailed investigations of the physicochemical properties and behaviors of individual molecules and their interactions. Studies of molecular interactions have increased our understanding of enzyme kinetics, such as those of DNA polymerase, ${ }^{1}$ and of molecular recognition processes, such as those that govern antibody-antigen interactions. ${ }^{2}$ This understanding of molecular interactions has allowed us to harness these molecules for applications and processes. ${ }^{3}$ For instance, enzyme-linked immunosorbent assay (ELISA) employs detailed knowledge of enzyme kinetics and molecular recognition, because the technique depends both on specific antibody-antigen interactions and on enzyme-based signal amplification. In fact, extending these principles has led to the design of artificial antibodies, known as aptamers. Aptamers are DNA or RNA segments that selectively bind to a specific molecule. ${ }^{4}$ Once the best aptamer for a target molecule is found, it can be synthesized in great quantities with high quality control. $^{4}$ This also gives the opportunity to target molecules that might not have a strong match found in nature. While ELISA, antibodies, and aptamers have led to 
powerful applications in biomedicine, ${ }^{5}$ limitations remain, for example, to have the high sensitivity and selectivity of ELISA, but at lower cost and with little training required. In response to these specific limitations, we seek to develop a reliable, sensitive, and specific detection technique that could improve healthcare by allowing for early detection of diseases or for monitoring for recurrences. ${ }^{6}$ Detection and monitoring of protein biomarkers of diseases is challenging, because there are about 10,000 different proteins ranging in concentration over nine orders of magnitude in blood and millions of possible DNA nucleotide sequences in organisms. ${ }^{7}$ With appropriate design, a single molecule detection method could potentially detect low concentrations of a specific molecule in a drop of blood or sequence a DNA strand, but a clinically useful single molecule detection technique should be: robust, easy to use, rapid, reliable and inexpensive. The target of clinical, and even bedside, utility is chosen for its potential to lower the cost of healthcare by making molecular-level diagnostics routine and to give patients results more quickly. The diagnostic goal is to deliver results in minutes versus hours or days. A nanometer sized hole, known as a nanopore, is a promising candidate for providing single molecule detection at the bedside, meeting the stringent demands on a clinically useful sensor.

Nanopores have recently emerged as a laboratory-based single molecule detection and analysis tool for biomolecules. Nanopore sensing is compelling because nanopores can be used for label-free detection of single molecules. Using nanopores is unique from existing commonly used techniques for single molecule sensing, such as single-molecule fluorescence sensing, because those techniques frequently require labels, such as fluorophores, to be attached to the target molecule. ${ }^{3,4,8}$ These labels can 
interfere with a molecule's function, as well as requiring time and training to attach them, in likely less than quantitative yield; with a nanopore, detection can be of the molecule directly, label-free, thereby eliminating such challenges. Nanopore sensing has received the most attention for DNA sequencing applications, promising potential capabilities such as single molecule sequencing with single-nucleotide resolution. ${ }^{9,10,11}$ Nevertheless, substantial technical barriers remain. A technique called nanopore force spectroscopy (NFS), though, provides a means for identifying nucleotide sequence in short nucleic acid oligomers by experimentally probing energy landscapes between molecules. ${ }^{12,13}$ This method has achieved preliminary success in a laboratory setting, but the extension of the method to a robust, point-of-use platform for detection of low concentrations of molecules remains challenging. To harness this sensitive tool requires a great deal of optimization. Preliminary results and literature demonstrate that, while fragments of DNA, for example, can be detected and identified with a nanopore, ${ }^{14,15}$ molecular surface interactions may cause the DNA to stick to the pore wall, affecting device lifetime, ease-of-use and reliability. ${ }^{16}$ Previous studies ${ }^{17,18,19,20}$ have shown that the surface of the pore and DNA, though, can be modified, as can the physicochemical properties of the pore environment, such as $\mathrm{pH}$ and ionic concentrations, ${ }^{21}$ and these modifications can affect the interactions between the pore surface and the molecule. Thus, judicious design of nanopore detection chemistry is one approach to overcome many of the challenges to nanopore point-of-care sensing. 


\subsection{Types of Nanopores}

There are two types of nanopores, biological and solid-state. The most frequently used biological nanopore, $\alpha$-hemolysin, is taken from nature and selfassembles in a lipid bilayer which can be mechanically, and frequently manually, formed across a nanometer- to micron-sized hole. ${ }^{22,23}$ While subtle modification of a biological nanopore is feasible using the techniques of molecular biology, ${ }^{24}$ millennia of evolution have fine tuned biological nanopores making some modifications, such as size and shape, difficult. Factors such as the pore internal diameter and the range of operating conditions in which the pores are stable cannot be easily modified and another biological nanopore or lipid bilayer compatible with the desired conditions would then need to be used instead, if a suitable combination can be found. ${ }^{13}$ Despite the limitations of working with biological nanopores, they have been used to detect proteins, ${ }^{24}$ small molecules, ${ }^{25}$ metal ions, ${ }^{26}$ and they have served as a useful test platform for developing and testing new nanopore methods. ${ }^{10,12}$

The second, and more recently adopted, type of nanopore is solid-state. Solidstate nanopores are man-made and more tunable, allowing for a greater range of applications and a larger variety of molecules to be detected. Solid-state nanopores have already been shown to be amenable to the detection of target analytes in pure samples. ${ }^{8,27,28}$ They can be polymer-based (i.e. polycarbonate, polyethylene terephthalate), ${ }^{29}$ or fabricated from other materials such as silicon nitride, silicon oxide, graphene, or aluminum oxide. ${ }^{8}$ These materials are, unlike biological nanopores in lipid bilayers, more robust ${ }^{30}$ and stable over a larger range of conditions (pH, ionic concentration, and temperature) ${ }^{13}$ These properties are more amenable to 
the demands of creating a tool for medical diagnostics, which is why solid-state nanopores, in particular fabricated from silicon nitride, were chosen to be used in this study.

\subsection{Solid-State Nanopore Fabrication}

The silicon nitride nanopores for this study were fabricated by drilling either with an electron or ion beam. ${ }^{8,31}$ The techniques could each readily produce nanopores of different radii, and the particular fabrication conditions were expected to produce different nanopore shapes. For the electron-beam-milled nanopores, a 200 $\mathrm{keV}$ transmission electron microscope was used to mill nanopores into a $30 \mathrm{~nm}$ thick silicon nitride chip; these pores were expected to be conical-cylindrical in shape (Figure 1A). The helium-ion-milled pores were expected to be cylindrical in shape (Figure 1B), and were fabricated in 20 and $30 \mathrm{~nm}$ thick silicon nitride membranes using a Zeiss Orion Plus Helium Ion Microscope. 


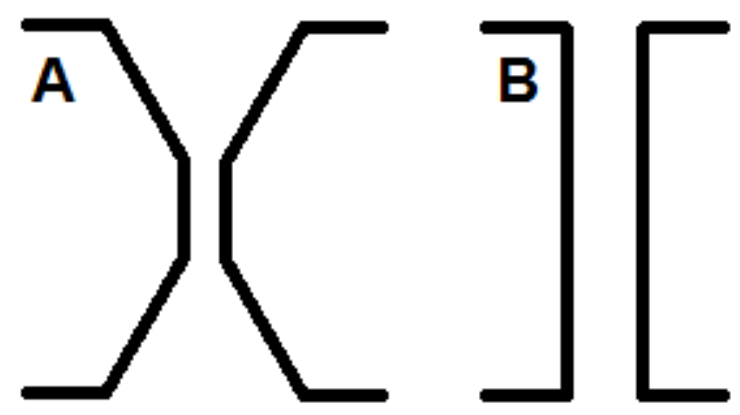

Figure 1. A) Nanopores milled with a correctly configured electron beam typically have a conical-cylindrical profile and B) helium-ion-milled pores typically have a cylindrical pore shape. 


\subsection{General Overview of Nanopore Sensing}

Nanopores are able to detect molecules through resistive-pulse sensing. ${ }^{32}$ In the simplest sense, when a molecule inside the nanopore is able to change the nanopore conductance, it can be sensed. In general practice, the nanopore is immersed in electrolyte and a voltage applied across the membrane gives an ionic current through the pore. When the nanopore is occupied by nothing other than electrolyte, the resulting current is known as the "open pore current". However, when a molecule in the pore changes the nanopore conductance, the measured current will change. Frequently molecules will reduce the measured ionic current magnitude, so that the signal can be described as the "blocked pore current" or "current blockage". Each type of molecule interacts with the pore chemistry differently, as some molecules will pass through the nanopore, or translocate, faster, leading to a shorter current blockage. Other molecules are bigger leading frequently to a larger current blockage. The detailed interactions between the molecule and the pore environment will be reflected in changes in the nanopore conductance, frequently to its duration and magnitude. The characteristic time and depth of this blockage can, in principle, be used to identify the molecule.

To use a nanopore as a sensor, first, the desired pore radius that will be suitable to the analyte molecule is chosen. The pore size needs to be large enough for the analyte molecule to travel through, yet small enough, so that there is a high signal-tonoise ratio. Small nanopore diameters place strong technical demands on the methods and experiments. The silicon nitride chip, with a nanopore drilled in it, is mounted between two silicone elastomer gaskets, and placed in an electrochemical cell (Figure 
2). Silver/silver chloride electrodes are placed on either side of the chip, and a voltage is applied, which will force an ion current to pass through the nanopore. Passage of a single molecule through the pore may perturb the electrolyte-only current (Figure 3), allowing detection and identification of the molecule. For complex samples, such as blood, that contain a large number of molecules of many different types, recognizing a single, low abundance protein, for example, by its current blockage characteristics, alone, is incredibly challenging. To deal with the complex samples with many molecular components expected in clinical diagnosis, a more sophisticated implementation of nanopore sensing, that leverages molecular recognition, was developed. 

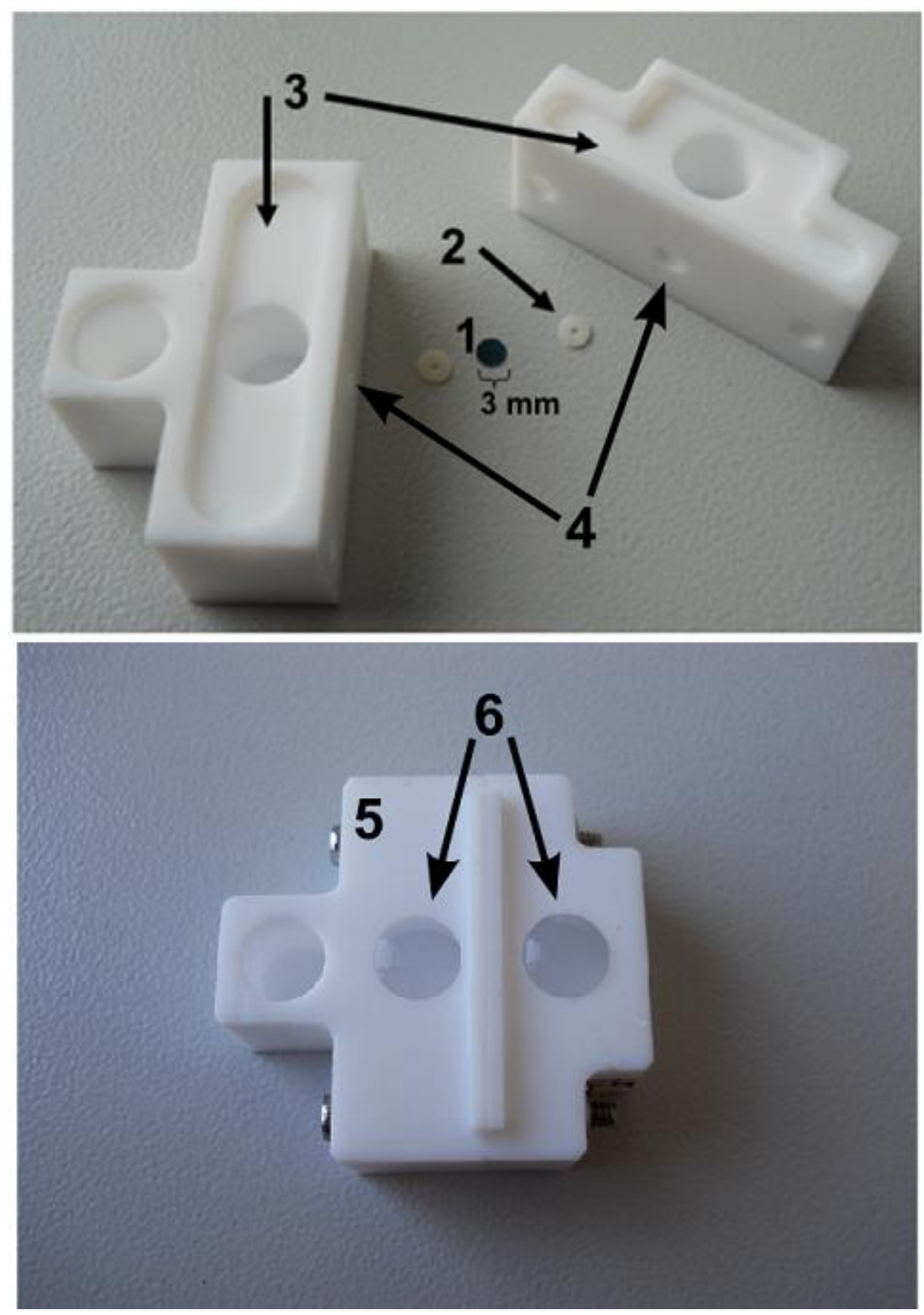

Figure 2. The silicon nitride chip (1) is placed between two silicone elastomer gaskets (2), and placed between the two halves of an electrochemical cell (3) in the channel connecting the two liquid reservoirs (4). In the assembled electrochemical cell (5), the electrodes are placed in the liquid reservoirs that hold the electrolyte (6). 


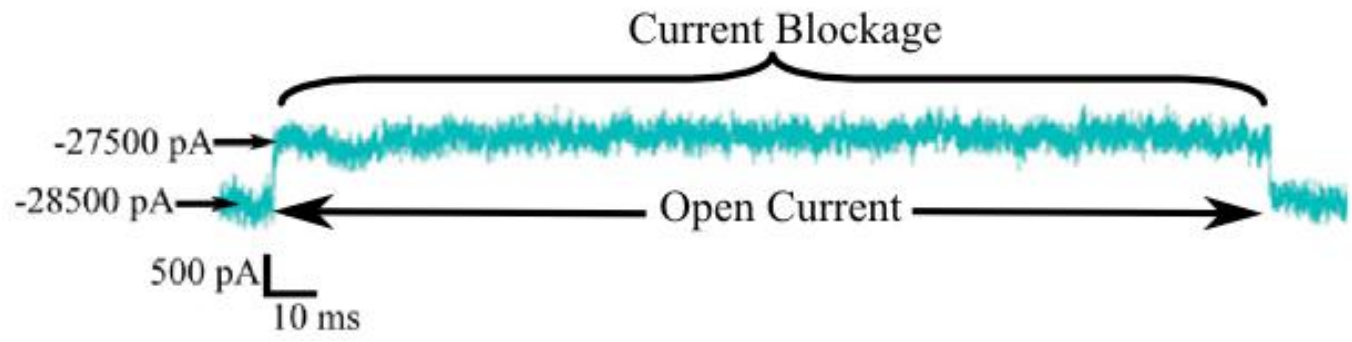

Figure 3. When a voltage is applied, a current passes through the pore the open current.) When a molecule enters that pore, the current may decrease (the blockage.) In this case, a negative voltage $(-200 \mathrm{mV})$ is applied, so that the $170 \mathrm{~ms}$, about 1000 pA blockage is shown as a rise towards 0 pA. 


\subsection{Nanopore Force Spectroscopy (NFS)}

In 2004, Nakane et al. ${ }^{10}$ demonstrated the new technique of nanopore force spectroscopy (NFS). Using a single, $\alpha$-hemolysin nanopore, they were able to demonstrate DNA sequence discrimination with a judiciously located single nucleotide mismatch out of fourteen nucleotides causing a two-order of magnitude change in the signal magnitude. Later, in 2007, Tropini et al. ${ }^{12}$ extended the method by performing nanopore force spectroscopy using about $100 \alpha$-hemolysin pores in parallel. The particular sensing method used, nanopore force spectroscopy (NFS), is a technique that can be used to probe the energy landscape between two interacting molecules. In these DNA genotyping experiments, it was used to probe the energy between two strands of DNA, a known probe oligomer and an unknown analyte oligomer, in order to identify the nucleotide sequence through the energetics underlying molecular recognition by the probe oligomer. ${ }^{10,12,13}$ The energy of duplex formation between any two DNA strands is determined by the particular sequence of base pairs and the degree of complementarity between the strands, making recognition of a specific molecule possible through knowledge of one strand sequence and measurement of the duplex interaction energy. ${ }^{10,12}$ In NFS-based profiling of a DNA sequence, special molecular constructs are required. A DNA oligomer, the "probe" molecule, possessing the complementary sequence to the target analyte oligomer is covalently linked via a longer DNA strand, the "spacer", to a biotin molecule which is subsequently bound to avidin; this is known as the probe DNA construct (Figure 4). The steps of NFS-based profiling of DNA (Figure 5) are as follows. A voltage is applied so that nucleic acid components of the probe DNA construct will be 
electrophoretically inserted into the pore, causing a decrease in current that reports on the successful insertion. The avidin protein is larger than the pore diameter $(5 \mathrm{~nm})$, thereby holding the probe DNA construct in the pore without allowing it to translocate. On the other side of the pore, an analyte will hybridize to the probe DNA, with a stability determined by the degree of probe-analyte sequence complementarity. A reversed voltage will drive the DNA duplex back in the direction of the original side. However, the pore is too small for the DNA duplex to go through, so the duplex unravels as it gets pulled through the pore. How well the analyte sequence matched the probe DNA sequence, that is the duplex binding energy, will affect the time it takes for the probe DNA to return to its original side. ${ }^{10}$ For example, if only one of the bases matched to the probe DNA, then the dissociation time would be shorter than if all the bases matched, because the binding energy is weaker than the energy of a perfect match. ${ }^{10}$ 


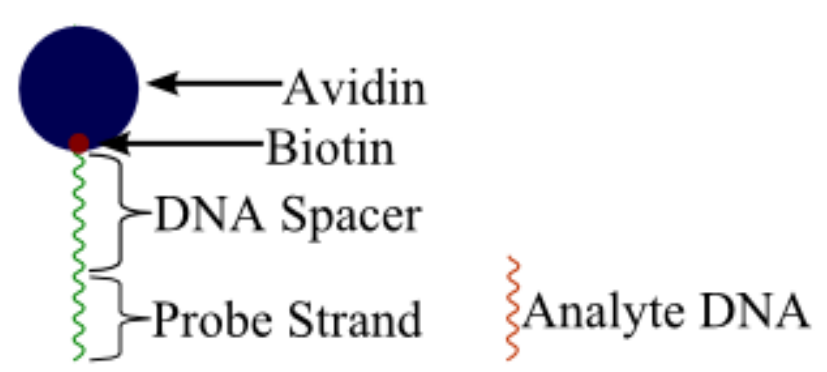

Figure 4. The probe DNA construct (not drawn to scale), where an avidin molecule is linked to a biotinylated-DNA strand. The DNA strand has a spacer to prevent misfolding and contains a probe sequence at the end which is complementary to the analyte DNA sequence. 


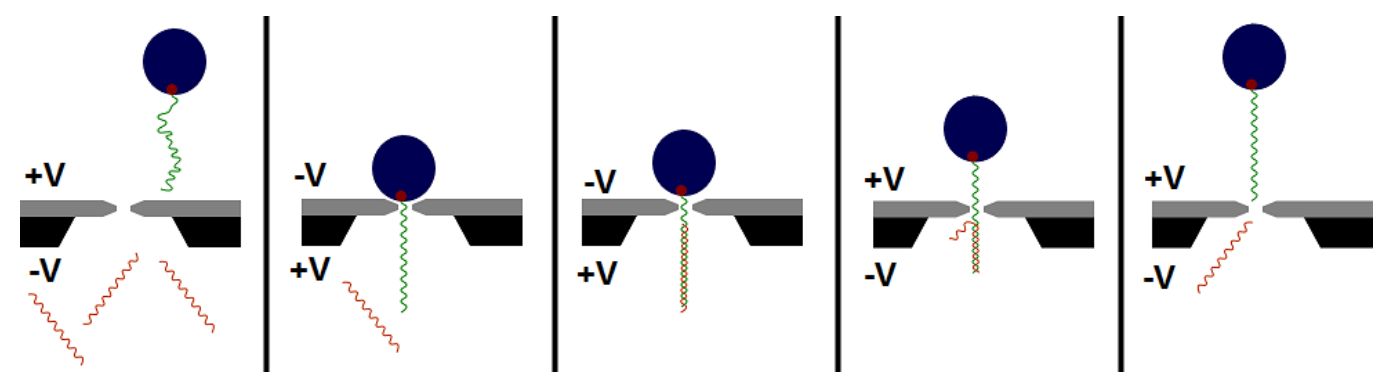

Figure 5. A schematic depiction of nanopore force spectroscopy (not drawn to scale). From left to right, the avidin is attached to a long biotinylated-DNA strand. With an applied voltage the long strand is driven into the pore, and an analyte molecule attaches, once the applied voltage is reversed the DNA and the analyte will dissociate from the DNA as it is driven back to its original side. 
These prior studies demonstrated the feasibility and promise of nanopore force spectroscopy-based detection. However, the limitations of the $\alpha$-hemolysin platform, the inability to easily change the size of the nanopore to accommodate other sensing molecules and the structural fragility of the supporting lipid bilayer, prevent ready clinical use outside the nanopore expert user community. In this study, we therefore replace the $\alpha$-hemolysin pore platform with a more flexible and more robust solid-state nanopore platform. While prior work ${ }^{13}$ has demonstrated that the change is possible, it remains extremely challenging. Surface modification of the pore or molecules is essential to prevent unwanted interfacial effects such as DNA sticking to solid-state nanopores. Various surface chemistry techniques on DNA and silicon nitride can be found in the literature, but require vetting for the nanopore milieu. ${ }^{8,17,18,19,28}$ The development of surface functionalization methods to engineer a more robust version of NFS for DNA recognition is the focus of this study. By measuring the interaction time between a DNA probe and DNA analyte, NFS can allow for enhanced chemical selectivity in nanopore sensing to cope with the many molecules in blood and other human fluids. More generally, NFS will be a useful technique for single molecule sensing once fully optimized..

${ }^{1}$ Benner, S.; Chen, R.; Wilson, N.; Abu-Shumays, R.; Hurt, N.; Lieberman, K.; Deamer, D.; Dunbar, W.; Akeson, M. Sequences-Specific Detection of Individual DNA Polymerase Complexes in Real Time Using a Nanopore. Nature Nanotechnology. 2007, 2, 718-724.

${ }^{2}$ Janeway, C.A. Jr.; Travers, P.; Walport, M. Immunobiology: The Immune System in Health and Disease, $5^{\text {th }}$ ed.; Garland Science: New York, 2001. 
${ }^{3}$ Liu, C.; Qu, Y.; Luo, Y.; Fang, N. Recent Advances in Single-Molecule Detection on Micro- and Nano-Fluidic Devices. Electrophoresis. 2011, 32, 3308-3318.

${ }^{4}$ Harris, D. Quantitative Chemical Analysis, $7^{\text {th }}$ ed.; Freeman: New York, 2007.

${ }^{5}$ Citartan, M.; Gopinath, S.; Tominaga, J.; Tan, S.; Tang, T. Assays for AptamerBased Platforms. Biosensors and Bioelectronics. 2012, 34, 1-11.

${ }^{6}$ Georganopoulou, D.; Chang, L.; Nam, J.; Thaxton, C.S.; Mufson, E.J.; Klein, W.L.; Mirkin, C.A. Nanoparticle-Based Detection in Cerebral Spinal Fluid of a Soluble Pathogenic Biomarker for Alzheimer's Disease. PNAS. 2005, 102, 2273-2276.

${ }^{7}$ Adkins, J.; Varnum, S.; Auberry, K.; Moore, R.; Angell, N.; Smith, R.; Springer, D.; Pounds, J. Toward a Human Blood Serum Proteome: Analysis by Multidimensional Separation Coupled with Mass Spectrometry. Molecular \& Cellular Proteomics. 2002, 1, 947-955.

${ }^{8}$ Miles, B.; Ivanov, A.; Wilson, K.; Dogan, F.; Japrung, D.; Edel, J. Single Molecules Sensing with Solid-State Nanopores: Novel Materials, Methods, and Applications. Chemical Society Reviews. 2013, 42, 15-28.

9 Maitra, R.; Kim, J.; Dunbar, W. Recent Advances in Nanopore Sequencing. Electrophoresis. 2012, 33, 3418-3428.

${ }^{10}$ Nakane, J.; Wiggin, M.; Marziali, A. A Nanosensor for Transmembrane Capture and Identification of Single Nucleic Acid Molecules. Biophysical Journal. 2004, 87, $615-621$.

${ }^{11}$ Ashkenasy, N.; Sanchez-Quesada, J.; Bayley, H.; Ghadiri, M.R. Recognizing a Single Base in an Individual DNA Strand: A Step Toward DNA Sequencing in Nanopores. Angewandte Chemie International Edition. 2005, 44, 1401-1404. 
${ }^{12}$ Tropini, C.; Marziali, A. Multi-Nanopore Force Spectroscopy for DNA Analysis. Biophysical Journal. 2007, 92, 1632-1637.

${ }^{13}$ Tabard-Cossa, V.; Trivedi, D.; Wiggin, M.; Jetha, N.; Marziali, A. Noise Analysis and Reduction in Solid-State Nanopores. Nanotechnology. 2007, 18, 305505-305510.

${ }^{14}$ Storm, A.J.; Chen, J.H.; Zandbergen, H.W.; Dekker, C. Translocation of DoubleStrand DNA Through a Silicon Oxide Nanopore. Physical Review E. 2005, 71, 051903-051912.

${ }^{15}$ Chen, P.; Gu, J.; Brandin, E.; Kim, Y.; Wang, Q.; Branton, D. Probing Single DNA Molecule Transport Using Fabricated Nanopores. Nanoletters. 2004, 4, 2293-2298.

16 Fologea, D.; Uplinger, J.; Thomas, B.; McNabb, D.; Li, J. Slowing DNA Translocation in a Solid-State Nanopore. Nanoletters. 2005, 5, 1734-1737.

${ }^{17}$ Wanunu, M.; Meller, A. Chemically Modified Solid-State Nanopores. Nanoletters. 2007, 7, 1580-1585.

${ }^{18}$ Rosso, M.; Nguyen, A.T.; de Jong, E.; Baggernan, J.; Paulusse, J.M.J.; Giesbers, M.; Fokkink, R.; Norde, W.; Schroen, K.; van Rijn, C.J.M.; Zuilhof, H. ProteinRepellent Silicon-Nitride Surfaces: UV-Induced Formation of Oligoethylene Oxide Monolayers. ACS Applied Materials and Interfaces. 2011, 3, 697-704.

${ }^{19}$ Wei, R.; Pedone, D.; Zurner, A.; Doblinger, M.; Rant, U. Fabrication of Metallized Nanopores in Silicon Nitride Membranes for Single-Molecule Sensing. Small. 2010, 6, 1406-1414.

20 He, Y.; Tsutsui, M.; Fan, C.; Taniguchi, M.; Kawai, T. Controlling DNA Translocation through Gate Modulation of Nanopore Wall Surface Charges. ACS Nano. 2011, 5, 5509-5518. 
${ }^{21}$ Firnkes, M.; Pedone, D.; Knezevic, J.; Doblinger, M.; Rant, U. Electrically Facilitated Translocations of Proteins through Silicon Nitride Nanopores: Conjoint and Competitive Action of Diffusion, Electrophoresis, and Electroosmosis. Nanoletters. 2010, 10, 2162-2167.

${ }^{22}$ Ma, L.; Cockroft, S. Biological Nanopores for Single-Molecules Biophysics. ChemBioChem. 2010, 11, 25-34.

${ }^{23}$ Schibel, A.; Heider, E.; Harris, J.; White, H. Fluorescence Microscopy of the Pressure-Dependent Structure of Lipid Bilayers Suspended across Conical Nanopores. Journal of the American Chemical Society. 2011, 133, 7810-7815.

${ }^{24}$ Rotem, D.; Jayasinghe, L.; Salichou, M.; Bayley, H. Protein Detection by Nanopores Equipped with Aptamers. Journal of the American Chemical Society. 2012, 134, 2781-2787.

${ }^{25}$ Gu, L.; Braha, O.; Conlan, S.; Cheley, S.; Bayley, H. Strochastic Sensing of Organic Analytes by a Pore-Forming Protein Containing a Molecular Adapter. Nature. 1999, $398,686-690$.

${ }^{26}$ Braha, O.; Gu, L.; Zhou, L.; Lu, X.; Cheley, S.; Bayley, H. Simultaneous Stochastic Sensing of Divalent Metal Ions. Nature Biotechnology. 2000, 18, 1005-1007.

${ }^{27}$ Vlassiouk, I.; Apel, P.; Dmitriev, S.; Healy, K.; Siwy, Z. Versatile Ultrathin Nanoporous Silicon Nitride Membranes. PNAS. 2009, 106, 21039-21044.

${ }^{28}$ Gyurcsanyi, R. Chemically-Modified Nanopores for Sensing. Trends in Analytical Chemistry. 2008, 27, 627-639.

${ }^{29}$ Cornelius, T.W.; Apel, P.Yu.; Schiedt, B.; Trautmann, C.; Toimil-Molares, M.E.; Karim, S.; Neumann, R. Investigation of Nanopore Evolution in Ion track-Etched 
Polycarbonate Membranes. Nuclear Instruments and Methods in Physics Research B. 2007, 265, 553-557.

${ }^{30}$ Fologea, D.; Gershow, M.; Ledden, B.; McNabb, D.; Golovchenko, J.; Li, J. Detecting Single Stranded DNA with Solid State Nanopore. Nanoletters. 2005, 5, 1905-1909.

${ }^{31}$ Yang, J.; Ferranti, D.; Stern, L.; Sanford, C.; Huang, J.; Ren, Z.; Qin, L.; Hall, A.R. Rapid and Precise Scanning Helium Ion Microscope Milling of Solid-State Nanopore for Biomolecule Detection. Nanotechnology. 2011, 22, 285310-285316.

${ }^{32}$ Bayley, H.; Martin, C. Resistive-Pulse Sensing- From Microbes to Molecules. Chem. Rev. 2000, 100, 2575-2594. 


\section{CHAPTER 2}

\section{CHARACTERIZING NANOPORE SENSING PERFORMANCE}

\subsection{Preparation of a Nanopore and Laboratory Set Up}

Before a nanopore can be mounted as detailed in chapter 1, the nanopore must be properly prepared. A variety of methods are available to make the surface hydrophilic, principally through removal of organic contaminants from the nanopore surface. Piranha solution cleaning is the most common approach in the semiconductor industry to clean silicon and silicon nitride surfaces. ${ }^{33}$ Since the solid-state nanopores used for this thesis are made in silicon nitride membranes on silicon wafers, they can be piranha cleaned. In the process, the desired surface for cleaning, in this case, a nanopore, is soaked in piranha solution (3:1 95-98\% sulfuric acid (Sigma Aldrich \#320501-2) to $30 \mathrm{wt} \%$ hydrogen peroxide (Sigma Aldrich \#216763)) at $70^{\circ} \mathrm{C}$ for 15 -

30 minutes. $^{34,35}$ Nanostrip (90\% sulfuric acid, 5\% peroxymonosulfuric acid, <1\% hydrogen peroxide, and 5\% water, OMG Cyantek \#539200) is a stabilized alternative to piranha solution having a longer effective lifetime allowing extended cleaning times; the duration used for nanostrip cleaning in this thesis was $2-6$ hours at $70^{\circ} \mathrm{C}$, depending on the particular application. After cleaning with either solution, chips were rinsed with UV-treated $18 \mathrm{M} \Omega . \mathrm{cm}$ at $25^{\circ} \mathrm{C}$ deionized water (Millipore Synergy UV \#SYNSV0000) for 5-10 minutes afterwards to remove possible residues. Both of these approaches necessitate the use of extremely corrosive solutions, that introduce operational and disposal challenges. An alternative and effective approach is to use 
oxygen plasma. The standard approach used in these experiments was to use a Glow Research AutoGlow plasma cleaner to plasma clean the chip at $50 \mathrm{~W}$ for 1-3 minutes using $\mathrm{O}_{2}$ plasma at $0.8-1.0$ Torr introduced into a chamber with a base pressure of 0.2 Torr. After cleaning, the chip was mounted into the electrochemical cell (Figure 2, Chapter 1), and filled with spectroscopic-grade ethanol (Sigma-Aldrich \#245119) for about 5 minutes to allow for wetting. The ethanol was then exchanged with $9 \mathrm{~mL}$ of the desired electrolyte solution in both wells. These three methods for chip cleaning are explained more in section 2.5 .

In the laboratory set up, the electrochemical cell was placed in an aluminum Faraday cage, which was then encased in a larger copper Faraday cage to reduce noise. The electrodes used in the cell are $\mathrm{Ag} / \mathrm{AgCl}$ electrodes prepared by soaking silver wire in 10-15\% sodium hypochlorite (Sigma Aldrich \#425044) overnight. During soaking, both electrodes were electrically connected to each other. For sensing, both electrodes were connected to a patch clamp amplifier (Axopatch 200B from Molecular Devices), which applies voltage and amplifies the current to be read by a data acquisition card (Model PCle-6251, 16-Bit, $1.25 \mathrm{MS} / \mathrm{s}$ (Max), $1 \mathrm{MS} / \mathrm{s}$ (Scanning), 16 Analog Inputs from National Instruments) for data analysis with custom Labview software. The temperature setpoint of the sample cell platform was set to $25^{\circ} \mathrm{C}$, and maintained using a thermoelectric cooling system which was backcooled using a fan to cool circulating coolant fluid (Thermaltake Big Water 760is, 2U Bay Drives Liquid Cooling System). The thermoelectrically-stabilized temperature of the Axopatch current-amplifying headstage was about $-27^{\circ} \mathrm{C}$. The entire setup was 
located on an isolation vibration table to reduce the influence of environmental noise.

Figure 1 shows the laboratory set up. 


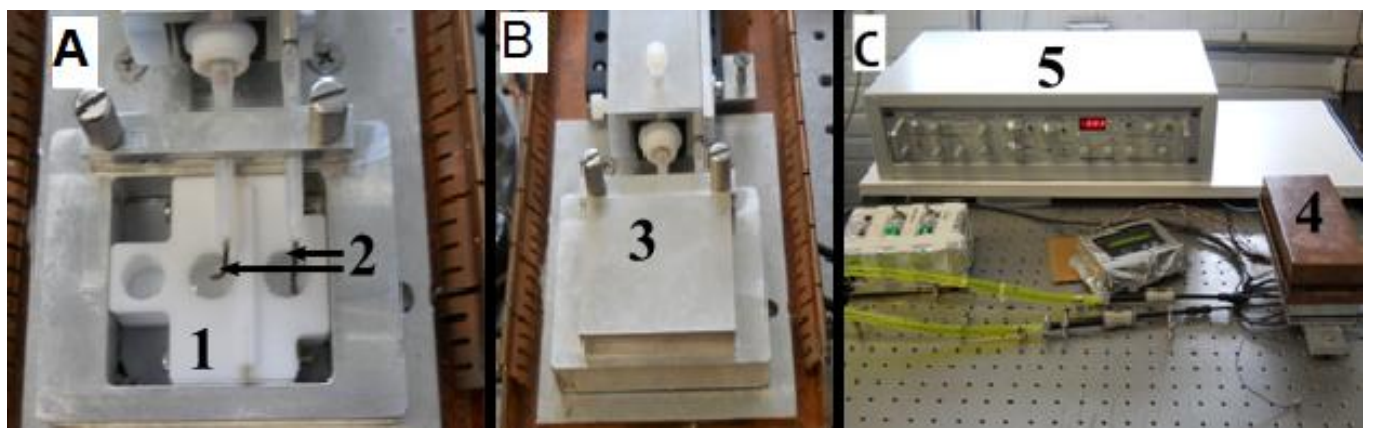

Figure 1. The laboratory set-up of (A) the electrochemical cell (1) with $\mathrm{Ag} / \mathrm{AgCl}$ electrodes (2) on either side, which is placed in (B) a primary aluminum (3) and $(C)$ secondary copper Faraday cage (4), and attached to a patch clamp amplifier (5) and placed on a vibration isolation table. 


\subsection{Current Characterization of Nanopores}

Two types of measurements are typically used to characterize the nanopore. Both of these are in situ measurements, where the nanopore is mounted in an electrochemical cell, rather than an ex situ measurement such as TEM imaging, where the nanopore chip needs to be unmounted to be measured. The advantages of having the in situ measurements of the pore size is that it allows for real-time characterization of the nanopore and removes the hassle and hazards of disassembling the electrochemical cell, an occasionally rough process which can cause the nanopore to break.

\subsubsection{Current-Voltage Plots}

The first type of measurement is using a measurement of ionic current (I) versus applied voltage (V), producing an IV plot (Figure 2). The slope of this plot gives the total conductance of the nanopore. The conductance is based on the pore size and shape, surface chemistry, and solution conductivity.

In the model used for this thesis, and supported by experimental

measurements, ${ }^{36}$ the total nanopore conductance can be expressed as the sum of two parts- the bulk and surface conductances inside the nanopore (Figure 3 ), ${ }^{37}$ such that

$$
G_{\text {total }}=G_{\text {bulk }}+G_{\text {surface }} \quad(\text { Eqn.2.1) }
$$

where $\mathrm{G}$ is the conductance. 


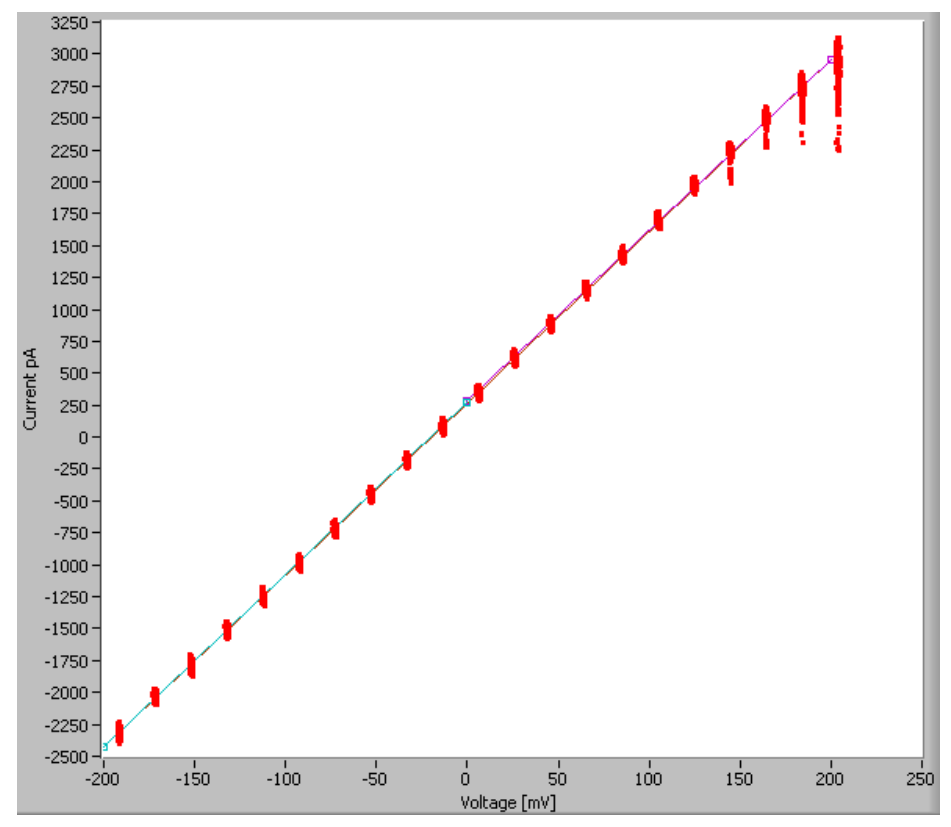

Figure 2. A representative current-voltage (IV) plot of a $4.5 \mathrm{~nm}$ pore in a $\mathrm{pH} 7$ aqueous solution of $1 \mathrm{M} \mathrm{KCl}$ and $10 \mathrm{mM} \mathrm{HEPES.} \mathrm{From} \mathrm{this} \mathrm{plot,} \mathrm{the} \mathrm{slope} \mathrm{will} \mathrm{give}$ the conductance. 


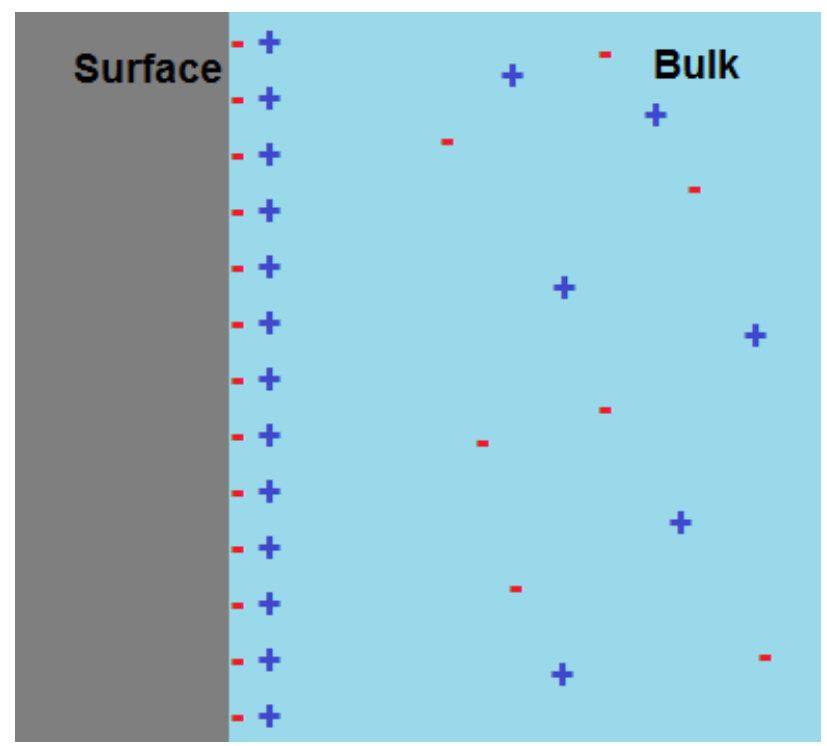

Figure 3. The presence of charges on the nanopore surface has a profound influence on the distribution of ions in the nanopore. The consequence is that the ions can be categorized as being in either a "surface zone" near the surface, or in bulk solution. Ions in each zone have different conductivities as a result of their environment. 
Given the small volume and large surface-area-to-volume ratio of the nanopore, the surface conductance, arising from the effects of the charged nanopore surface in solution, can dominate the conductance at low electrolyte concentrations. The silicon nitride surface is terminated by a mixture of $\mathrm{Si}-\mathrm{NH}$ and $\mathrm{Si}-\mathrm{OH}$ surface functional groups, and, thus, can be charged in solution depending on the $\mathrm{pH}$. This surface charge causes counter ions to accumulate at the nanopore surface. Solution ions can then be divided between "surface" and "bulk" ions. The movement of the surface-proximal counter ions produces a noticeable conductance, described as the surface conductance. There are thus two conductive regions: the surface and the bulk solution. Knowledge of the nanopore size, shape, surface chemistry, and key solution physiochemical properties is sufficient to calculate the nanopore conductance. In the bulk solution of the pore, the conductance is given by

$$
G_{b u l k}=K\left(\int \frac{d z}{\pi(r(z))^{2}}\right)^{-1} \quad(E q n .2 .2)
$$

where $\mathrm{K}$ is the electrolyte conductivity and $\mathrm{r}(\mathrm{z})$ is the nanopore radius as a function of distance, $\mathrm{z}$, from the membrane surface (that is, the nanopore shape). In this model, the bulk conductance in the pore is the electrolyte conductivity multiplied by the volume of the bulk solution inside the nanopore. The surface conductance of the nanopore is given by

$$
G_{\text {surface }}=\mu \sigma\left(\int \frac{d z}{2 \pi r(z)}\right)^{-1} \quad(\text { Eqn. 2.3) }
$$

where $\sigma$ is the surface charge density and $\mu$ is the mobility of the counter ions. This shows that the surface conductance is the surface charge multiplied by the surface area 
of the inside of the pore. The total conductance is the sum of the bulk and surface terms as shown by,

$$
G(K, \sigma)=\pi K A_{\text {bulk }}+2 \pi \mu \sigma B_{\text {surface }}(\text { Eqn.2.4) }
$$

where $A_{\text {bulk }}$ and $B_{\text {surface }}$ are functions of geometric parameters, only, accounting for the shape of the nanopore (e.g. cylindrical, conical; compare Figure 1 of Chapter 1). It is possible to determine the conductance of the nanopore at a given electrolyte concentration by measuring an IV curve at that electrolyte concentration. The data of the conductance at varying electrolyte concentrations can then be fitted to determine

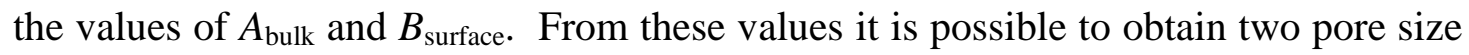
parameters (e.g. radius and nanopore length) by solving the functional form of $A_{\text {bulk }}$ and $B_{\text {surface }}$ under the assumption of a reasonable nanopore shape. However, an exact determination of the size and shape cannot be obtained just from the conductance, because any shape with at least two parameters can yield the same $A_{\text {bulk }}$ and $B_{\text {surface. }}$ Similarly any shape comprised of more than two unknown size parameters will result in an infinite set of possible solutions, so that any parameters above two unknowns will have to be approximated. ${ }^{37,37}$ For characterizing a nanopore with a reasonably well-known shape, as in this thesis work, this two-parameter model with $A_{\text {bulk }}$ and $B_{\text {surface }}$ is adequate.

Besides giving the conductance, the IV curve can also show if there is contamination in the pore (Figure 4). 


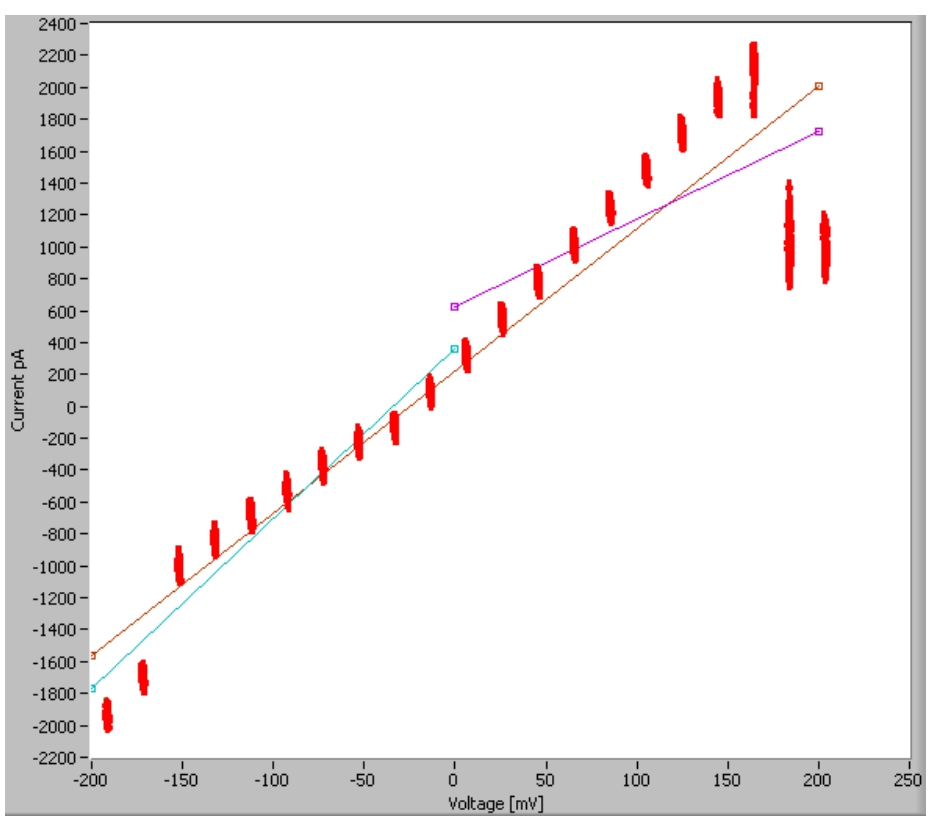

Figure 4. An IV curve can show contamination, any unwanted molecule, inside the pore. This is indicated by the asymmetrical nature of the curve. It is possible to distinguish which side of the nanopore is contaminated by looking at if the positive or negative voltage is asymmetrical. In this case, a $4.5 \mathrm{~nm}$ pore in a $\mathrm{pH} 7$ aqueous solution containing $1 \mathrm{M} \mathrm{KCl}$ and $10 \mathrm{mM}$ HEPES, both sides display a curvature, indicating that both sides are contaminated. 


\subsubsection{Current Trace Measurements}

The second measurement that can be done to analyze the nanopore in its standard laboratory configuration is to apply a constant voltage and measure the current as a function of time. In this thesis, this type of data will be known as a current trace. As described in chapter 1, the current may decrease when a molecule is in the pore because the ion flow in the pore is perturbed by the molecule in the pore. For a cylindrical, uncharged, molecule filling the entire length of the nanopore, the expected current blockage would arise from the number of ions excluded by the volume of the molecule:

$$
I_{\text {block }}=I_{\text {open }}\left[1-\left(\frac{r_{\text {analyte }}}{r_{\text {pore }}}\right)^{2}\right] \quad(\text { Eqn. 2.5) }
$$

where $\mathrm{I}_{\text {block }}$ is expected blocked current, $\mathrm{I}_{\mathrm{open}}$ is the open current, $\mathrm{r}_{\text {analyte }}$ is the radius of the analyte, and $r_{\text {pore }}$ is the radius of the open pore. Contaminant molecules will also cause nanopore current blockages. To control for the presence of contaminants, background current traces are always conducted. These background traces help to characterize the conductance stability and cleanliness of the pore, and the characteristics of the sample matrix, so that it will be possible to distinguish between the analyte-free current and the current when analyte is present in the pore. A stable current in time is considered to be indicative of a stable, uncontaminated pore, while a fluctuating current could indicate that there is interference due to a possible contaminant in solution in the pore or on the pore membrane surface (Figure 5). 


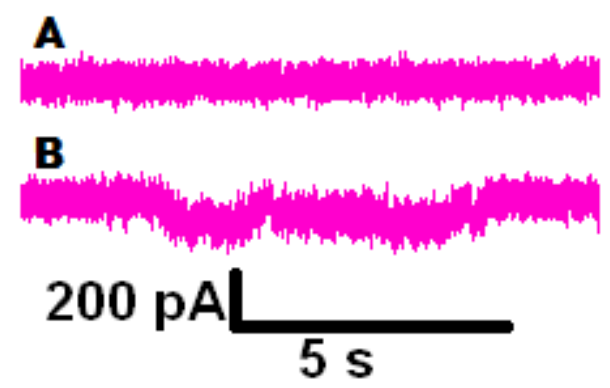

Figure 5. A current trace can reveal how stable the pore is. Here is a current sample from a conical-cylindrical shaped $4.4 \mathrm{~nm}$ sized pore in a $30 \mathrm{~nm}$ thick silicon nitride chip in an aqueous solution of $0.1 \mathrm{M} \mathrm{KCl}$ buffered to $\mathrm{pH} 7.4$ with $10 \mathrm{mM} \mathrm{HEPES}$ with $200 \mathrm{mV}$ applied voltage. It can be noted that there can be slight changes in the current due to noise or possible contaminants. A) The pore is clean and stable, while B) the fluctuation of current reveals that there is something in the pore. 
Current trace experiments allow us to monitor current drift. In an experiment to test how much current drift can be expected, a mounted $8 \mathrm{~nm}$ nanopore in a $\mathrm{pH} 7$ aqueous solution of $1 \mathrm{M} \mathrm{KCl}$ and $10 \mathrm{mM}$ HEPES was run with either a continuous applied voltage of $200 \mathrm{mV}$ for 30 minutes or applying $200 \mathrm{mV}$ for 3 seconds every minute for 30 minutes. To quantify the current drift, the current was measured at $200 \mathrm{mV}$ for 1 minute before and after each trial. To see if the order they were run mattered, on the first day the trials with the continuous applied voltage was done first, and on the second day it was done second. From Figure 6A, there was a noticeable drift after the continuous applied voltage, but a much smaller drift over the same time period when the voltage was applied only intermittently. The observed trends for the relative rate of current drift, $I_{t}^{d}$, are summarized in Table 1 , where $I_{t}^{d}$ is defined by

$$
I_{t}^{d}=\frac{\Delta I / I_{0}^{\text {peak }}}{\Delta t} \text { (Eqn. 2.6) }
$$

where $\Delta \mathrm{I}$ is the change in the current distribution peaks between the 30 minute scan and the 1 minute scan (from Figure 6), $I_{0}^{\text {peak }}$ is the centerpoint of the current distribution peak of the 30 minute scan, and $\Delta \mathrm{t}$ is 30 minutes.. For the continuous voltage scan, $I_{t}^{d}$ was $1.25 \times 10^{-5} / \mathrm{s}$ and for the scan every 3 seconds was $-3.67 \times 10^{-6} / \mathrm{s}$. The order of magnitude of the scan every 3 seconds $\left(10^{-6}\right)$ was the same as the tests when the every 3 seconds scan was done first (Figure 6B); similarly, the order of magnitude of the continuous applied voltage $\left(10^{-5}\right)$ was the same as when the continuous applied voltage was applied after the intermittent (every 3 second) scan (Figure 6B). When the intermittent scan was applied first, there was some drifting $\left(I_{t}^{d}=4.17 \times 10^{-6} / \mathrm{s}\right)$ on the order of magnitude of $10^{-6}$ as was with the previous 
scan for the application every 3 seconds, while the drifting with a continuous applied voltage $\left(I_{t}^{d}=2.44 \times 10^{-5} / \mathrm{s}\right)$ was also on the same order of magnitude as the previous continuous voltage scan $\left(10^{-5}\right)$. In Figure $6 \mathrm{~B}$, the data for the intermittent (3 second) scan was fit was a Gaussian curvature to smooth the data and $I_{0}^{\text {peak }}$ was the center of the fit curve. Regardless of order of the measurements, the current drift following continuous current measurement was an order of magnitude higher than the drift following intermittent measurements. This may be because of resistive heating of the solution in the former case increasing the solution conductivity, in addition to any physiochemical changes to the electrodes. Finally, to control for the possible effects of electrode wetting, the electrodes were left soaking in the cell without any voltage being applied between two 1 minute current traces at $200 \mathrm{mV}$ (Figure 6C). The data shows that even when no voltage was being applied, there was still some drifting $\left(I_{t}^{d}=3.62 \times 10^{-6} / \mathrm{s}\right)$. This drifting was on the same order of magnitude as the drifting after 3 seconds of applied voltage every minute. These experiments indicate that current drifting happens, and the largest effect should be expected after the continuous application of voltage. 


\begin{tabular}{|c|c|c|}
\hline $\begin{array}{l}\text { Experimental } \\
\text { Description } \\
\text { (All for } 30 \mathrm{~min} . \text { ) }\end{array}$ & $\begin{array}{l}I_{t}^{d} \text { for Continuous Scan }\left(\mathrm{s}^{-}\right. \\
\left.{ }^{-}\right)\end{array}$ & $I_{t}^{d}$ for Scan V Every $3 \mathrm{~s}\left(\mathrm{~s}^{-1}\right)$ \\
\hline $\begin{array}{l}\text { 1.Continuous } \\
\text { Voltage Scan } \\
\text { 2. Scan Every } 3 \\
\text { Seconds }\end{array}$ & $1.25 \times 10^{-5}$ & $-3.67 \times 10^{-6}$ \\
\hline $\begin{array}{l}\text { 1. Scan Every } 3 \\
\text { Seconds } \\
\text { 2. Continuous } \\
\text { Voltage Scan }\end{array}$ & $2.44 \times 10^{-5}$ & $4.17 \times 10^{-6}$ \\
\hline $\begin{array}{l}\text { Experimental } \\
\text { Description } \\
\text { (For } 30 \mathrm{~min} .)\end{array}$ & \multicolumn{2}{|c|}{$I_{t}^{d}$ for Continuous Soaking $\left(\mathrm{s}^{-1}\right)$} \\
\hline $\begin{array}{l}\text { Electrodes Left } \\
\text { Soaking, } 1 \text { min. scans } \\
\text { before and after }\end{array}$ & \multicolumn{2}{|l|}{$3.62 \times 10^{-6}$} \\
\hline
\end{tabular}

Table 1. The relative rate of current drift $\left(I_{t}^{d}\right)$ for scans of 30 minutes, calculated from the data in Figure 6. 

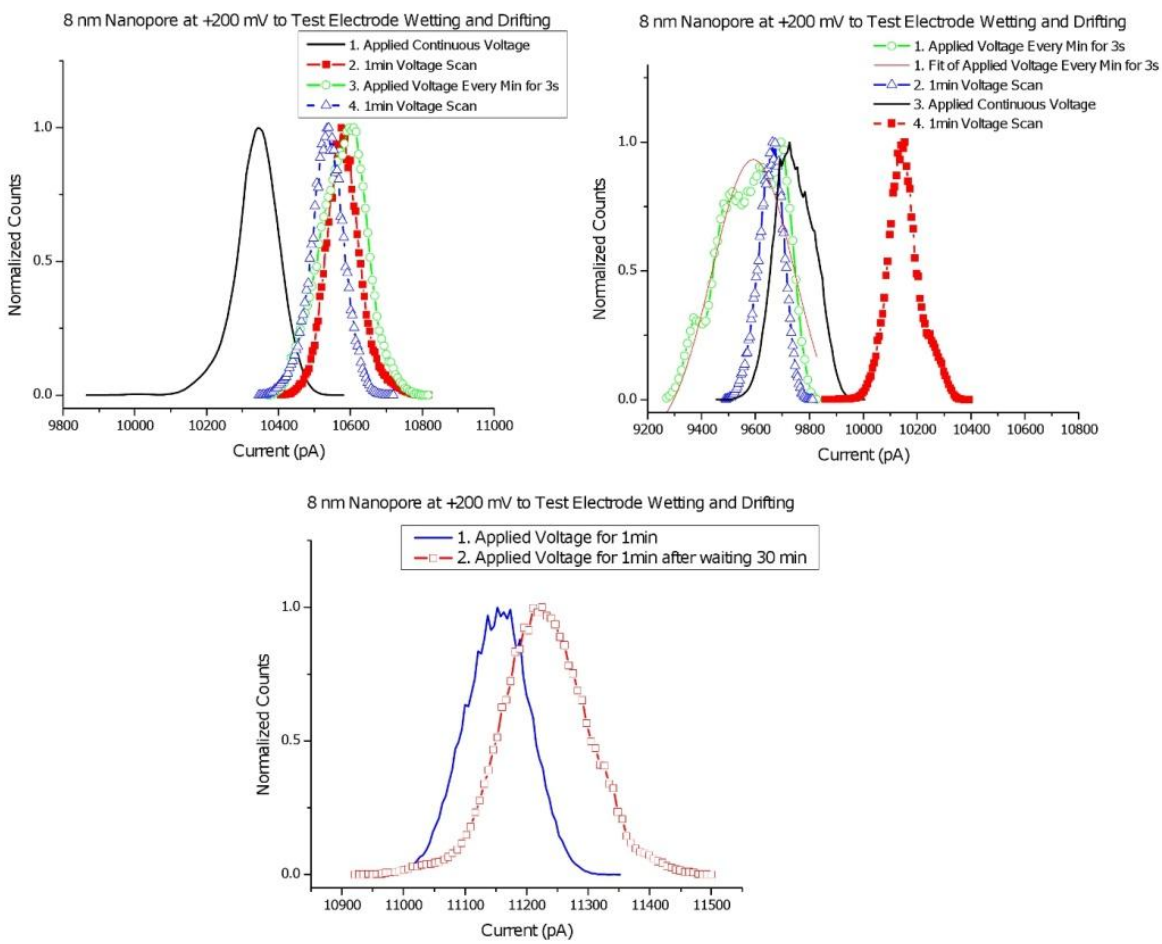

Figure 6. Data of the drifting tests were run in an $8 \mathrm{~nm}$ nanopore in a $\mathrm{pH} 7$ aqueous solution of $1 \mathrm{M} \mathrm{KCl}$ and $10 \mathrm{mM} \mathrm{HEPES.} \mathrm{In} \mathrm{A,} \mathrm{the} \mathrm{continuous} 200 \mathrm{mV}$ (black line) was applied first and the 3 seconds of applied $200 \mathrm{mV}$ every minute (green circles) was done after. Both of these current traces were followed by a one minute current trace with $200 \mathrm{mV}$ applied voltage (red filled squares and blue triangles, respectively). In B, the continuous $200 \mathrm{mV}$ (black line) was applied second and the 3 seconds of applied $200 \mathrm{mV}$ (green circles), which was fit with a Gaussian curvature to smooth the data (red line), was done first. Both of these current traces were followed by a one minute current trace with $200 \mathrm{mV}$ applied voltage (red filled squares and blue triangles, respectively). In $C$, a one minute current trace was applied before (blue line) and after (red open squares) a 30 minute waiting period, where the electrodes sat in the electrochemical cell without any interference. All these indicate that drifting happens. 


\subsection{Detection of Molecules with Bare Silicon Nitride Pores}

The wells of the custom Teflon electrochemical cell can hold approximately $0.5 \mathrm{~mL}$ of solution. In these experiments, they were filled with aqueous electrolyte comprised of potassium chloride (KCl, Sigma Aldrich \#60130) and buffer 4-(2Hydroxyethyl)piperazine-1-ethanesulfonic acid (HEPES, Sigma H0527). All solutions were made with $18 \mathrm{M} \Omega . \mathrm{cm}$ deionized water and the $\mathrm{pH}$ was adjusted using 2 M hydrogen chloride (diluted from $\mathrm{HCl}$, Sigma Aldrich \#H1758) or $2 \mathrm{M}$ potassium hydroxide (prepared from KOH, Sigma Aldrich \#30614). The conductivities and pH of solutions were measured after $\mathrm{pH}$ adjustment with a conductivity/pH meter (Thermo Scientific Orion 4 Star \#1116000). Typically, solutions of $0.1 \mathrm{M} \mathrm{KCl}$ and 10 $\mathrm{mM}$ HEPES varied in conductance from about $1.2 \mathrm{~S} / \mathrm{m}$ to $1.6 \mathrm{~S} / \mathrm{m}$, and solutions of 1 $\mathrm{M} \mathrm{KCl}$ and $10 \mathrm{mM}$ HEPES varied in conductance from about $11 \mathrm{~S} / \mathrm{m}$ to $13 \mathrm{~S} / \mathrm{m}$. There did not appear to be a correlation between $\mathrm{pH}$ and conductance value, but each solution was independently adjusted to the desired $\mathrm{pH}$ and the adjustment varied from solution to solution.

\subsubsection{Detection of 5-(and-6)-Carboxyfluorescein Dye}

As an example of how a nanopore detects molecules, two types of molecules, a mixture of 5-(and-6)-carboxyfluorescein dye (M.W 376.32, Invitrogen \#C194, Figure 7), were able to be detected by the nanopore. As stated in chapter 1, a molecule is detected by the change in current, a blockage, when a molecule enters a nanopore and perturbs the current. These current blockages are sometimes referred to as "events" in the nanopore literature and "blockage" and "event" may be used interchangeably. ${ }^{38,39}$ 
The dye molecules were able to be detected in a conical-cylindrical shaped $11 \mathrm{~nm}$ sized pore in a $30 \mathrm{~nm}$ thick silicon nitride membrane. 

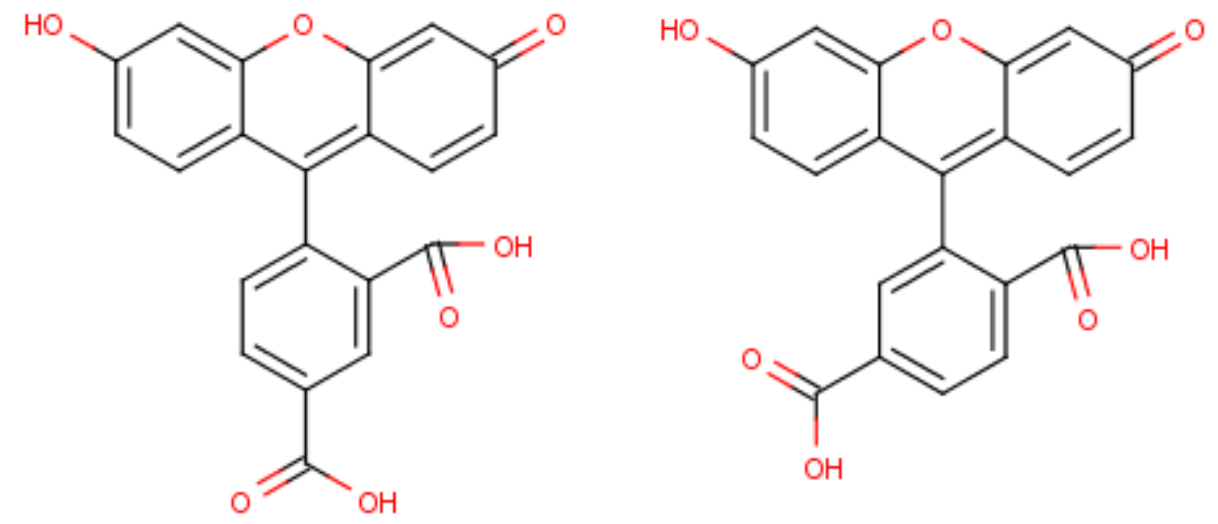

Figure 7. 5-carboxyfluorescein dye (left) and 6-carboxyfluorescein dye (right). 
Based on bond lengths, this molecule can be estimated to be about $1.2 \mathrm{~nm}$ in width. ${ }^{40}$ Various concentrations were run of these carboxyfluorescein dye samples, and two types of characteristic blockages were observed. Of the total 160 blockages, $14 \%$ of the total showed a two-step blockage (Figure 8); the other 86\% were one-step blockages. Figure 8 shows a two-step and one-step blockage in an $11 \mathrm{~nm}$ pore with $100 \mu \mathrm{L}$ of $1 \times 10^{-8} \mathrm{M}$ dye injected into one $0.5 \mathrm{~mL}$ well containing a $\mathrm{pH} 6.99$ aqueous solution of $0.1 \mathrm{M} \mathrm{KCl}$, and $10 \mathrm{mM}$ HEPES at an applied voltage of $-500 \mathrm{mV}$. The two-step blockages could indicate that the molecules stayed around the entrance of the pore, before inserting all the way inside, or they could reveal nanopore substructure, but the characteristic blockage was used for sensing only, without detailed analysis of the origin of the substructure. Analysis of the events captured at $-300 \mathrm{mV}$ in an $11 \mathrm{~nm}$ nanopore with a dye concentration of $1 \times 10^{-6} \mathrm{M}$ in a $\mathrm{pH} 6.99$ aqueous solution of $0.1 \mathrm{M} \mathrm{KCl}$ and 10mM HEPES indicate that the average blockage depth for both types of events (one-step and two-step) normalized to the average open current was $15 \%$ blocked when this mixture of 5-(and-6)-carboxyfluorescein dye molecules was in the pore as shown in a histogram plot of the events (Figure 9). The blockage percent was calculated by

$$
\%_{\text {block }}=\left(1-\frac{\langle I\rangle}{\left\langle I_{0}\right\rangle}\right) \times 100 \% \quad(E q n .2 .7)
$$

where $\langle I\rangle$ is the mean of the blocked current, and $\left\langle I_{0}\right\rangle$ is the mean of the open current and both the ratio $\langle I\rangle /\left\langle I_{0}\right\rangle$ and the $\%$ block are measures of the blockage depth. The blockage depth is fairly narrowly distributed around a \% block of $15 \%$, but the event durations are more widely distributed, over more than an order of magnitude. 

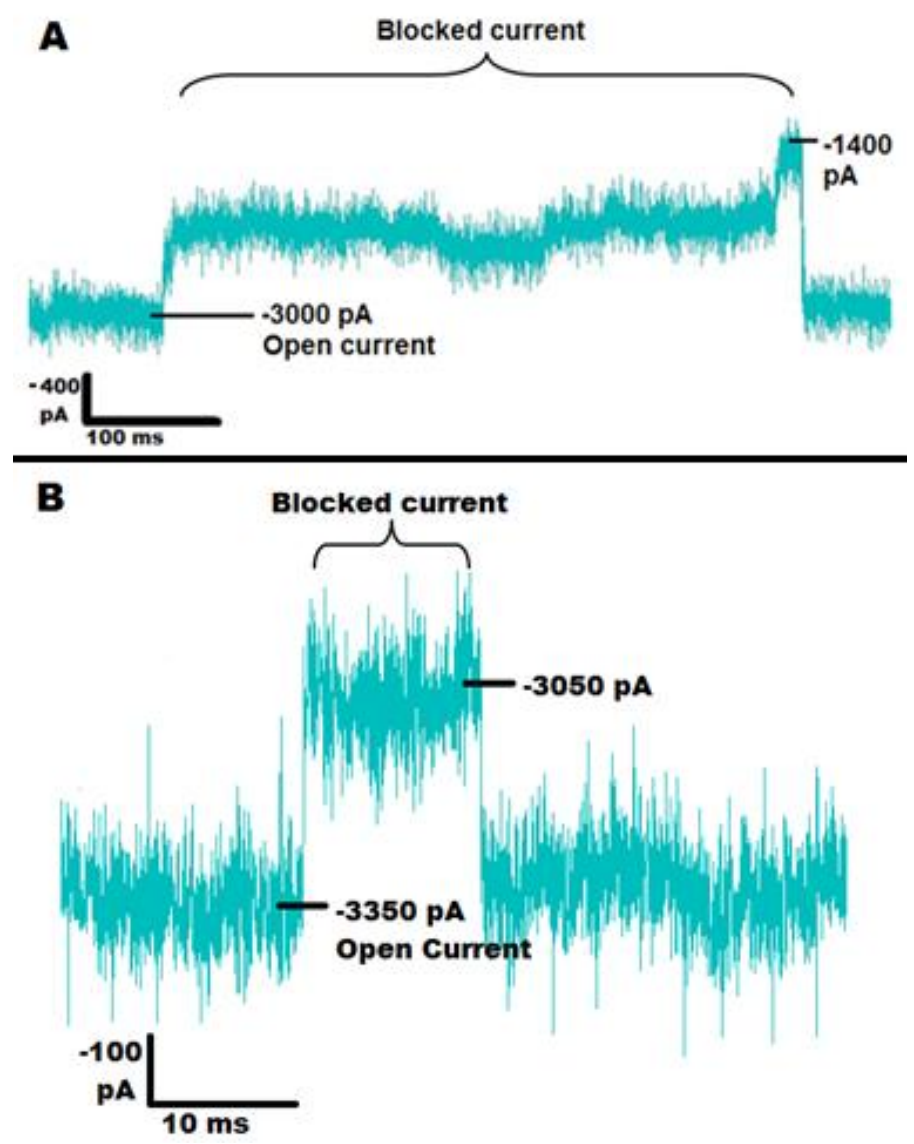

Figure 8. In an $11 \mathrm{~nm}$ pore with $100 \mu \mathrm{L}$ of $1 \times 10^{-8} \mathrm{M}$ 5-(and-6)-carboxyfluorescein dye injected into one $0.5 \mathrm{~mL}$ well containing a pH 6.99 aqueous solution of $0.1 \mathrm{M} \mathrm{KCl}$, and $10 \mathrm{mM}$ HEPES at an applied voltage of $-500 \mathrm{mV}$, there were two types of blockages. The figures show the two types of current blockages characteristic of the detection signals; the event durations are not representative of each type but are drawn from broad event duration distributions. Figure A shows a two-step blockage. The deeper blockage at the end is a signature of 5-(and-6)-carboxyfluorescein dye in this pore, and could indicate that the molecule may stay around the entrance of the pore before inserting all the way. Figure B shows a one-step blockage with the typical blockage depth. 


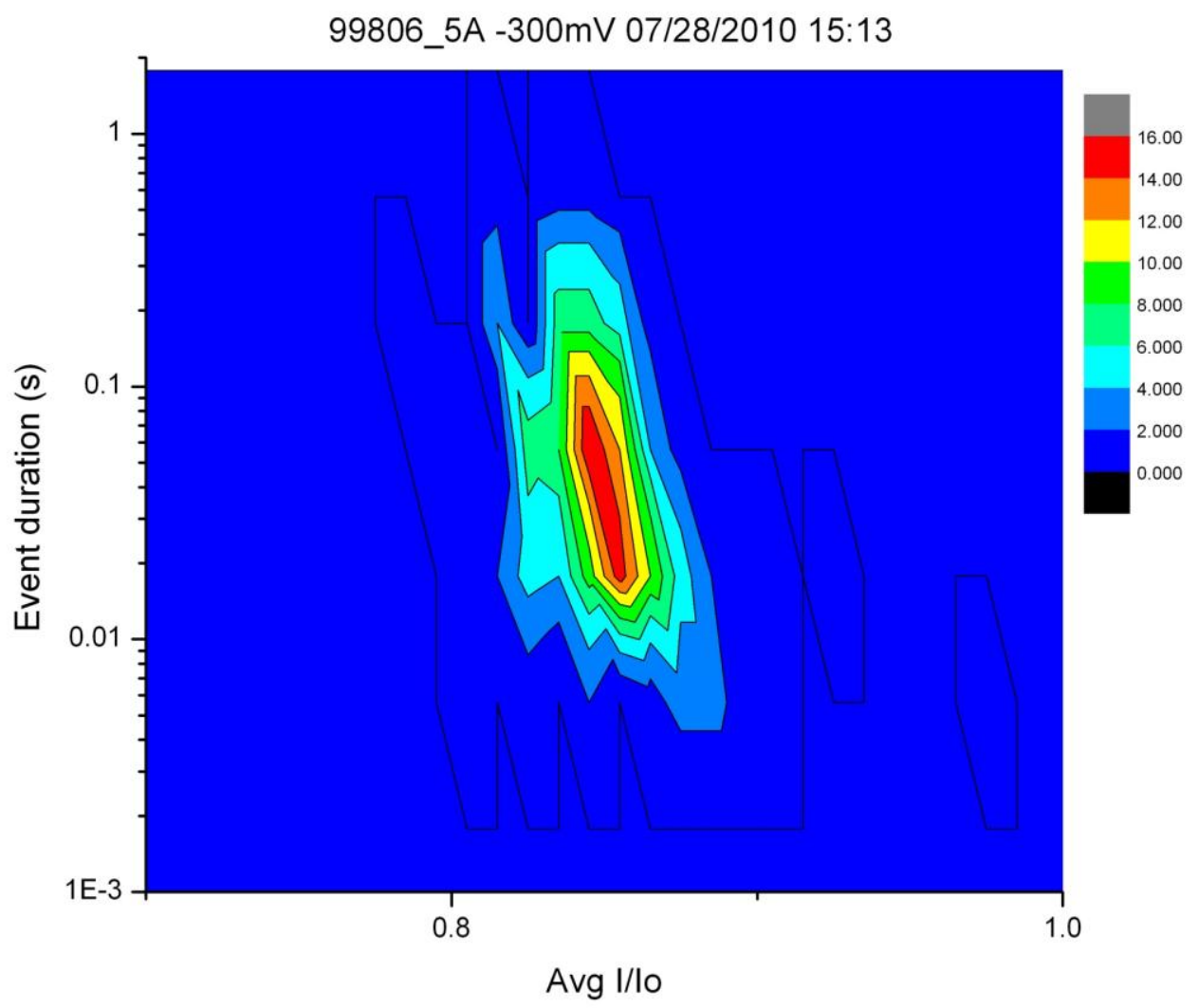

Figure 9. Histogram of the event blockage ratio and the event duration of a concentration of $1 \times 10^{-6} \mathrm{M}$ dye molecules through an $11 \mathrm{~nm}$ nanopore in a pH 6.99 aqueous solution of $0.1 \mathrm{M} \mathrm{KCl}$ and $10 \mathrm{mM}$ HEPES run with an applied voltage of $300 \mathrm{mV}$, where average $I / I_{0}$ is the depth of the blockage, where I is the blocked current and $I_{0}$ is the open current. 


\subsubsection{Detection of $\lambda$-DNA}

One of the most popular molecules used to characterize a pore is $\lambda$-DNA, because its nanopore signal is well-established. ${ }^{41,42,43,44} \lambda$-DNA has very well defined and studied events, making it a useful molecule to determine if the particular nanopore delivers the expected single-molecule signal. $\lambda$-DNA is double stranded DNA that is isolated from bacteriophage lambda from E. coli. It is 48502 base pairs in length. ${ }^{45}$ For these experiments, $\lambda$-DNA, obtained from New England BioLabs (\#N3011L), is isolated from purified bacteriophage by phenol extraction and dialyzed against $10 \mathrm{mM}$ Tris-HCl and $1 \mathrm{mM}$ EDTA at $\mathrm{pH} 8.0 .^{45} \lambda$-DNA for injection into the pore was prepared by taking $10 \mu \mathrm{L}$ of $500 \frac{\mathrm{mg}}{\mathrm{mL}}$ stock $\lambda$-DNA and adding $80 \mu \mathrm{L}$ of a $\mathrm{pH} 7$ aqueous solution of $1 \mathrm{M} \mathrm{KCl}$, and $10 \mathrm{mM}$ HEPES. Another $10 \mu \mathrm{L}$ of a pH 7 aqueous solution of $2 \mathrm{M} \mathrm{KCl}$, and $20 \mathrm{mM}$ HEPES was added to ensure that the electrolyte concentration was at $1 \mathrm{M} \mathrm{KCl}$ and $10 \mathrm{mM}$ HEPES. Samples were stored at $-20^{\circ} \mathrm{C}$ when not in use. For event detection, $5 \mu \mathrm{L}$ of this diluted solution would be injected into the $0.5 \mathrm{~mL}$ well to give a final concentration of $16.8 \mathrm{pM}$. As $\lambda$-DNA is a long polymer, it can fold and bend. Different characteristic conformations of the DNA have been previously detected with solid-state nanopores, ${ }^{42}$ meaning that the shape and duration of each blockage event in a testing experiment can be characterized and compared to known results. The expected current blockage given in equation 2.5 can be used for $\lambda$-DNA, as well as, single-stranded DNA.

Solid-state nanopores used in the experiments for this thesis were able to detect $\lambda$-DNA events (Figure 10), however, electrostatic interactions between the DNA and the pore surface caused the DNA to "stick" to the pore surface, terminating detection 
until the nanopore could be cleaned or replaced. Long lasting blockages to the nanopore, referred to as clogging, are a severe challenge to the method. 


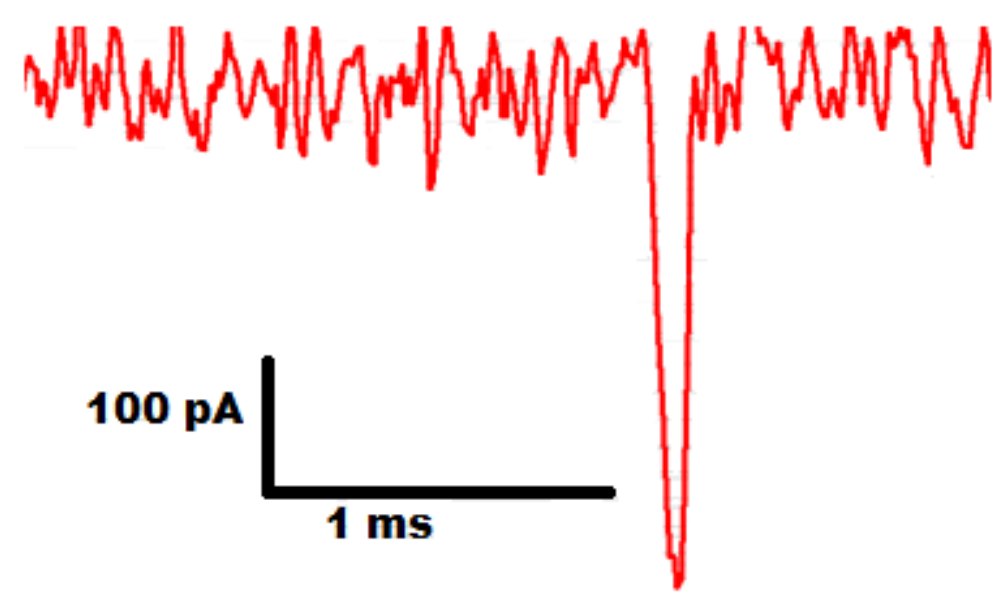

Figure 10. A $\lambda$-DNA event at $+50 \mathrm{mV}$ applied voltage through a $25 \mathrm{~nm}$ pore with a pH 7 aqueous solution of $1 \mathrm{M} \mathrm{KCl}$ and $10 \mathrm{mM} \mathrm{HEPES}$ in which $5 \mu \mathrm{L}$ of a diluted $\lambda$ DNA solution (10 $\mu$ L of $500 \frac{\mathrm{mg}}{\mathrm{mL}} \lambda$-DNA in $10 \mathrm{mM} \mathrm{Tris-HCl}(\mathrm{pH} 8.0), 1 \mathrm{mM}$ EDTA into $10 \mu \mathrm{L}$ of a $\mathrm{pH} 7$ aqueous solution of $2 \mathrm{M} \mathrm{KCl}$ and $20 \mathrm{mM} \mathrm{HEPES}$ and $80 \mu \mathrm{L}$ of a $\mathrm{pH} 7$ aqueous solution of $1 \mathrm{M} \mathrm{KCl}$ and $10 \mathrm{mM} \mathrm{HEPES)}$ was injected into both sides of the pore to give a concentration of 16.8pM in the well. 


\subsection{Clearing a Clogged Silicon Nitride Nanopore}

When the pore becomes clogged, there are a few techniques to clear it out. These techniques include applying high voltage; Deoxyribonuclease I (DNase I); phosphate buffer; $\mathrm{O}_{2}$ plasma cleaning; and piranha solution and nanostrip solution.

The first technique mentioned is applying a high voltage. This is usually the first method that is tried because it does not require disassembling the pore and should not damage the pore. During experiments voltages ranging from 0 to $\pm 1000 \mathrm{mV}$ are applied to the pore to try to capture molecules. When a molecule becomes stuck to a pore for an extended period of time, applying a voltage of $\pm 1000 \mathrm{mV}$ may drive the molecule away from the pore. Applying high voltage is most successful when the molecule is clogging the outside of the pore. When a clog is deep inside the pore, usually indicated by a larger depth of the current blockage, it could be more difficult to remove. A high voltage can be applied from an hour to over a couple days. After each application of voltage, the solution in each well is exchanged to fresh electrolyte solution. This is to ensure that if there are any molecules that were freed, they will not return to the pore and clog again. The possibility of the molecule being electrophoretically driven deeper into the pore or reattaching is a limitation of the high voltage method and other methods will have to be tried.

The second technique is to use Deoxyribonuclease I (DNase I), a polypeptide that will degrade single and double-stranded DNA by cleaving the DNA into small segments. $^{46,47,48}$ This method is only applicable when it is DNA that is stuck in the pore; other molecules will not be attacked by DNase. A $2500 \mathrm{U} / \mathrm{mL}$ solution of DNase (Thermo Scientific \#90083) was diluted with a $\mathrm{pH} 7$ aqueous solution of $1 \mathrm{M}$ 
$\mathrm{KCl}$ and $10 \mathrm{mM}$ HEPES in order to get a $1 \mathrm{U}$ DNase solution. One unit of DNase solution is used to remove $1 \mathrm{mg}$ DNA in 10 minutes, and the effect will decrease with high amounts of $\mathrm{K}^{+}$ions in the solution. ${ }^{46}$ While about $1 \mathrm{mg}$ of DNA, requiring $1 \mathrm{U}$ DNase to digest it, had been injected initially into the cell, the electrolyte solution in the wells was exchanged to remove the free solution DNA before injection of $2 \mathrm{U}$ DNase, so that the substantial excess of DNase was to target only the single molecule of DNA stuck to the nanopore over the 15 minute treatment time. The electrolyte was subsequently exchanged for fresh solution to remove the DNase and partially digested DNA. This method worked 1 of the three times it was employed, but its function was not systematically examined.

The use of phosphate buffer (Sigma Aldrich \#P5655) is not a very common technique being that hot phosphoric acid is used to etch silicon nitride; the increasing conductance of silicon nitride nanopores has been used to suggest physical pore growth through chemical etching when the pores have been immersed in neutral, room temperature phosphate buffer. ${ }^{49}$ A systematic study, however, has not been performed to determine if it was phosphate buffer etching or an artifact of the particular nanopore fabrication conditions leading to apparent size instability. Due to the possibility that the phosphate buffer will etch the silicon nitride, this third technique is mainly used for silicon nitride pores that are closed off, which may happen after drilling a pore, when the silicon nitride may structurally relax to fill the hole again, or if a pore is not thoroughly drilled. A closed off pore is indicated by the current being at or close to zero when a voltage is applied. Trials were performed with a pH 7 aqueous solution of $0.1 \mathrm{M} \mathrm{KCl}$ and $10 \mathrm{mM}$ phosphate buffer. The phosphate buffer then replaced the 
usual HEPES in the solution. Voltages of \pm 800 and $\pm 1000 \mathrm{mV}$ were applied to the cell for times varying from one to three hours. Of the five trials performed to try to open a closed silicon nitride pore, none of them worked. While the high applied voltage could have heated up the phosphate buffer, especially in the pore given its high-resistance, the concentration might have been too low to etch. Overall, this was not an effective method for opening the pores tested.

As mentioned in section 2.1 of this thesis, $\mathrm{O}_{2}$ plasma cleaning, the fourth method, will remove organics from the silicon nitride chip. This technique, as well as the following ones, is usually used as an extreme procedure, because it requires disassembling the electrolyte cell setup. Due to the roughness of the handling, it is possible that the nanopore membrane may break during the disassembly process. For cleaning a nanopore clog with oxygen plasma cleaning, the standard initial mounting conditions are used first: $50 \mathrm{~W}$ for 1-3 minutes, as outlined in Section 2.1. Afterward, the pore is remounted, allowed to wet with the electrolyte solution overnight, and an IV curve is used to test whether or not the pore opened. Only if this does not work are more intense conditions applied: $100 \mathrm{~W}$ for $1-5$ minutes or $10 \mathrm{~W}$ for 5-10 minutes. This method has worked 17 times out of 26 in removing clogs.

The final methods are using piranha solution and Nanostrip solution. As mentioned in section 2.1, piranha is a $3: 1$ mixture of $95-98 \%$ sulfuric acid to $30 \mathrm{wt} \%$ hydrogen peroxide. This is a strong oxidizing agent, which is why it is very useful to remove unwanted materials that could be inside the pore. While these final methods have not been used to remove clogs, they have been used to try to open pores that were not thoroughly electron- or helium ion milled. Limited stability and lifetime 
requires that piranha solution be made fresh for each use. In contrast, Nanostrip is a stabilized formulation that allows for storage for extended periods of time and for longer treatment times approaching 2 hours or longer at $70^{\circ} \mathrm{C}$. The necessity for extensive dilutions and rinsing when using either piranha or Nanostrip solution introduced nanopore chip handling challenges and frequently resulted in broken nanopores when using tweezers for manipulation. A chemically resistant Teflon holder (Figure 11) was designed to securely hold the nanopore during Nanostrip cleaning. While the Nanostrip was unsuccessful to open pores that were not thoroughly electron or helium ion milled, there is still a possibility that it may be useful to remove clogs, because it is a strong oxidizing agent. 


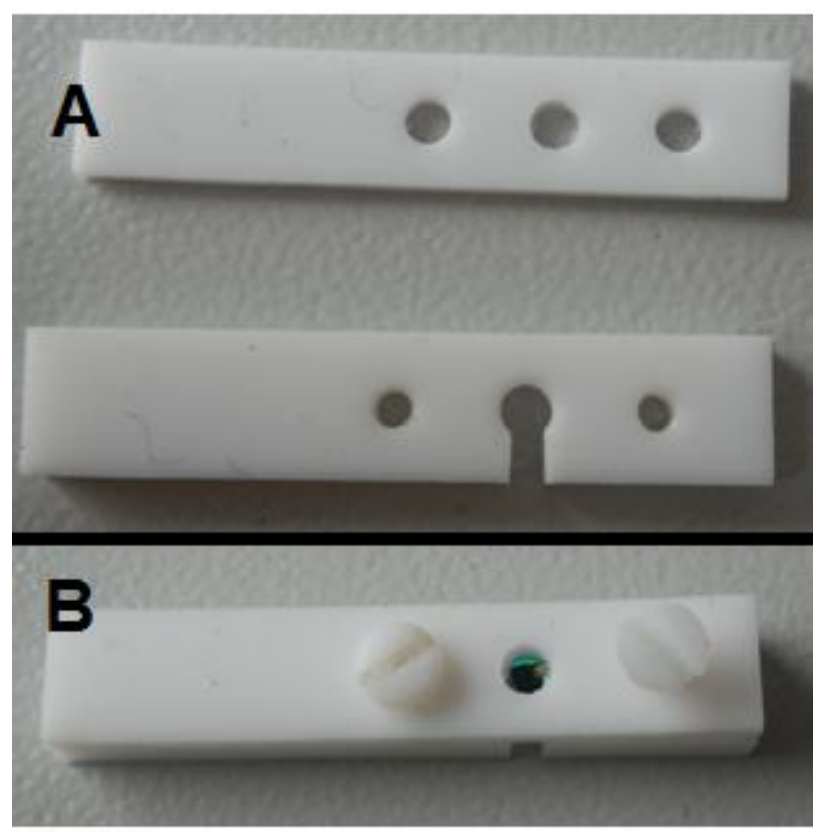

Figure 11. A Teflon chip holder designed for Nanostrip solution cleaning to reduce handling damage. The Teflon is stable in the Nanostrip solution so it will not degrade. The silicon nitride chip is sandwiched between two Teflon pieces (A) and they are screwed together with Teflon screws (B). The holder with the chip is submerged into the Nanostrip solution. 
Of the five techniques mentioned here, high voltage and $\mathrm{O}_{2}$ plasma cleaning proved to be the most effective methods for removing clogs. However, they may only work for clogs at the surface of the pore, because not all the clogs could be removed. Due to the complexity of having to clear out pores, the next step would be to surface functionalize the pore to try to minimize the frequency of analyte sticking to the pore.

33 McIntire, T.M.; Smalley, S.R.; Newberg, J.T.; Lea, A.S.; Hemminger, J.C.; Finlayson-Pitts, B.J. Substrate Changes Associated with the Chemistry of SelfAssembled Monolayers on Silicon. Langmuir. 2006, 22, 5617-5624.

${ }^{34}$ Yusko, E.; Johnson, J.; Majd, S.; Prangkio, P.; Rollings, R.; Li, J.; Yang, J.; Mayer, M. Controlling Protein Translocation Through Nanopores with Bio-Inspired Fluid Walls. Nature Nanotechnology. 2011, 6, 253-260.

${ }^{35}$ Wanunu, M.; Meller, A. Chemically Modified Solid-State Nanopores. Nanoletters. 2007, 7, 1580-1585.

${ }^{36}$ Liebes, Y.; Drozdov, M.; Avital, Y., Kauffmann, Y.; Rapaport, H.; Kaplan, W.; Ashkenasy, N. Reconstructing Solid State Nanopore Shape from Electrical Measurements. Applied Physics Letters. 2010, 97, 223105.

37 Frament, C.; Dwyer, J.R. Conductance-Based Determination of Solid-State Nanopore Size and Shape: An Exploration of Performance Limits. Journal of Physical Chemistry C. 2012, 116, 23315-23321.

38 Tropini, C.; Marziali, A. Multi-Nanopore Force Spectroscopy for DNA Analysis. Biophysical Journal. 2007, 92, 1632-1637. 
${ }^{39}$ Miles, B.; Ivanov, A.; Wilson, K.; Dogan, F.; Japrung, D.; Edel, J. Single Molecule Sensing with Solid-State Nanopores: Novel Materials, Methods, and Applications. Chemical Society Reviews. 2013, 42, 15-28.

${ }^{40}$ CRC: Handbook of Chemistry and Physics. Lide, D.R. Ed.; Taylor \& Francis: Boca Raton, 2005-2006; Vol 86.

${ }^{41}$ Yang, J.; Ferranti, D.; Stern, L.; Sanford, C.; Huang, J.; Ren, Z.; Qin, L.; Hall, A.R. Rapid and Precise Scanning Helium Ion Microscope Milling of Solid-State Nanopore for Biomolecule Detection. Nanotechnology. 2011, 22, 285310-285316.

${ }^{42}$ Chen, P.; Gu, J.; Brandin, E.; Kim, Y.; Wang, Q.; Branton, D. Probing Single DNA Molecule Transport Using Fabricated Nanopores. Nanoletters. 2004, 4, 2293-2298.

${ }^{43}$ Storm, A.J.; Chen, J.H.; Zandbergen, H.W.; Dekker, C. Translocation of DoubleStrand DNA Through a Silicon Oxide Nanopore. Physical Review E. 2005, 71, 051903-051912.

${ }^{44}$ Tabard-Cossa, V.; Trivedi, D.; Wiggin, M.; Jetha, N.; Marziali, A. Noise Analysis and Reduction in Solid-State Nanopores. Nanotechnology. 2007, 18, 305505-305510.

45 New England BioLabs Inc. Lambda DNA. https://www.neb.com/products/n3011lambda-dna (accessed Jan. 18, 2013).

$\begin{array}{lll}{ }^{46} \text { Thermo } & \text { Scientific. } & \text { DNase }\end{array}$ http://www.piercenet.com/browse.cfm?fldID=06010485 (accessed Jan. 19, 2013).

${ }^{47}$ Campbell, V.W.; Jackson, D.A. The Effect of Divalent Cations on the Mode of Action of DNase I: The Initial Reaction Products Produced from Covalently Closed Circular DNA. Journal of Biological Chemistry. 1980, 255, 3726-3735. 
${ }^{48}$ Melgar, E.; Goldthwait, D.A. Deoxyribonucleic Acid Nucleases: The Use of a New Method to Observe the Kinetics of Deoxyribonucleic Acid Degradation by Deoxyribonucleases I, Deoxyribonuclease II, and Escherichia Coli Endonuclease I. Journal of Biological Chemistry. 1968, 243, 4401-4408.

49 van Gelder, W.; Hauser, V.E. The Etching of Silicon Nitride in Phosphoric Acid with Silicon Dioxide as a Mask. Journal of The Electrochemical Society. 1967, 114, 869-872. 


\section{CHAPTER 3}

\section{SURFACE FUNCTIONALIZATION OF A NANOPORE}

\subsection{Nanopore Surface Functionalization with Silane}

Control over the surface properties of a nanopore will help to direct interactions with various analytes. ${ }^{50,51}$ Surface modification of the nanopore can be done to be able to control the chemical functionality, hydrophobicity, and surface charge. Another benefit of coating an inorganic pore, such as silicon nitride, is that it will make the pore more biologically compatible. Wanunu et al. ${ }^{50}$ performed a series of surface coatings on silicon nitride nanopores, similar in size and shape to the nanopores used frequently within this thesis. In their work, one of the surface functionalizing molecules they investigated is methoxyethoxyundecyltrichlorosilane (1, Gelest, Inc. \#SIM6491.5, Figure 1A), which is a methoxyethylene gycol, or a polyethylene glycol-like (PEG, Figure 1B) molecule. PEG modified surfaces are known to lower interactions between biomolecules and the surface. ${ }^{52,53}$ As DNA tends to interact with the silicon nitride surface, previously published literature shows that PEGylation of the surface will minimize this interaction, and that without PEG, long-

term clogging of the nanopore will occur. ${ }^{54}$ Therefore, coating a nanopore with PEG would be a good option to lower any unwanted interactions and prevent DNA from sticking to the nanopore. It was hypothesized that by surface coating the pore, it would lower any unwanted interactions, allowing for nanopore force spectroscopy (NFS, see chapter 1) to be routinely possible in solid-state nanopores. 


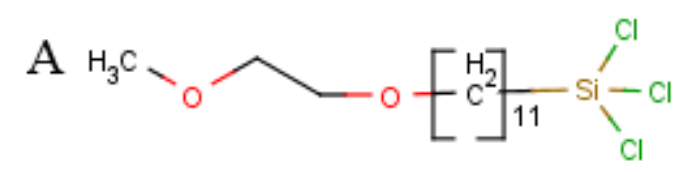

Methoxyethoxyundecyltrichlorosilane (1)

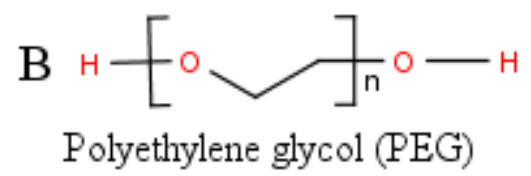

Figure 1. A) Methoxyethoxyundecyltrichlorosilane (1) was used in an effort to coat pores and is a B) polyethylene glycol (PEG) type molecule. 


\subsubsection{Silane Functionalization Methods}

Silane functionalization of nanopores was first reported by Wanunu et al.Error! Bookmark not defined. They pursued two different routes: so-called ex situ coating on large $(\sim 10-25 \mathrm{~nm}$ in diameter) and in situ coating on nanopores smaller than $10 \mathrm{~nm}$. In the former approach, nanopores were simply soaked in a bulk solution of the reagents, whereas in the latter approach, the nanopores were exposed to reagent in a typical nanopore sensing configuration and applied voltage was used to drive the reagents into the nanopore. In an extension of this work, coating with 1 was tried in situ on a large pore whose diameter, based on conductance, was estimated to be about $88 \mathrm{~nm}$. It is important to note that $\mathbf{1}$ will polymerize in water. Therefore, certain steps must be taken to avoid this. Once the pore is mounted into the electrochemical cell with a $\mathrm{pH} 7.0$ aqueous solution of $1.0 \mathrm{M} \mathrm{KCl}$ and $10 \mathrm{mM}$ HEPES and background current traces and IV curves are taken, the electrolyte was exchanged with $9.0 \mathrm{~mL}$ of $18 \mathrm{M} \Omega . \mathrm{cm}$ deionized water in both wells to remove solutes that could precipitate in methanol, and then subsequently exchanged for $9.0 \mathrm{~mL}$ of HPLC grade methanol (Sigma Aldrich \#34860) in both wells by directly injecting methanol into the water and simultaneously withdrawing out the resulting mixture so as not to overflow the liquid well. Finally, the methanol was exchanged with $9.0 \mathrm{~mL} \quad 0.50 \mathrm{M}$ tetrabutylammonium chloride (TBACl, Sigma-Aldrich \#86870) in methanol in both wells. To prevent the polymerization of $\mathbf{1}$ in aqueous solution, silane coating was performed in the methanol electrolyte. In keeping with the published procedures, no additional precautions against water-induced polymerization of the silane were taken other than the use of methanol solvent. ${ }^{50}$ First, background IV curves and current 
traces were used to characterize the pore in methanol-based electrolyte. Then $60 \mu \mathrm{L}$ of 1 was injected into both wells of the electrochemical cell. Voltages of \pm 400 and $\pm 800 \mathrm{mV}$ were applied for 200 seconds each, at a time, resulting in a 30 minute current trace with IV curves in between each 30 minute current trace. After 4 hours, the nanopore conductance decreased from $847 \mathrm{nS}$ to $14 \mathrm{nS}$. Then the solutions in the wells were exchanged for fresh, silane-free $0.5 \mathrm{M} \mathrm{TBACl}$ in methanol $(9.0 \mathrm{~mL}$ on both sides). After this exchange, the nanopore conductance was about $80 \mathrm{nS}$. This solution was then exchanged with methanol, followed by $18 \mathrm{M} \Omega . \mathrm{cm}$ deionized water, and finally with a $\mathrm{pH} 7.0$ aqueous solution of $1.0 \mathrm{M} \mathrm{KCl}$ and $10 \mathrm{mM}$ HEPES. In the $\mathrm{pH}$ 7.0 aqueous solution of $1.0 \mathrm{M} \mathrm{KCl}$ and $10 \mathrm{mM}$ HEPES, the pore size after silane treatment was about $63 \mathrm{~nm}$, a decrease from its original estimated size of $88 \mathrm{~nm}$. To further characterize the pore, $100 \mu \mathrm{L}$ of $\lambda$-DNA (see chapter 2.2 for solution prep) was injected into the cell reservoir, yielding a final concentration of $282 \mathrm{pM}$ in the $0.5 \mathrm{~mL}$ well. No events were detected, which could have been due to the pore and/or the magnitude of the noise in the current trace to be too large, or that the structure of the coated pore (Figure 2) was incompatible with single-molecule translocation. Another pore of about $7 \mathrm{~nm}$ was also in situ silane coated. The same procedures were followed. After silane was injected into the pore, the pore conductance, measured in $0.5 \mathrm{M} \mathrm{TBACl}$ in methanol decreased to about $0.25 \mathrm{nS}$. When the electrolyte was once again a $\mathrm{pH} 7.0$ aqueous solution of $1.0 \mathrm{M} \mathrm{KCl}$ and $10 \mathrm{mM}$ HEPES, the pore conductance was essentially zero, indicating that the nanopore was closed. After extended soaking in the methanol-based $\mathrm{TBACl}$ electrolyte and return to the aqueous potassium chloride-based electrolyte, the conductance was no longer zero, but was 
rather $4 \mathrm{~nm}$. In both instances of in situ silane coating, a measureable reduction in the nanopore conductance, suggesting a reduction in its diameter, was recorded. The inability to detect DNA in the larger pore, coupled with the variability in modeldependent inferred nanopore diameter, suggested the need for additional characterization steps, however. A sample of lambda DNA was used in an attempt to characterize the $7 \mathrm{~nm}$ bare to $4 \mathrm{~nm}$ coated nanopore, as had been attempted previously for the $88 \mathrm{~nm}$ bare to $63 \mathrm{~nm}$ nanopore. 

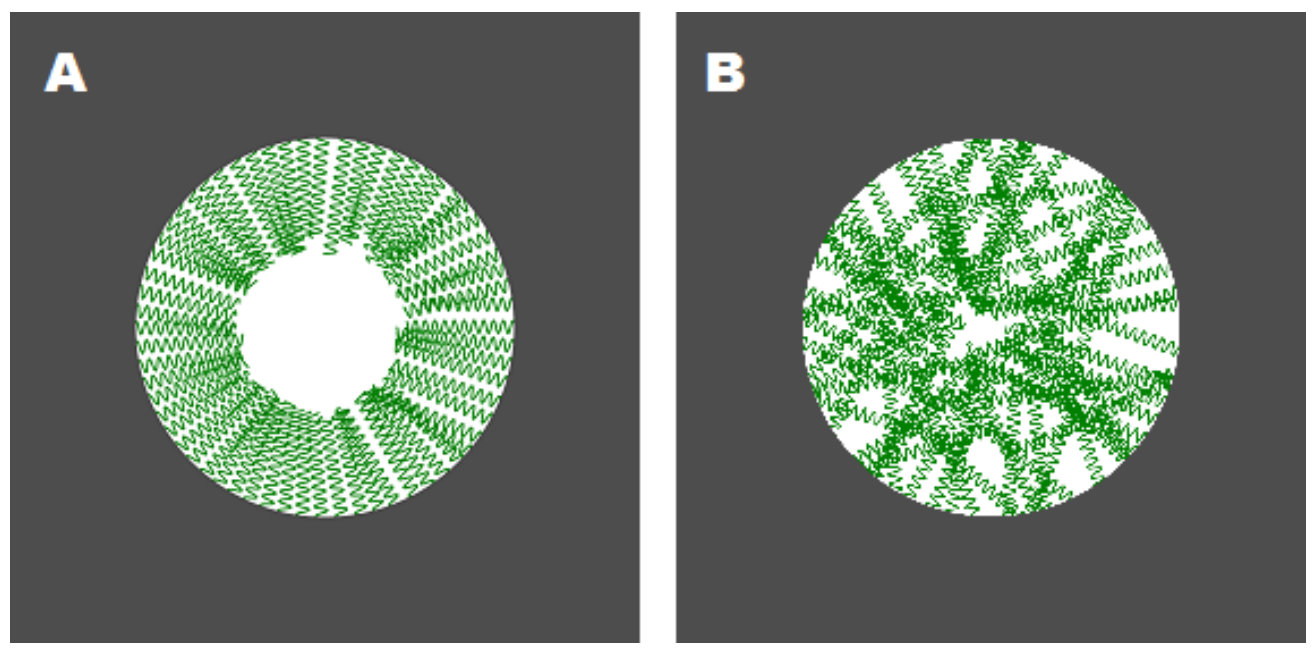

Figure 2. A) An ideal depiction of what a silane-coated nanopore will look like. B) A depiction of what could happen when 1 polymerizes the pore. 


\subsubsection{Probe DNA Construct Preparation}

Given the lowered conductance of the $4 \mathrm{~nm}$ silane-treated pore, single-stranded probe DNA, biotinylated at the 5' end and coupled with neutravidin (hereafter referred to as the "probe DNA construct"; see section 1.3 for description, and Figure 4 in Chapter 1) was used to characterize the pore. The purpose to using the probe DNA construct instead of the well-characterized $\lambda$-DNA is that the probe DNA construct is an important element in NFS and can be held in the nanopore for extended measurements of both the nanopore and the nanopore-DNA interaction. The hypothesis was that surface functionalization would make NFS possible, so characterizing with the probe DNA construct was the next logical step toward NFS.

The probe DNA construct was prepared first by making a neutravidin stock solution. Neutravidin, obtained from Thermo Scientific (\#31000), has a lower isoelectric point and a higher specific binding to biotin than avidin. ${ }^{55}$ First, $1.0 \mathrm{~mL}$ of $18 \mathrm{M} \Omega . \mathrm{cm}$ deionized water and $0.67 \mathrm{~mL}$ of $25 \mathrm{mM}$ HEPES was degassed under argon for about 10 minutes. Second, $0.010 \mathrm{~g}$ of neutravidin was dissolved in the $1.0 \mathrm{~mL}$ of $18 \mathrm{M} \Omega . \mathrm{cm}$ deionized water. The $0.67 \mathrm{~mL}$ of HEPES was mixed in to form $100 \mu \mathrm{M}$ neutravidin in $10 \mathrm{mM}$ HEPES. After neutravidin stock was prepared, the DNA stock was prepared. The sequence for the probe DNA is $5^{\prime}$-biotin- $(\mathrm{A})_{30} \mathrm{C}(\mathrm{A})_{29} \mathrm{C}(\mathrm{A})_{19}$ CCAC CAA CCA AAC C-3', and was obtained from Integrated DNA Technologies after IE HPLC purification. The stock powder, $6.1 \mathrm{nmol}(0.18 \mathrm{mg})$, was centrifuged for about 1 minute to ensure that all of the powdered DNA was at the bottom of the container. To the $6.1 \mathrm{nmol}$ of powder, $61 \mu \mathrm{L}$ of degassed $10 \mathrm{mM}$ HEPES was added to make a final concentration of $100 \mu \mathrm{M}$ DNA. The $100 \mu \mathrm{M}$ DNA solution was 
vortexed for 15 seconds and left to sit for 30 minutes. Finally, the DNA could be attached to the neutravidin to form the probe DNA. This was done by mixing $10 \mu \mathrm{L}$ of a pH 7.0 aqueous solution of $2.0 \mathrm{M} \mathrm{KCl}$ and $20 \mathrm{mM}$ HEPES, with $10 \mu \mathrm{L}$ of a $\mathrm{pH}$ 7.0 aqueous solution $1.0 \mathrm{M} \mathrm{KCl}$ and $10 \mathrm{mM}$ HEPES, and $10 \mu \mathrm{L}$ each of the DNA stock and neutravidin stock solutions for a final concentration of $10 \mu \mathrm{M}$ probe DNA in a pH 7.0 aqueous solution of $1.0 \mathrm{M} \mathrm{KCl}$ and $10 \mathrm{mM}$ HEPES. With a vortexer, this solution was mixed for 30 seconds and then centrifuged for 2 seconds to return all the liquid to the bottom. This solution was allowed to complex at room temperature for 30 minutes. If the solution was for immediate usage, it would then be stored at $4.0^{\circ} \mathrm{C}$ overnight; for long term storage, the probe DNA construct was stored at $-20^{\circ} \mathrm{C}$. Usually about $2-5 \mu \mathrm{L}$ of the probe DNA solution was injected into a $500 \mu \mathrm{L}$ well to give a final concentration of about $100 \mathrm{nM}$.

\subsubsection{Characterization of Probe DNA Construct in the Silane-Coated Pore}

Using the apparently silane-modified $4 \mathrm{~nm}$ pore, the probe DNA was run with an applied voltage of $-200 \mathrm{mV}$. Current blockages indicating insertion of the probe into the nanopore were not detected, and after about an hour of applied voltage, the apparent pore size had been reduced to $2.8 \mathrm{~nm}$. The underlying reduction in nanopore conductance could have been caused by DNA or protein sticking to the pore, or due to changes to the silane coating. The combination of no observed current blockages consistent with molecule insertion into the nanopore, the decrease in conductivity of the pore after silane coating, and the possibility of DNA sticking to the silane-treated pore, could support the existence of a silane "coating" as shown in Figure 2. The decrease in nanopore conductivity, in that instance, was caused not by a uniform 
coating of the nanopore edge, reducing the diameter by a fixed amount, but by the random filling of the nanopore that prevented molecular insertion and reduced the conductance to provide a reduced effective nanopore diameter. This could have happened by silane polymerizing in the bulk of the pore (Figure $2 \mathrm{~B}$ ), which allowed for ions to pass through to give a measurable current, but not for molecules, such as DNA, to pass through. Further polymerization of the silane in the aqueous electrolyte could have been the reason the pore size decreased after about an hour.

Based on the results obtained here, it can be concluded that coating the outer rim of the nanopore with a monolayer of $\mathbf{1}$ in situ, so that the nanopore can be used as a single molecule detector, did not successfully work when reproducing the literature procedure. While silane coating of planar surfaces is itself frequently challenging, the conformal silane coating of a nanopore is even more dramatically challenged by its reproducibility. ${ }^{56}$ For example, while the literature ${ }^{50}$ reports that the coating on the rim of the nanopore should be $2.2 \mathrm{~nm}$, the experiment here showed that the longer 1 stayed in the pore, the more the size decreased. Overall, these challenges make it difficult to control the silane-based functionalization of a nanopore, and alternative approaches are reported to offer the possibility of greater control and reproducibility.

\subsection{Nanopore Surface Functionalization with a Fluid Lipid Bilayer}

Inspired by lipid-coated nanopores in insects, Yusko et al. ${ }^{57}$ coated nanopores with a fluid lipid bilayer to prevent clogging. In their work they used a few different types of lipids to coat nanopore walls, including 1,2-dilauroyl-sn-glycero-3phosphocholine (DLPC), 1,2-dimyristoyl-sn-glycero-3-phosphocholine (DMPC), and 
1-palmitoyl-2-oleoyl-sn-glycero-3-phosphocholine (POPC). For the work in this thesis, POPC was used, because it is an electrically neutral bilayer over the $\mathrm{pH}$ range that was used in this work $(\mathrm{pH}$ 7-7.5) and it was shown to have anti-clogging capabilities. ${ }^{57}$ However, at very acidic conditions (below $\mathrm{pH} 4$ ) the bilayer becomes positively charged, and at very basic conditions (above $\mathrm{pH} 10$ ) the bilayer becomes negatively charged causing the bilayer to fold. ${ }^{58}$ The end-to-end length of POPC is $1.9 \mathrm{~nm}$, so that it is expected to physically reduce the nanopore diameter by about 8 nm.

\subsubsection{Preparation of POPC}

POPC solution was prepared by dissolving 0.0015 g POPC (Avanti Polar Lipids \#770557) in chloroform (Sigma-Aldrich \#372978); once the chloroform evaporated, the lipid was resuspended in $1.0 \mathrm{~mL}$ of a pH 7.5 aqueous solution of 0.15 $\mathrm{M} \mathrm{KCl}$ and $10 \mathrm{mM}$ HEPES for a final concentration of $2.0 \mathrm{mM}$ POPC. This $1.0 \mathrm{~mL}$ solution was extruded 11 times through a filter with $50 \mathrm{~nm}$ pores (Whatman \#800308) using a mini-extruder from Avanti Lipids (\#610000) at $25^{\circ} \mathrm{C}$ to allow for uniform 50 $\mathrm{nm}$ liposomes to form. ${ }^{59}$

\subsubsection{Formation of a Fluid Lipid Bilayer on the Nanopore}

The formation of the lipid bilayer on the nanopore surface was tried via a number of methods. In the first method, an in situ approach was used, where $150 \mu \mathrm{L}$ of the $2.0 \mathrm{mM}$ POPC was injected into one side of the $0.5 \mathrm{~mL}$ well containing a $\mathrm{pH} 7$ aqueous solution of $1.0 \mathrm{M} \mathrm{KCl}$ and $10 \mathrm{mM}$ HEPES. The initial pore size was estimated to be $41 \mathrm{~nm}$ (Figure 3A) from its conductance, assuming the conicalcylindrical shape typical of TE-based fabrication. The liposomes were allowed to sit 
in solution for about 20 minutes, and the solution was refreshed. Afterwards, the pore was about $18 \mathrm{~nm}$ in diameter (Figure 3B). This is a much larger change than expected, because the bilayer thickness is reported to be about $3.7 \mathrm{~nm}$ in the literature, so an overall $8 \mathrm{~nm}$ change in diameter should have occurred. ${ }^{57}$ 


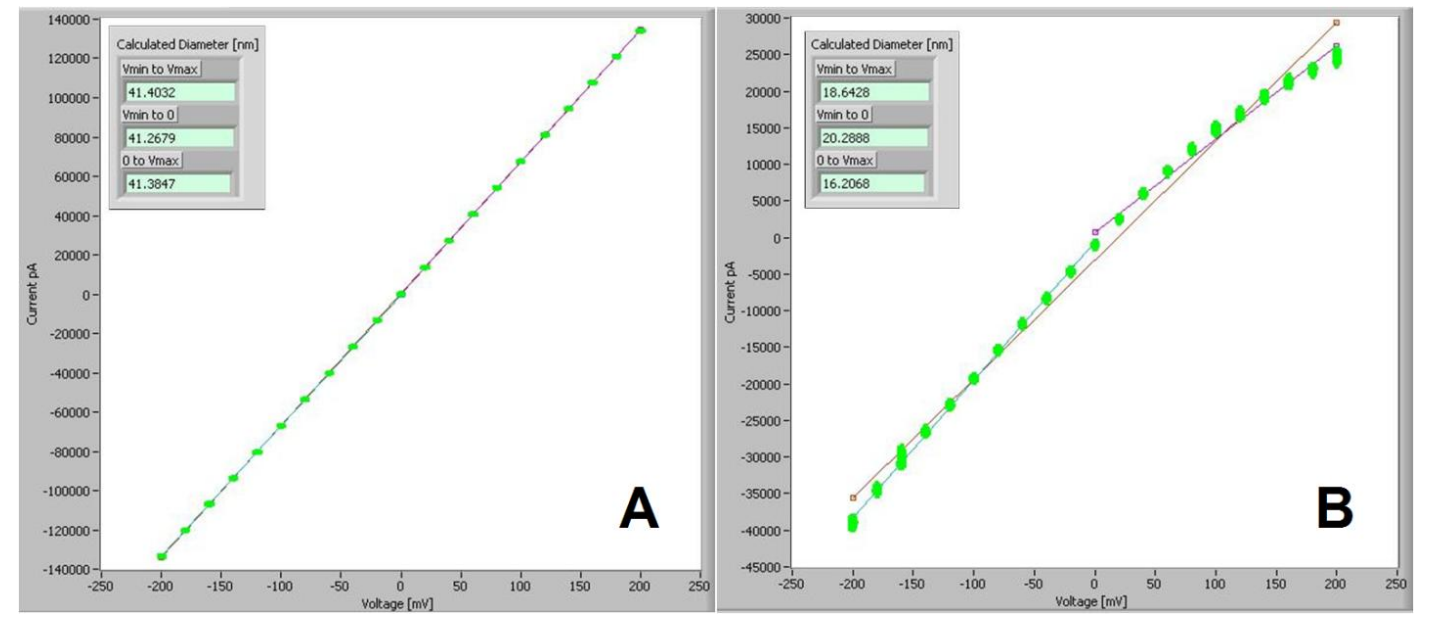

Figure 3. Before and after injection of $2 \mathrm{mM} \mathrm{POPC}$ to one side of a well with a pH 7.0 aqueous solution of $1.0 \mathrm{M} \mathrm{KCl}$ and $10 \mathrm{mM} \mathrm{HEPES.} \mathrm{A)} \mathrm{Before} \mathrm{POPC} \mathrm{the} \mathrm{pore} \mathrm{size} \mathrm{is}$ shown to be about $41 \mathrm{~nm}$, and the IV curve is very linear. B) After POPC, the pore size decreases to about $18 \mathrm{~nm}$, and the IV curve is bent indicating that something is in the pore. 
However, besides indicating the decrease in size, the IV curves also showed that something was in or on the pore because it was asymmetrical after the POPC injection (Figure 3B). It was assumed that POPC had coated the pore, and to test this $\lambda$-DNA was used to characterize it. $10 \mu \mathrm{L}$ of $1.70 \mathrm{nM} \lambda$-DNA (see chapter 2.2 for preparation) was added to one side of the well to a final concentration of $33 \mathrm{pM}$. A total of 182 events recorded in the current trace at $-200 \mathrm{mV}$ were automatically extracted using a current threshold algorithm. A characteristic event is shown in Figure 4. The duration of these events was longer than characteristic $\lambda$-DNA events in uncoated nanopores (seconds compared to milliseconds), but the longer timescale was consistent with translocation time slowing in lipid bilayer coated pores. ${ }^{57}$ Figure 5 is a histogram of the principal current blockage characteristics of duration and blockage depth

$$
\%_{\text {block }}=\left(1-\frac{\langle I\rangle}{\left\langle I_{0}\right\rangle}\right) \times 100 \% \quad(E q n .2 .7)
$$

where average $\mathrm{I} / \mathrm{I}_{0}$ is the depth of the blockage, where $\mathrm{I}$ is the blocked current and $\mathrm{I}_{0}$ is the open current. The current blockage magnitude shows a narrow distribution about a magnitude of approximately $5 \%$. Using the bare pore diameter of $41 \mathrm{~nm}$, and a bilayer thickness of $3.7 \mathrm{~nm}$, Equation 2.5 would suggest a blockage depth of $200 \mathrm{pA}$, or a $1 \%$ blockage magnitude, which is closely supported by the observation here. Other methods for coating the nanopore were attempted without demonstrated success. One such method was to allow the POPC to sit in the well for longer than 20 minutes, and instead sat for about 60 minutes; this was tried 12 times without success. Another method was disassembling the electrochemical cell and placing a $150 \mu \mathrm{L}$ drop of 2 $\mathrm{mM}$ POPC on top the nanopore chip directly and allowed to sit for 15-60 minutes; this 
was tried 3 times without success. Finally, an increase of concentration of the POPC from $2 \mathrm{mM}$ to $20 \mathrm{mM}$ was used instead; this was tried once, and did not work. A reason that this might not have worked is that no pressure was being applied across the membrane (see Section 3.3), and the liposome was expected to float gently onto the pore and collapse to form a bilayer coating the surface. Applying a voltage during this process in the future may allow the liposome to reach the pore. Another challenge of applying voltage is that the fluid lipid bilayer may go through the pore instead of coating it. From the single successful trial, coating a pore with POPC appears to prevent sticking from occurring, and if perfected will be a very good surface functionalization method to stop clogging. It requires a change in the apparatus to allow a pressure difference to be applied across the nanopores, however, and this work is underway. 


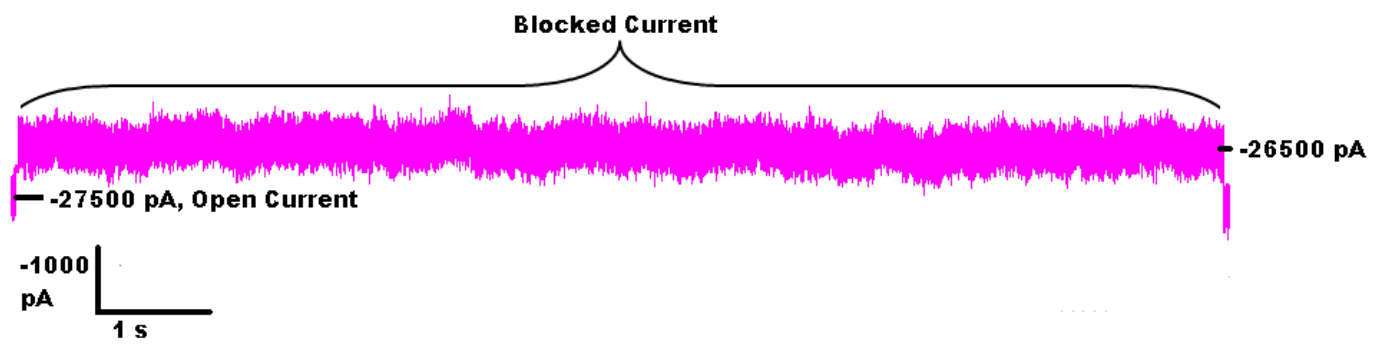

Figure 4. An example of a current blockage of $33 \mathrm{pM}$ of $\lambda$-DNA in an $18 \mathrm{~nm}$ sized nanopore coated with POPC in an electrochemical cell with containing a pH 7 aqueous solution of $1 \mathrm{M} \mathrm{KCl}$ and $10 \mathrm{mM}$ HEPES. While this particular blockage duration was about 6 seconds, the mean blockage duration was about 1 second, which is longer than the mean blockage duration of $\lambda$-DNA on bare silicon nitride pores. 


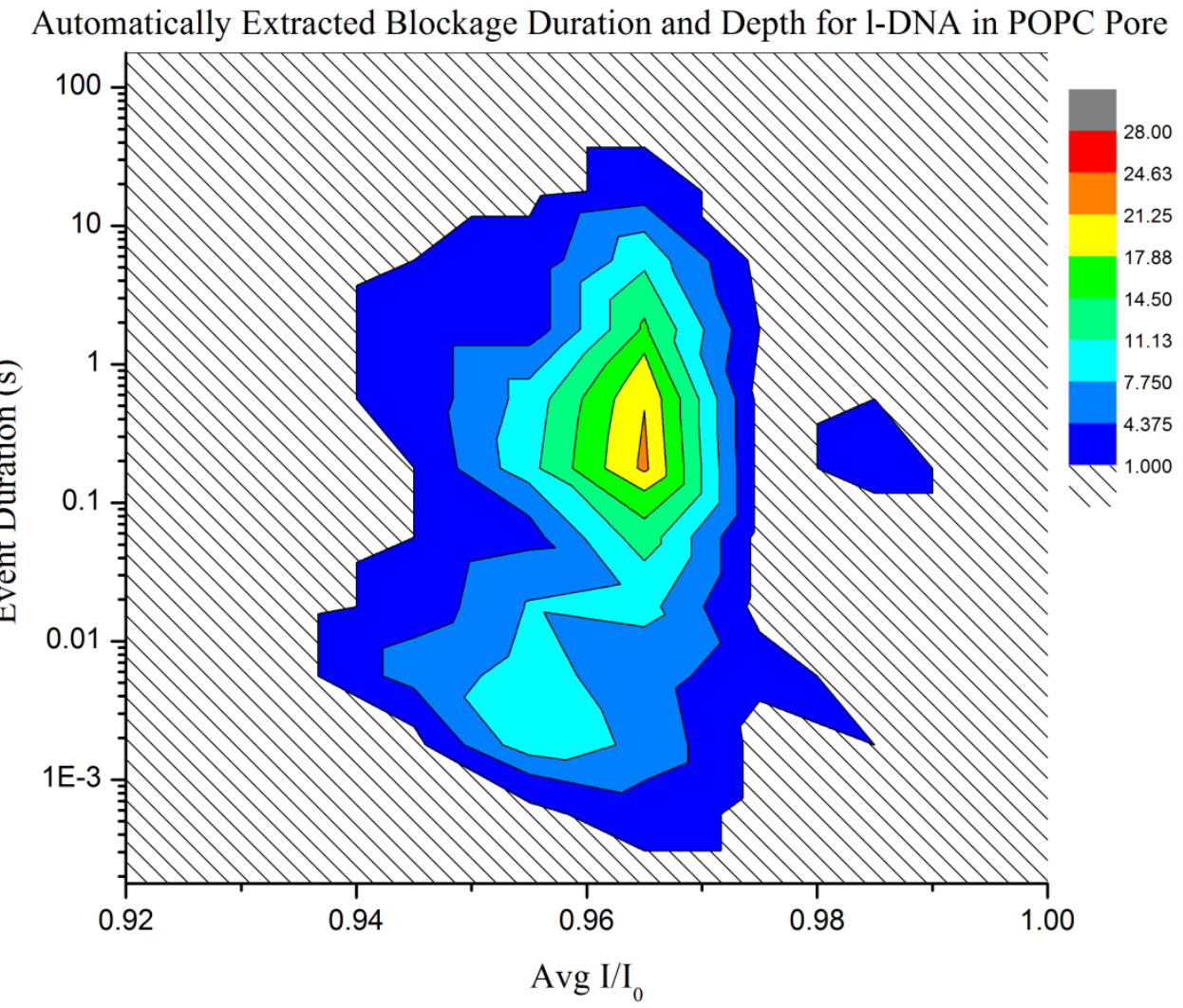

Figure 5. Histogram of the event blockage depth and the event duration of a concentration of $33 \mathrm{pM}$ of $\lambda$-DNA through an $18 \mathrm{~nm}$ nanopore coated with a POPC lipid bilayer in a pH 7 aqueous solution of $1 \mathrm{M} \mathrm{KCl}$ and $10 \mathrm{mM}$ HEPES run with an applied voltage of $-200 \mathrm{mV}$, where average $I / I_{0}$ is the depth of the blockage, where I is the blocked current and $I_{0}$ is the open current. 


\subsection{Formation of a Lipid Bilayer in a Solid-State Pore with the Nanion}

The Nanion Port-a-Patch ${ }^{60}$ system affords the opportunity to explore the interaction of pressure-driven lipid bilayer vesicles with micropores before the more demanding interaction of $50 \mathrm{~nm}$ vesicles with $\sim 10 \mathrm{~nm}$ nanopores. The Nanion system applies a pressure gradient across a glass micropore with diameter close to 1 micrometer, and thereby draws in $~ 30$ micrometer giant unilamellar vesicles (GUVs) that have been formed via electroswelling in a Nanion Vesicle Prep ${ }^{61}$ Pro system. This system allows the straightforward investigation of solution and GUV composition and resulting lipid bilayer properties, in a configuration compatible with nanopore sensing. In this testing configuration, the bilayer can be suspended across the open, approximately 1 micrometer borosilicate glass aperture of the disposable micropore. While it is possible to monitor the bilayer stability simply by applying a voltage and measuring to see if a measured current indicates bilayer rupture, it is also convenient to introduce $\alpha$-hemolysin nanopores in the bilayer so that the trans-pore current can be used to monitor the bilayer stability. A stable, well-characterized ahemolysin conductance will then indicate acceptable bilayer properties. Since the first documented use in 1996 by Kasianowicz et al. ${ }^{62} \alpha$-hemolysin nanopores have been the biological nanopore of choice to analyze single stranded DNA and RNA molecules. ${ }^{63,64,65,66}$

\subsubsection{GUV and Bilayer Formation}

The pores for this work were micropores with a resistance of 3-5 $\mathrm{M} \Omega$ on glass chips (Nanion NPC-1). Along with pore size, shape, and surface chemistry, the resistance is an indication of whether the micropore is open or closed, and hence, 
whether a bilayer had formed a seal over the top. IV curves can be used with these micropore chips to measure the resistance, as in the standard approach to characterizing nanopores. Bilayers were formed using giant unilamellar vesicles (GUVs) composed of a mixture of $10 \mathrm{mM}$ 1,2-diphytanoyl-sn-glycero-3phosphocholine (DPhPC, Avanti Lipids \#850356C) with $1.0 \mathrm{mM}$ cholesterol (Avanti Lipids \#700001P) in 1.0 M d-sorbitol (Sigma-Aldrich \#S1876). DPhPC and cholesterol solution was prepared by dissolving the $10 \mathrm{mM}$ lipid and $1.0 \mathrm{mM}$ cholesterol in chloroform. Cholesterol is important to keep the bilayers stable. ${ }^{67}$ Using a Nanion Vesticle Prep Pro ${ }^{68}$ (Figure 6) to automate the electroswelling process, giant unilamellar vesicles (GUVs, Figure 7) were formed by taking $25 \mu \mathrm{L}$ of the $\mathrm{DPhPC}$ and cholesterol solution and placing it on a conductive glass slide. The chloroform was allowed to evaporate and $250 \mu \mathrm{L}$ of $1.0 \mathrm{M}$ d-sorbitol was added. Another conductive glass slide was place on top of this, allowing the solution to be sandwiched between the conductive slides. An alternating voltage of $\pm 3.0 \mathrm{~V}$ and frequency of $5.0 \mathrm{~Hz}$ applied over was applied for 2 hours at $36^{\circ} \mathrm{C}$. After the 2 hours, the GUVs were removed by pipette and stored at $4^{\circ} \mathrm{C}$. If under the microscope, the GUVs appear to be aggregated, the GUVs were prepared again with an addition of 2 mM EDTA (Sigma \#E5134) to the d-sorbitol solution. 


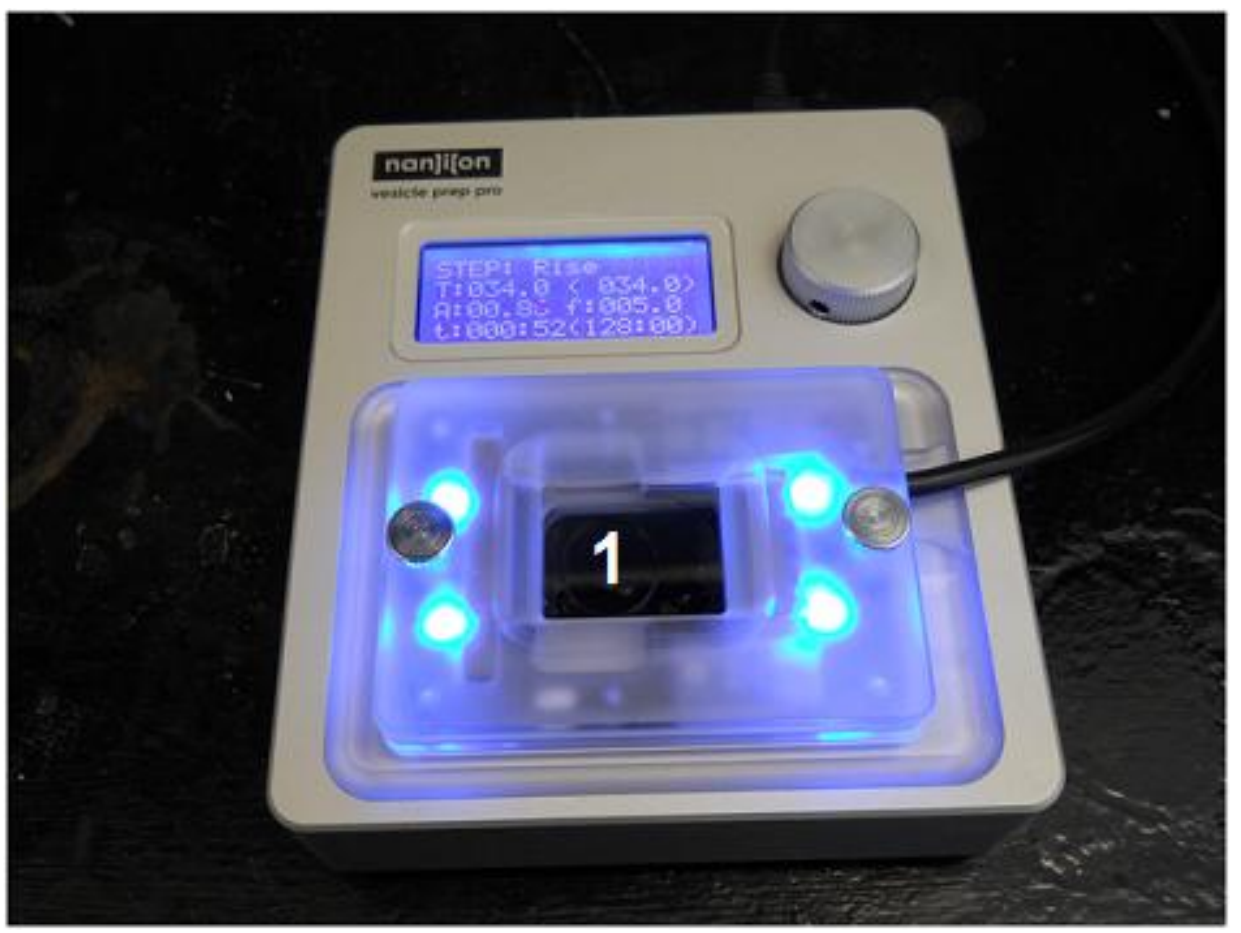

Figure 6. The Nanion Vesticle Prep Pro an instrument that automates electroswelling process to make GUVs. The lipids and d-sorbitol are placed in an $O$-ring sandwiched between two conductive glass slides (1), where an alternating voltage of $\pm 3.0 \mathrm{~V}$ and frequency of $5.0 \mathrm{~Hz}$ applied over was applied for 2 hours at $36^{\circ} \mathrm{C}$ to create the GUVs. 


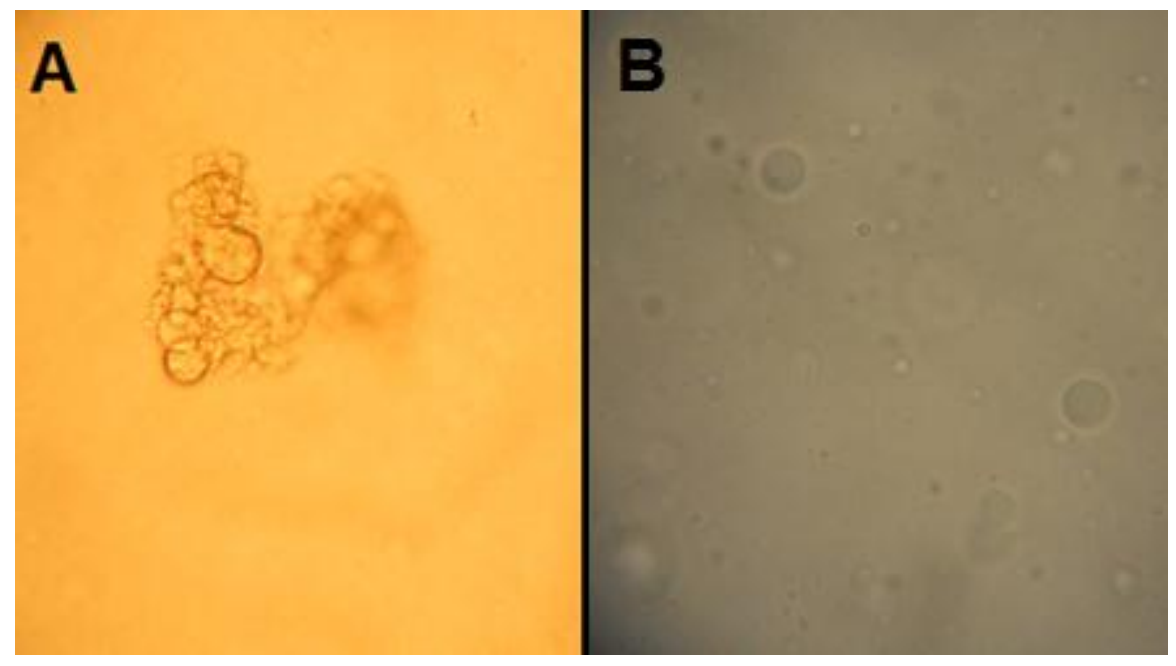

Figure 7. The GUVs formed by the Nanion Vesticle Prep Pro are aggregated (A), when lipids clump together, or (B) "good", single round GUVS. 
In the Nanion Port-a-Patch system (Figure 8), $5.0 \mu \mathrm{L}$ of electrolyte is placed on either side of the micropore-containing glass chip. The glass micropores were characterized with an IV curve (Figure 9). The IV curves of blank micropores were linear between $\pm 50 \mathrm{mV}$, and showed a typical conductance of about 200-300 nS, which matches the typical reported micropore resistance, for $0.1 \mathrm{M} \mathrm{KCl}$ and $10 \mathrm{mM}$ HEPES and $1800-2000 \mathrm{nS}$ for $1.0 \mathrm{M} \mathrm{KCl}$ and $10 \mathrm{mM}$ HEPES. The reduced voltage range here, compared to the smaller nanopores, is to avoid saturating the patch clamp amplifier. ${ }^{69}$ For lipid bilayer formation, $5.0 \mu \mathrm{L}$ of the GUV was added to one side of the chip and a pressure from -10 to $-25 \mathrm{mB}$ was applied.

Seven trials at $\mathrm{pH}$ 7.0, 1.0 M KCl, and $10 \mathrm{mM}$ HEPES were performed, where only one trial created a bilayer that lasted a few hours with a $+100 \mathrm{mV}$ applied voltage. A good, stable bilayer will only burst at voltages of $450-550 \mathrm{mV} .^{70}$ The other trials were unsuccessful. A bilayer will reduce the current passing through to about $0 \mathrm{pA}$, which was either indicated with a current trace showing $0 \mathrm{pA}$ or with an IV curve showing no conductance (Figure 10). 


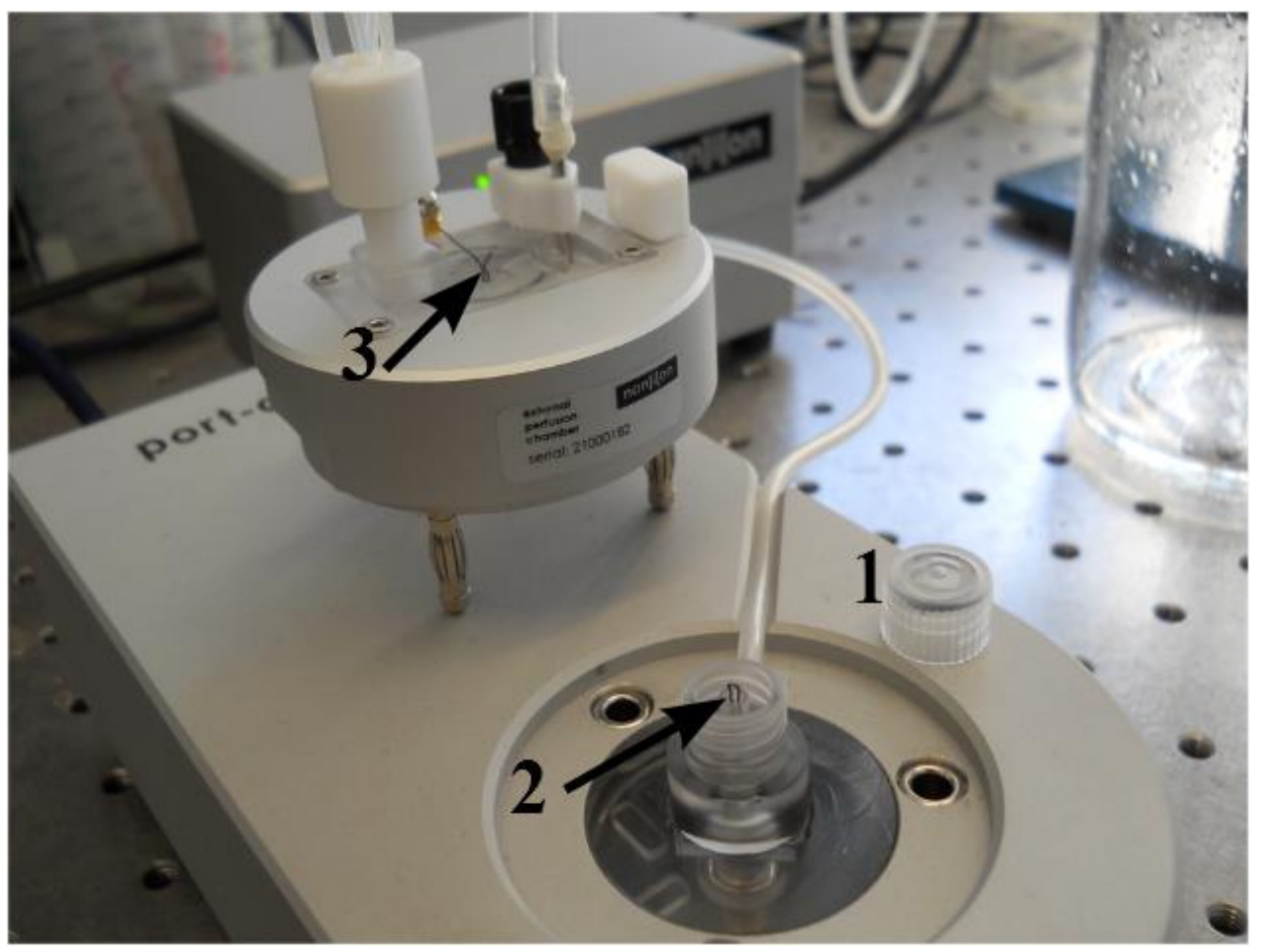

Figure 8. The Nanion Port-a-Patch system for the systematic formation of lipid bilayers. The chip (1) with a 3-5 MS resistance micropore in the center, where electrolyte is placed, is screwed on so that the electrodes (2 and 3) will be touching solution on either side of the micropore. This system will apply a cross-pore pressure to help form the bilayer across the micropore. 


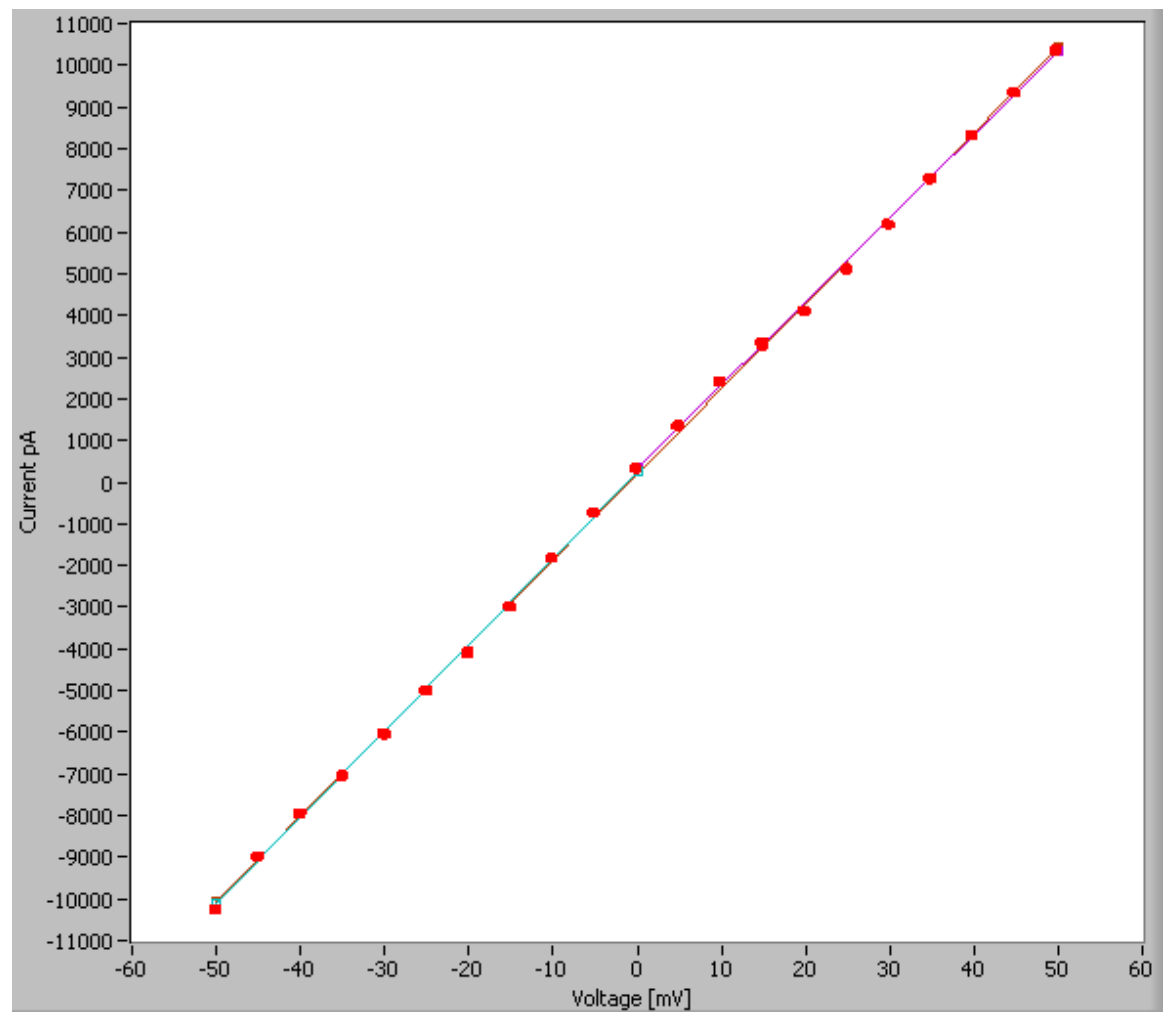

Figure 9. An IV-curve of the glass micropore with a $\mathrm{pH}$ gradient from 7 on the top and 6 on the bottom in an aqueous solution of $0.1 \mathrm{M} \mathrm{KCl}$, and $10 \mathrm{mM}$ HEPES. The conductance, from the slope, is $205.04 \mathrm{nS}$. 


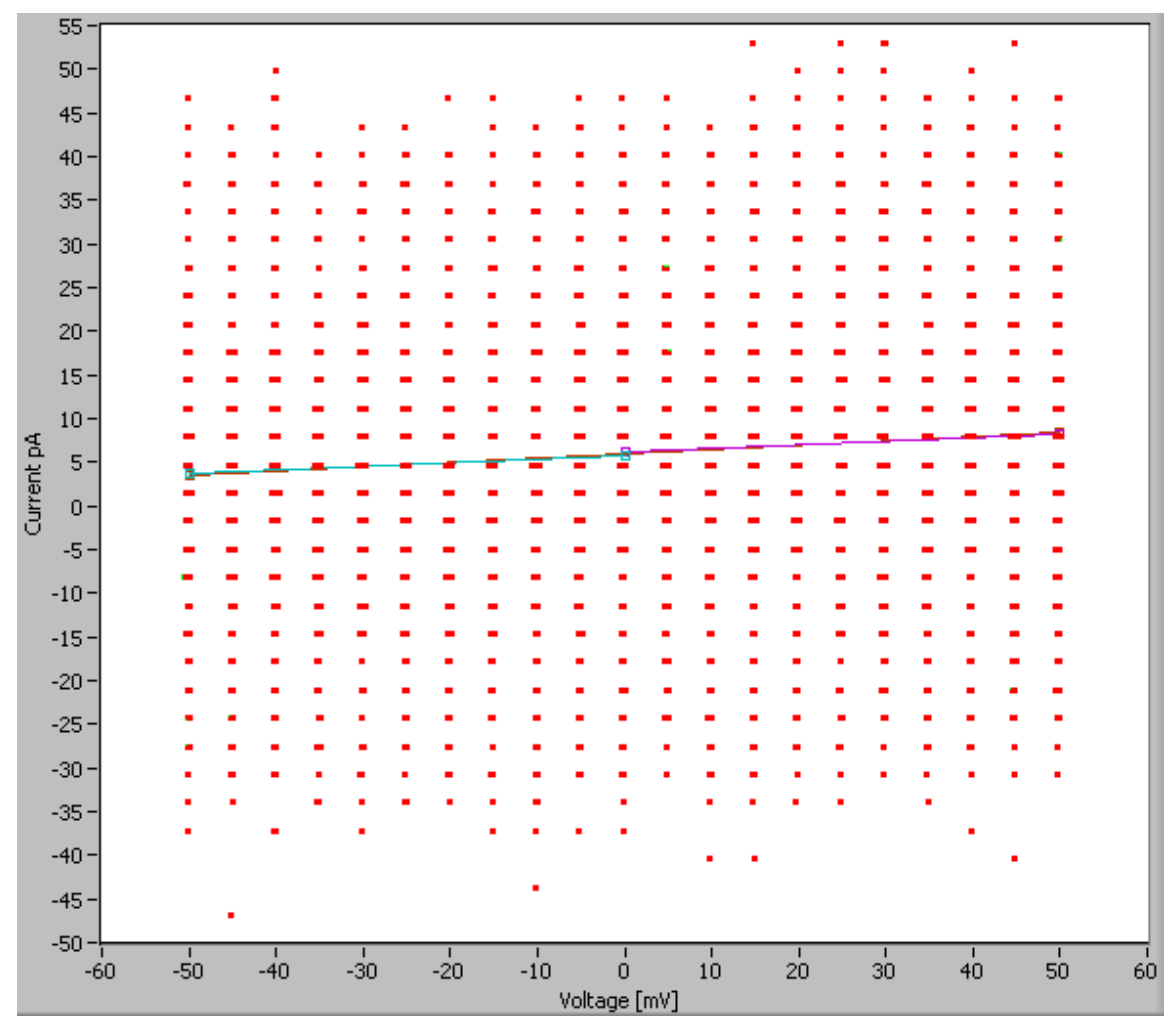

Figure 10. An IV-curve of the glass micropore with a $p H$ gradient from 7 on the top and 6 on the bottom in an aqueous solution of $0.1 \mathrm{M} \mathrm{KCl}$, and $10 \mathrm{mM} \mathrm{HEPES} \mathrm{after} \mathrm{the}$ formation of a bilayer displays an almost flat line, very close to $0 \mathrm{pA}$ at all applied voltages, indicating a bilayer. The red dots are the standard deviation. 
The bilayer formation process needed optimization. A few changes were made to try to make a more stable bilayer in the micropore. The first was the electrolyte concentration; it was decreased from $1.0 \mathrm{M} \mathrm{KCl}$ to $0.1 \mathrm{M} \mathrm{KCl}$, because the higher salt concentration might have been interfering with the stability of the GUVs. The second change was to create a $\mathrm{pH}$ gradient from one side of the micropore to the other, where the $\mathrm{pH}$ on one side of the chip would be $\mathrm{pH} 7.0$ and on the other side it would be $\mathrm{pH}$ 6.0 , because this method was previously shown to stabilize the bilayer on the chip. ${ }^{71}$ Of the 17 trials performed at $0.1 \mathrm{M} \mathrm{KCl}$ with a $\mathrm{pH}$ gradient, 6 formed bilayers that lasted at least 5 minutes, with the longest lasting about 20 minutes under an applied voltage of $+100 \mathrm{mV}$. If the bilayer did form, the side with $\mathrm{pH} 6.0$ would be exchanged to $\mathrm{pH} 7.0$ after about 5-10 minutes, so as to run experiments with symmetrical $\mathrm{pH}$ on both sides. However, these bilayers were still not stable, and broke during perfusion. Of the six bilayers formed, four broke before perfusion did take place and one broke when perfused.

One trial did remain stable for about 30 minutes after formation, and $\alpha$ hemolysin-containing solution was injected to form pores. The $\alpha$-hemolysin solution was injected into solution on top of the micropore so that the final concentration would be $5.0 \times 10^{-4} \mathrm{mg} / \mathrm{mL}^{72}$ To prepared the $\alpha$-hemolysin solution, $1.0 \mathrm{~mL}$ of 18 $\mathrm{M} \Omega . \mathrm{cm}$ deionized water was mixed with $1 \mathrm{mg}$ of powder $\alpha$-hemolysin to give a 1.0 $\mathrm{mg} / \mathrm{mL}$ stock solution of $\alpha$-hemolysin. Then this stock solution was diluted to make a concentration of $1.5 \times 10^{-3} \mathrm{mg} / \mathrm{mL}$.

The incorporation of $\alpha$-hemolysin into the bilayer was initiated by placing 5.0 $\mu \mathrm{L}$ of the $1.5 \times 10^{-3} \mathrm{mg} / \mathrm{mL}$ solution on one side of the micropore. If $\alpha$-hemolysin 
incorporated into the bilayer, it would be indicated by a characteristic increase in the measured current. However, this did not happen for this particular trial, so it may be that a multilayer formed. A multilayer is also evidenced by how the current remained stable after electroporation and applied pressure up to $-200 \mathrm{mB}$ was attempted - that is, how both of these perturbations failed to rupture a multilayer with greater mechanical stability than a bilayer. It is clear from all these trials that further optimization will need to be done for the formation of a stable lipid bilayer in the micropore.

The goal of using the Nanion system is to form a stable lipid bilayer with $\alpha$ hemolysin nanopores. It will be possible to characterize DNA with these nanopores. While the Nanion will ease the bilayer formation process, there is still some configuration that must be done to be able to create reproducible and stable bilayers.

${ }^{50}$ Wanunu, M.; Meller, A. Chemically Modified Solid-State Nanopores. Nanoletters. 2007, 7, 1580-1585.

${ }^{51}$ Miles, B.; Ivanov, A.; Wilson, K.; Dogan, F.; Japrung, D.; Edel, J. Single Molecule Sensing with Solid-State Nanopores: Novel Materials, Methods, and Applications. Chemical Society Reviews. 2013, 42, 15-28.

${ }^{52}$ Lu, H.; Campbell, C.; Castner, D. Attachment of Functionalized Poly(ethylene glycol) Films to Gold Surfaces. Langmuir. 2000, 16, 1711-1718.

$53 \mathrm{Yu}$, S.; Lee, S.; Kang, M.; Martin, C. Size-Based Protein Separations in Poly(ethylene glycol)-Derivatized Gold Nanotubule Membranes. Nanoletters. 2001, 1, 495-498. 
${ }^{54}$ Wei, R.; Pedone, D.; Zurner, A.; Doblinger, M.; Rant, U. Fabrication of Metallized Nanopores in Silicon Nitride Membranes for Single-Molecule Sensing. Small. 2010, 6, 1406-1414,

55 Thermo Scientific. NeutrAvidin Protein and Conjugates. http://www.piercenet.com/browse.cfm?fldID=01030702 (accessed Jan. 30, 2013).

${ }^{56}$ M. Wanunu, personal communication (2012).

${ }^{57}$ Yusko, E.; Johnson, J., Majd, S.; Prangkio, P.; Rollings, R.; Li, J.; Yang, J.; Mayer, M. Controlling Protein Translocation Through Nanopores with Bio-Inspired Fluid Walls. Nature Nanotechnology. 2011, 6, 253-260.

${ }^{58}$ Goertz, M.; Goyal, N.; Montano, G.; Bunker, B. Lipid Bilater Reorganization under Extreme pH Conditions. Langmuir. 2011, 27, 5481-5491.

${ }^{59}$ Avanti Polar Lipids. The Mini-Extruder, Instruction Manual. (Obtained Apr. 20, 2011).

${ }^{60}$ Nanion. Port-a-Patch. http://nanion.de/products/port-a-patch.html (accessed Mar. 14, 2013).

${ }^{61}$ Nanion. Vesticle Prep Pro. http://nanion.de/products/vesicle-prep-pro.html (accessed Mar. 14, 2013).

${ }^{62}$ Kasianowicz, J.; Brandin, E.; Branton, D.; Deamer, D. Characterization of Individual Polynucleotide Molecules Using a Membrane Channel. PNAS. 1996, 93, 13770-13773.

${ }^{63}$ Ashkenasy, N.; Sanchez-Quesada, J.; Bayley, H.; Ghadiri, M.R. Recognizing a Single Base in an Individual DNA Strand: A Step Toward DNA Sequencing in Nanopores. Angewandte Chemie. 2005, 44, 1401-1404. 
${ }^{64}$ Tropini, C.; Marziali, A. Multi-Nanopore Force Spectroscopy for DNA Analysis. Biophysical Journal. 2007, 92, 1632-1637.

${ }^{65}$ Cockroft, S.; Chu, J.; Amorin, M.; Ghadiri, M.R. A Single-Molecule Nanopore Device Detects DNA Polymerase Activity with Single-Nucleotide Resolution. Journal of the American Chemical Society. 2008, 130, 818-820.

${ }^{66}$ Mitchell, N.; Howorka, S. Chemical Tags Facilitate the Sensing of Individual DNA Strands with Nanopores. Angewandte Chemie. 2008, 47, 5565-5568.

${ }^{67}$ van Uitert, I.; Le Gac, S.; van den Berg, A. The Influence of the Different Membrane Components on the Electrical Stability of Bilayer Lipid Membranes. Biochimica et Biophysica Acta. 2010, 1798, 21-31.

${ }^{68}$ Nanion Technologies. Vesticle Prep Pro: Smart Tools for Ion Channel Research, Instruction Manual. (Obtained Nov. 26, 2012).

${ }^{69}$ Nanion Technologies. Smart Tools for Ion Channel Research, Instruction Manual. (Obtained Nov. 26, 2012).

${ }^{70}$ Jetha, N.; Wiggin, M.; Marziali, A. Forming an $\alpha$-Hemolysin Nanopore for SingleMolecule Analysis. In Micro and Nano Technologies in Bioanalysis: Methods in Molecular Biology; Lee, J.W. and Foote, R.S., Ed.; Humana Press: New York, 2009; Vol. 544; p113.

${ }^{71}$ David Guinot from Nanion, personal communication (Dec. 13, 2012).

${ }^{72}$ Akeson, M.; Branton, D.; Kasianowicz, J.; Brandin, E.; Deamer, D. Microsecond Time-Scale Discrimination Among Polycytidylic Acid, Polyadenylic Acid, and Polyuridylic Acid as Homopolymers or as Segments Within Single RNA Molecules. Biophysical Journal. 1999, 77, 3227-3233. 


\section{CHAPTER 4}

\section{MOLECULAR SURFACE FUNCTIONALIZATION TO ENHANCE NFS}

\section{PERFORMANCE}

\subsection{The Promise of Solving DNA Sticking with a Cationic Surfactant}

The sticking of $\lambda$-DNA to the silicon nitride surface has been a major problem in the majority of the work presented in this thesis and within the nanopore research community, because for the single molecule detector to work, the molecule being detected needs to translocate through the pore, or to interact with it only transiently. If the molecule sticks, it will, firstly, interfere with other molecules from entering the pore, and secondly, the pore might become permanently clogged so that a new pore will be needed. While a number of possible cleaning techniques have been presented in chapter 2 , it would be ideal to have a nanopore detection scheme that requires little maintenance while providing high functionality. In chapter 3, different surface functionalization techniques on the silicon nitride nanopore were introduced, and from those results it can be understood that a lot of fine-tuning must be done to create the vision of a robust, easy to use, rapid, and inexpensive tool. In previous chapters, we have explored controlling the molecule-surface interaction through functionalizing the surface of the nanopore. In this chapter, instead of functionalizing the surface of the nanopore for control of the molecule-surface interaction, functionalizing the surface of the analyte molecule, in this case, DNA, will be done. Not only does this approach have the potential to control unwanted molecule-nanopore interactions, it also allows 
for control over the physicochemical properties, such as charge, of the molecule being sensed. In addition to modifying the surface chemistry, self-assembly approaches will allow us to tune the effective size of the DNA molecule. It is important to note that both molecular size and surface charge are key parameters in determining the measured signal in nanopore single-molecule sensing. In addition, since the NFS method manipulates molecules through their effective charge, using self-assembly of cationic surfactants on the negatively-charge DNA polymer to tune the net macromolecule charge, allows for molecular-level control of the technique. The detection of simple surfactant-driven self-assembled complexes here are also a proxy for the study of more sophisticated molecular assembly approaches, for example, the detection of site-specific binding of proteins to DNA or the measurement of whether or not a drug molecule has bound to a protein surface. In addition to these fundamental aims, this molecular surface functionalization approach serves an extremely practical purpose. Since DNA is the molecule sticking to the surface, it might be possible to reduce the charges on the DNA molecule in order to reduce the interaction between the pore surface and the molecule.

The strong electrostatic interaction between the cationic surfactant cetyltrimethylammonium bromide (CTAB, Sigma \#H9151) and DNA has long been exploited to selectively precipitate DNA during DNA extractions. ${ }^{73,74,75}$ The interaction received greater scrutiny in the context of DNA-based molecular electronics, in which literature reports revealed the well-ordered molecular structure of this interaction. Previous literature on the molecular-level fabrication of DNA has shown that it is possible to create a film using DNA, which has a negatively charged 
phosphate backbone, complexed with a positively charged cationic surfactant. The ready formation of films of surfactant:DNA complexes allowed for x-ray diffractionbased studies that revealed a highly ordered structure of surfactant brushes on a DNA polymer. $^{74}$ Thus, in addition to charge neutralization of the phosphate backbone, the CTAB may also allow for a rigid structure of DNA (Figure 1). The rigid structure will alter how the complex enters into the pore, compared to the more flexible DNA polymer. As stated in Section 2.4, the flexible DNA polymer can bend and fold in many ways, allowing a variety of conformations of DNA to enter the pore, and each conformation has a different characteristic translocation event through a pore. ${ }^{76}$ By making the DNA rigid, it will decrease the variety of conformations. The CTAB:DNA complex will also increase the radius of the structure, as the length of CTAB is about $2.2 \mathrm{~nm}^{77}$ Twice this length will add on to the original $2 \mathrm{~nm}$ diameter of double stranded DNA. ${ }^{73}$ Being able to the change the size of the molecule will possibly allow for a larger range of more easily fabricated pore sizes to be used. 


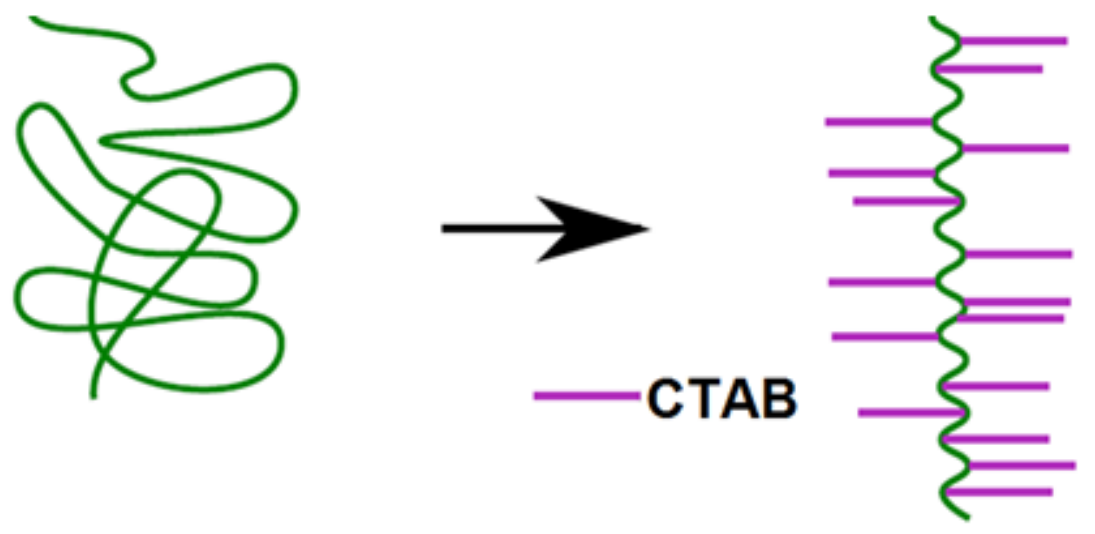

Figure 1. Cetyltrimethylammonium bromide (CTAB) may allow for charge neutralization on the DNA molecule as well as creating a more rigid structure affecting how the DNA molecule enters into the pore. Before DNA was a very flexible polymer, as shown on the left, but, as modeled on the right, the DNA becomes a more rigid structure once the CTAB is attached. Also, as the model shows, it is evident that the CTAB will also increase the diameter of the DNA molecule (diameter of DNA is about $2 \mathrm{~nm}^{73}$ and of CTAB is $2.2 \mathrm{~nm}^{77}$ ), allowing for size modification of a molecule. Not drawn to scale. 


\subsection{Preparation of the CTAB:DNA Complexes}

The CTAB:DNA complexes were prepared in various ratios with numbers of $\mathrm{CTAB}$ molecules to the number of DNA bases using the following procedure. First, the length of the DNA was expressed in terms of the number of nucleotides for singlestranded DNA (ssDNA), or nucleotide pairs for double-stranded DNA (dsDNA), $L_{N}$. Second, the desired number of CTAB molecules per DNA molecule was specified in terms of the total number of bases (ssDNA) or base pairs (dsDNA): a target 1:1 CTAB:DNA complex had 1 CTAB molecule for every base (ssDNA), in which $0 \%$ of the phosphate backbone would be free of CTAB, or base pair (dsDNA), in which $50 \%$ of the phosphates would be free. The necessary solution concentration of CTAB was calculated assuming quantitative self-assembly of the CTAB on the charged DNA phosphate backbone. Table 1 gives the concentrations used for making CTAB: $\lambda$-DNA base pairs ratios. The composition of the CTAB: $\lambda$-DNA solution was $10 \mu \mathrm{L}$ of stock

$500 \frac{m g}{m L} \lambda$-DNA; $10 \mu \mathrm{L}$ of a $\mathrm{pH} 7$ aqueous solution of $1 \mathrm{M} \mathrm{KCl}, 10 \mathrm{mM}$ HEPES, and the appropriate concentration of $\mathrm{CTAB}$ from Table $1 ; 70 \mu \mathrm{L}$ of a $\mathrm{pH} 7$ aqueous solution of $1 \mathrm{M} \mathrm{KCl}$ and $10 \mathrm{mM}$ HEPES; and $10 \mu \mathrm{L}$ of a $\mathrm{pH} 7$ aqueous solution of $1.11 \mathrm{KCl}$ and $10 \mathrm{mM}$ HEPES to give a final $100 \mu \mathrm{L}$ aliquot solution. 


\begin{tabular}{|l|l|}
\hline Ratio (\# CTAB: \# base pairs) & {$[$ CTAB] $(\mathrm{M})$} \\
\hline $1: 50$ & $1.65 \times 10^{-5}$ \\
\hline $1: 100$ & $8.23 \times 10^{-6}$ \\
\hline $1: 200$ & $4.12 \times 10^{-6}$ \\
\hline $1: 500$ & $1.65 \times 10^{-6}$ \\
\hline $1: 1000$ & $8.23 \times 10^{-7}$ \\
\hline
\end{tabular}

Table 1. A table of the concentrations of CTAB used to make each ratio of number of CTAB molecules to the number of base pairs in $\lambda$-DNA for a $\lambda$-DNA concentration of $1.7 n M$. 


\subsection{CTAB: $\lambda$-DNA Experimental}

$30 \mu \mathrm{L}$ of the CTAB: $\lambda$-DNA complex with the ratio of $1 \mathrm{CTAB}$ to every 1000 base pairs was injected into one side of the electrochemical cell with an $11 \mathrm{~nm}$ nanopore in a $\mathrm{pH} 7$ aqueous solution of $1 \mathrm{M} \mathrm{KCl}$ and $10 \mathrm{mM}$ HEPES, yielding a concentration of $96 \mathrm{pM}$ of $\lambda$-DNA in the $0.5 \mathrm{~mL}$ well. A voltage of $-200 \mathrm{mV}$ was applied to drive the $\lambda$-DNA complex through the pore, and no characteristic current blockage events to indicate that the $\lambda$-DNA translocated were detected, but it appears that clogging occurred because the current decreased for an extended period of time, unlike a regular blockage event where the current decreases only for a finite amount of time. The small number of CTABs per DNA polymer may have been insufficient to prevent appreciable electrostatic interaction between the DNA and nanopore surface. Other ratios were tested, namely $1 \mathrm{CTAB}$ for every $500,200,100$, and 50 base pairs. Testing of these latter ratios (1:500, 1:200, 1:100, and 1:50) used a $19 \mathrm{~nm}$ nanopore in an aqueous solution buffered to $\mathrm{pH} 7$ with $10 \mathrm{mM}$ HEPES containing $1 \mathrm{M} \mathrm{KCl}$. For these latter ratios, $100 \mu \mathrm{L}$ of CTAB: $\lambda$-DNA complex was injected into the pore, yielding a concentration of $282 \mathrm{pM}$ of $\lambda$-DNA in the $0.5 \mathrm{~mL}$ well. In the increased pore size, the $6 \mathrm{~nm}$ diameter of the CTAB: $\lambda$-DNA complex would be about a third of the pore size. This would be a noticeable current blockage in the current trace based on equation 2.5, repeated below, but, in fact, there were no translocation events detected.

$$
I_{\text {block }}=I_{\text {open }}\left[1-\left(\frac{r_{\text {analyte }}}{r_{\text {pore }}}\right)^{2}\right](\text { Eqn. 2.5) }
$$

Instead, in one trial in the $19 \mathrm{~nm}$ nanopore with $282 \mathrm{pM}$ of $\lambda$-DNA with 1 CTAB for every 500 base pairs (1:500) in a $\mathrm{pH} 7$ aqueous solution of $1 \mathrm{M} \mathrm{KCl}$ and $10 \mathrm{mM}$ 
HEPES, the current only blocked about a third to a half of the expected blockage for an extended period of time, never unblocking, indicating that the pore became clogged. This may be an indication that the 1:500 ratio was not great enough to sufficiently minimize electrostatic interactions between the DNA and the nanopore surface, and that more $\mathrm{CTAB}$ would be needed. It may be that at the higher ratios, the decrease of the molecular charge lowers the applied force on the molecule, so that it is not readily drawn into the pore for translocation; it could also be that the increasing rigidity from the CTAB brush structures also diminishes the likelihood of DNA capture. In the electrostatic sense, the applied force on a molecule depends on factors such as the molecular charge and the applied voltage, such that

$$
F \propto z \times e \times V \quad(E q n .4 .1)
$$

where $\mathrm{F}$ is the applied force, $\mathrm{z} \times \mathrm{e}$ is the effective molecular charge in the pore, where $\mathrm{z}$ is the effective charge on each DNA phosphate group and e is electron charge, and V is the applied voltage. From the equation, a decrease in molecular charge will also decrease the applied force. Therefore, since CTAB decreases the molecular charge on the DNA, a higher applied voltage is need to be equivalent to the applied force at lower voltage without CTAB on the DNA.

\subsection{Probe Escape}

Since there were no translocation events that were detected and extended blockages indicating clogging at the ratios used for the number of CTAB to $\lambda$-DNA base pairs suggested that the ratio of number of $\mathrm{CTAB}$ molecules to base pairs needed more fine-tuning to determine the perfect ratio to prevent the molecule from sticking 
to the nanopore surface. Another problem could be that since $\lambda$-DNA has so many bases, the CTAB molecules might not be as evenly spaced as desired and there could be large gaps between clusters of CTAB molecules. These large gaps would leave bare DNA that could then stick to the nanopore surface. In addition, a stated 1:1 ratio of CTAB to lambda DNA left $50 \%$ of phosphates without charge neutralization. In response to this, the shorter 94 nucleotide probe DNA construct was used instead (see section 3.1.2 for probe DNA construct description and preparation, Figure 2), because instead of large gaps of perhaps hundreds of nucleotides in the case of non-random CTAB distribution on the polymer, there would be much smaller gaps, thereby lowering the chance of sticking. Also, the probe DNA construct is used in NFS, which is ultimately the goal of this research: to perfect NFS in solid-state nanopores to a reliable single molecule sensing technique. Using the probe DNA construct to analyze the system is a preliminary step toward this goal. 


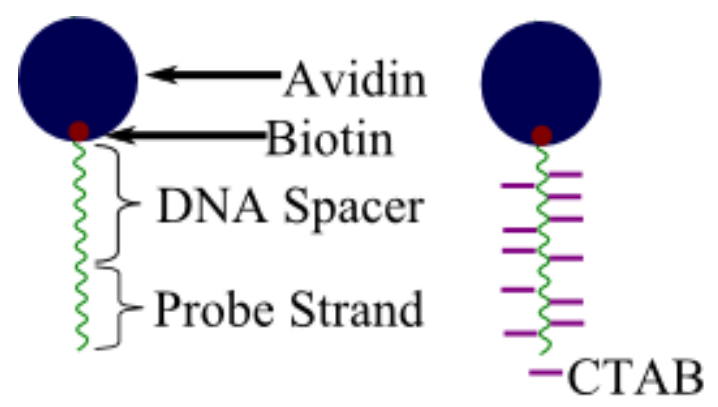

Figure 2. The probe-DNA construct on the left, as shown in Chapter 1 (Section 3.1.2 for details about sequence and preparation). An avidin molecule is linked to a biotinylated-DNA strand, which has a DNA spacer to prevent misfolding and contains a probe sequence at the end which is complementary to the analyte DNA sequence. On the right, a model of what the probe-DNA contract with CTAB attached might look like. Not drawn to scale. 
To begin, a mixture of $10 \mathrm{CTAB}$ molecules to 94 bases was used in an experiment called probe escape. Literature reports indicated that probe escape had been previously demonstrated on bare, fully charged, DNA when using both biological and solid-state nanopores. ${ }^{78,79}$ In probe escape (Figure 3), a voltage, known as the "capture voltage," is applied to drive the probe DNA construct into the pore. Once the probe is in the pore, the voltage sign is unchanged, but its magnitude is decreased, known as the "hold voltage," and it is held at that value for 2 seconds or until the probe escapes, a process whereby the probe leaves the pore by escaping against the hold potential and returns to the original side. If the probe did not escape after 2 seconds, the voltage was reversed to try and force the probe back to the original side. 

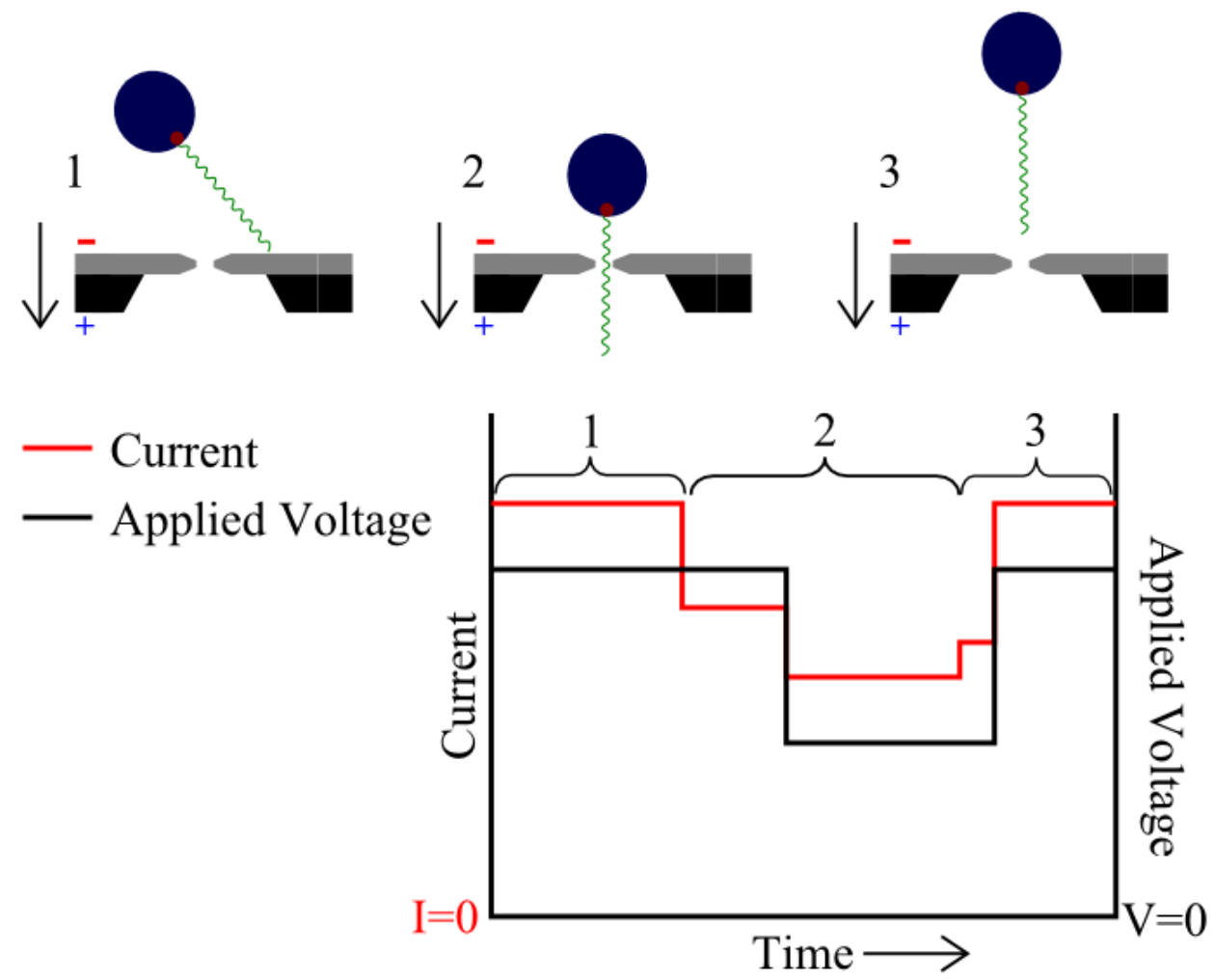

Figure 3. A schematic of probe escape. At 1, the probe is on one side of the pore and the capture voltage is applied to drive it into the pore. The probe molecule is not in the pore, as indicated by the open current. At 2, the probe has entered the pore, as indicated by a decrease in current, and from there the applied voltage is lowered to the hold voltage to allow the probe the escape the pore. At 3, the probe molecule escapes at the hold voltage, as indicated by the increase in current, at which point, the voltage is returned to the original capture voltage in order to capture another probe molecule. 
For the probe escape experiment, the $\mathrm{CTAB} /$ probe DNA construct mixture was injected into the reservoir on one side of a $3 \mathrm{~nm}$ pore to give a concentration of 100 $\mathrm{nM}$ in the well with an aqueous solution at $\mathrm{pH} 7$, containing $1 \mathrm{M} \mathrm{KCl}$, and $10 \mathrm{mM}$ HEPES. At the ratio of 10 CTAB molecules to 94 bases (10:94) with a $-200 \mathrm{mV}$ capture voltage, there were no insertion events. A possible explanation is that -200 $\mathrm{mV}$ was not strong enough to push the CTAB-decorated probe into the pore. As described in the equation 4.1, the applied force will increase with a higher applied voltage. Therefore, a higher voltage of $-400 \mathrm{mV}$ was applied to the side of the well containing the CTAB:DNA complex in an attempt to detect the molecule. At this voltage with the same concentrations, there were no insertion events of the probe DNA molecule. Instead, the current trace indicated that the molecule had become stuck to the outside of the pore. An explanation for the sticking could be that there was not enough CTAB on the probe DNA construct molecule, leaving bare DNA exposed to stick to the nanopore surface, yet still preventing complete and reversible insertion of the complex into the nanopore. To remedy this sticking, the number of CTAB molecules per molecule was doubled to 20 molecules for a new ratio of 20 CTAB molecules to 94 bases (20:94). For this new ratio, capture voltage was set to $400 \mathrm{mV}$ and the hold voltage was set to $-300 \mathrm{mV}$ for escape. However, as with the lower ratio of CTAB:DNA, there were no insertion events of the probe DNA construct through the nanopore. A probable explanation was that the force applied to drive the complex into the pore for detection was insufficient. As shown in equation 4.1, the applied force will decrease with a decrease in molecular charge, and each CTAB molecules neutralizes the charge of a phosphate group on the DNA. By increasing the 
CTAB:DNA ratio, more negative charges on the phosphate backbone were neutralized, thereby decreasing the charge and decreasing the applied force for a given applied voltage. A greater driving force was needed, therefore, so the capture voltages were then increased in magnitude to $-500 \mathrm{mV}$ or $-600 \mathrm{mV}$ and the hold voltages were set to $-500,-400$, or $-300 \mathrm{mV}$. The hold voltage magnitudes for the CTAB:DNA constructs exceeded the typical hold voltages for the published probe escape results for bare DNA probe molecules. However, those literature results were explained by expressing the applied force as

$$
f(V)=z \times e \times \frac{n}{L} \times V(E q n .4 .2)
$$

where $f(V)$ is the applied force in Newtons, $z$ is the formal charge on each base inside the nanopore where $\mathrm{e}$ is the electron charge, $\mathrm{n}$ is the number of nucleotides in the pore, $\mathrm{L}$ is the length of the pore in meters, so that $\mathrm{n} / \mathrm{L}$ is the inverse of nucleotide spacing (a constant of $0.45 \mathrm{~nm}^{-1}$ ), and $\mathrm{V}$ is the applied voltage. By complexing the anionic phosphate groups with cationic CTAB, the average magnitude of $\mathrm{z}$ is decreased so that if the section of DNA polymer constrained inside the pore is CTAB-coated, a given applied voltage will exert a lower force on that complex than if the DNA were uncoated, or if the partial CTAB coating were not inside the nanopore. It was expected, therefore, that these hold voltages, while higher in magnitude than the literature results for bare DNA, would nevertheless allow probe escape. The time taken for the CTAB:DNA complex to exit the pore, however, was much faster than for the probe escape experiments published in the literature. ${ }^{78,79}$ The timescales were in fact more in keeping with the literature timescales for rupture of the neutravidin-biotin bond $^{80}$ via NFS. It was likely, therefore, that the incomplete coverage of the DNA 
molecule with CTAB, or perhaps voltage-induced stripping or migration of the CTAB molecules, allowed for entrained CTAB:DNA constructs to feel an applied force somewhat comparable to that of bare DNA. Alternatively, a CTAB-coated DNA molecule could possibly be inserted into a nanopore, but come to rest with a bare section in the nanopore, at least some fraction of the time. Based on the pore clearance time suggesting rupture of the biotin-avidin bond instead of probe escape, the experiment was reconfigured to attempt to directly measure this timescale.

\subsection{Neutravidin-Biotin Rupture}

In previous literatureError! Bookmark not defined. the neutravidin-biotin bond rupture was performed using bare DNA in solid-state nanopores and with voltages ranging from 400 to $900 \mathrm{mV}$. These published experiments were challenged by DNA-nanopore sticking, in keeping with the experimental results observed here. For this thesis, the results of the neutravidin-biotin bond rupture using DNA coated with $\mathrm{CTAB}$ were compared to the literature values using DNA free of CTAB. In the rupture experiment (Figure 4), the probe DNA molecules (CTAB-free in the literature reports and CTAB coated here) are on one side of the pore and a voltage is applied to drive one into the pore. Once the probe DNA molecule enters the pore, the current will decrease. Whereas in the probe escape experiments the capture voltage is switched to the hold voltage once the molecule enters into the pore, in the bond rupture experiments, the voltage is unchanged. After some time, the neutravidinbiotin bond will rupture, which will cause the probe molecule and the neutravidin 
molecule to go to separate sides of the pore. The time required for this bond rupture can be used directly to uncover the neutravidin-biotin binding energy.

The ratio for the neutravidin-biotin bond rupture experiment was $30 \mathrm{CTAB}$ molecules to 94 bases (30:94). Based on concentrations given in the literature,Error! Bookmark not defined. $5 \mu \mathrm{L}$ of the $30 \mathrm{CTAB}$ to one probe DNA strand was injected to one side of the well to give a concentration of about $100 \mathrm{nM}$ in the well. The voltage applied for rupture was $-500 \mathrm{mV}$, and 66 ruptures were captured in one experiment (Figure 5). These 66 rupture times varied from 0.002 to 25 seconds. 


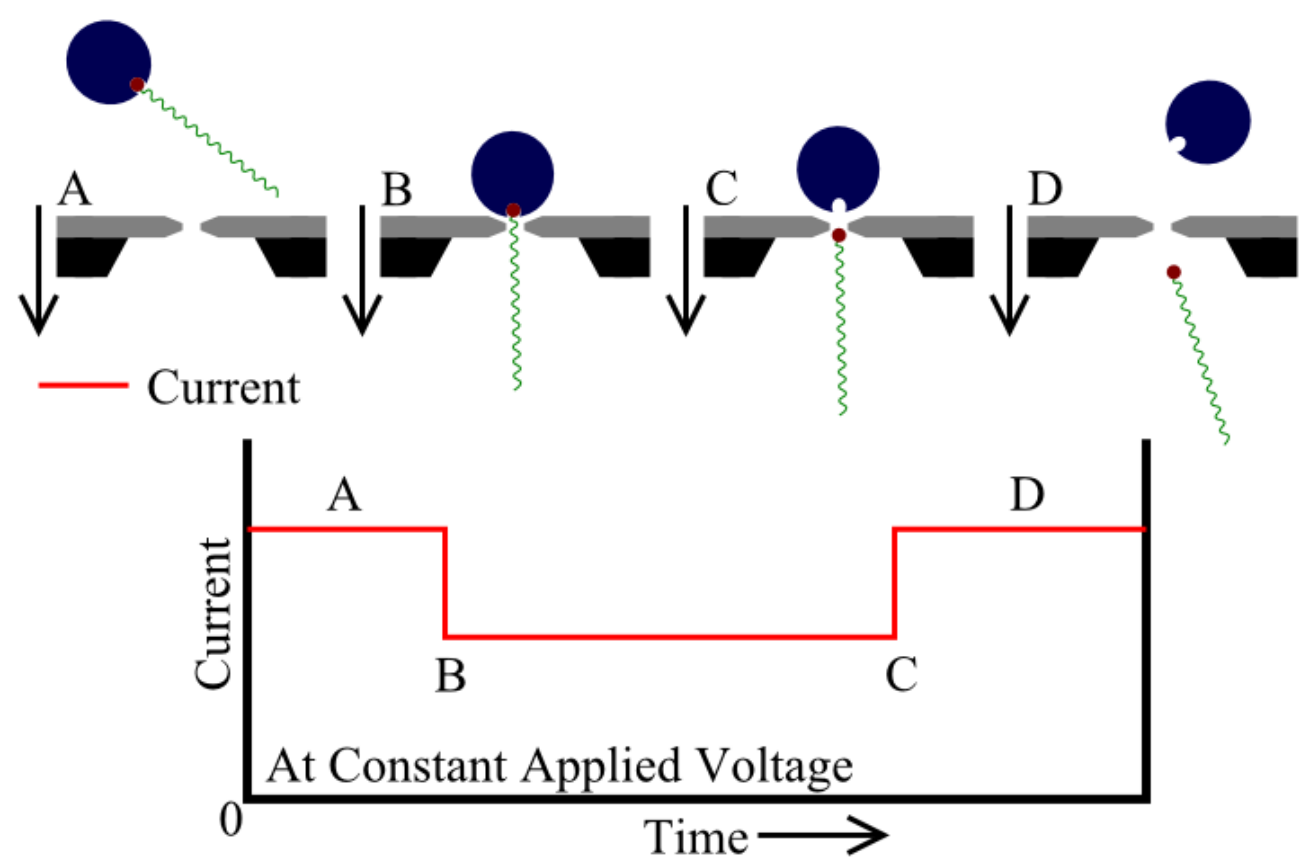

Figure 4. A schematic of neutravidin-biotin bond rupture. At A, the probe DNA molecule, tethered to a neutravidin protein via a biotin linkage, is on one side of the pore and a voltage is applied, which will lead to $B$, where the applied voltage has driven the probe DNA construct into the pore, thus decreasing the current. After a period of time, the applied force will break the neutravidin-biotin bond as shown in C, and this will cause the pore to be clear again, leading to an open current once again at $D$. 


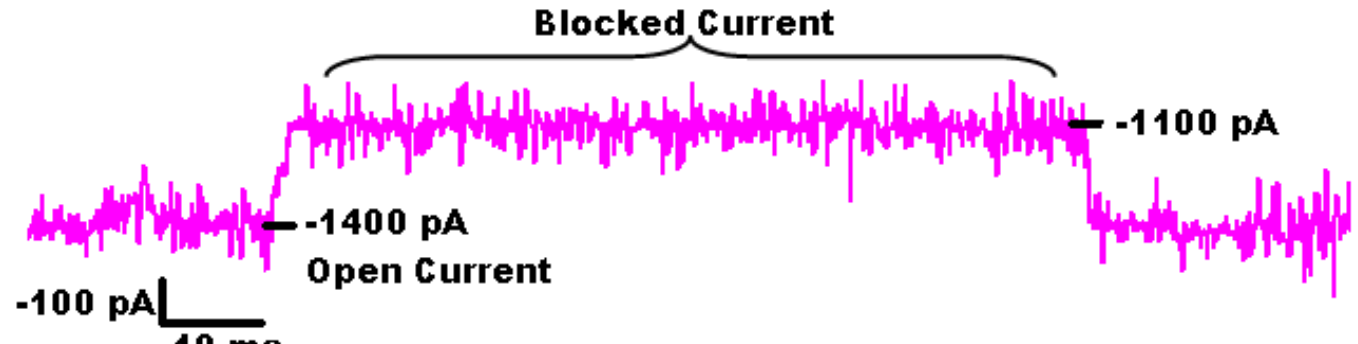

$10 \mathrm{~ms}$

Figure 5. One of the rupture events captured at an applied voltage of $-500 \mathrm{mV}$ with $100 \mathrm{nM}$ probe DNA in an electrochemical cell with a pH 7 aqueous solution of $1 \mathrm{M}$ $\mathrm{KCl}$ and $10 \mathrm{mM} \mathrm{HEPES}$. 
In Figure 6, the distribution of the dissociation times for the data with $\mathrm{CTAB}$ is compared to the values from the literature for uncoated DNA in a $\mathrm{pH} 7$ aqueous solution of $1 \mathrm{M} \mathrm{KCl}$ and $10 \mathrm{mM}$ HEPES. According to the literature,Error! Bookmark not defined. the probability of survival as an exponential function could be described by the following stretched exponential

$$
P_{\text {survival }}(t)=A e^{\left[-\left(\frac{t}{\tau_{0}}\right)\right]^{\alpha}} \quad(\text { Eqn.4.3) }
$$

where $0<\alpha \leq 1, \tau_{0}$ is a parameter with units of seconds, and A accounts for the systematic error in detecting short events. From this probability of survival, the expectation value of the time distribution can be derived as

$$
<\tau>=\tau_{0} \Gamma\left(1+\frac{1}{\alpha}\right) \quad \text { (Eqn.4.4) }
$$

where $\Gamma$ is the gamma function. ${ }^{80}$ This expectation value of time is the the characteristic bond lifetime in seconds. In the literature,Error! Bookmark not defined. for an applied voltage of $500 \mathrm{mV}$ in a $3 \mathrm{~nm}$ pore in a $\mathrm{pH} 7$ aqueous solution of $1 \mathrm{M} \mathrm{KCl}$ and $10 \mathrm{mM}$ HEPES with no CTAB, $<\tau>$ was reported as $1.78 \mathrm{~s}$. At these same conditions with cationic $\mathrm{CTAB},<\tau>$ was reported as $3.41 \mathrm{~s}$, which is twice that without CTAB. The results are not surprising, because it is consistent with the equation 4.2, above, in which the applied force at a given voltage is reduced when the charge on the molecule is reduced. This reduction in applied force lengthens the time required for bond rupture, a trend consistent with the data shown here. By lowering the net charge on the DNA with cationic CTAB, the applied force should also be lowered, and thus, lengthening the bond lifetime under force. This is consistent with the literature,Error! Bookmark not defined. as when a lower voltage was applied the bond lifetime was longer. 


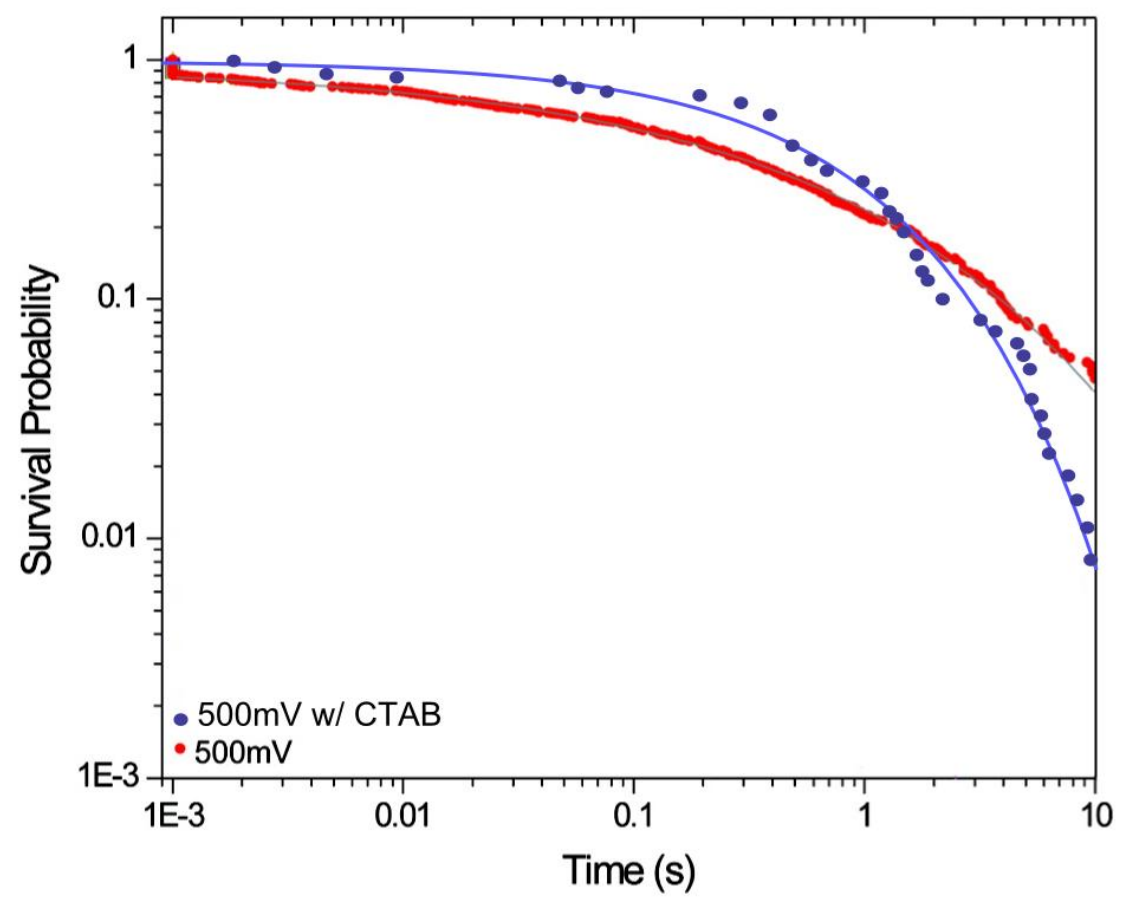

Figure 6. Distribution of the dissociation times at $500 \mathrm{mV}$ for probe DNA molecules with $C T A B$ attached with the ratio of $30 C T A B$ to 94 bases at a concentration in the nanopore well of $100 \mathrm{nM}$ (Blue) compared to the values from the literature ${ }^{80}$ without CTAB (red) in a pH 7 aqueous solution of $1 \mathrm{M} \mathrm{KCl}$ and $10 \mathrm{mM}$ HEPES. 
${ }^{73}$ Okahata, Y.; Tanaka, K. Oriented Thin Films of a DNA-Lipid Complex. Thin Solid Films. 1996, 284-285, 6-8.

${ }^{74}$ Yang, C.Y.; Yang, W.J.; Moses, D.; Morse, D.; Heeger, A.J. DNA Alignment and Characterization. 2003, 137, 1459-1460.

${ }^{75}$ Spink, C.; Chaires, J. Thermodynamics of the Binding of a Cationic Lipid to DNA. Journal of the American Chemical Society. 1997, 119, 10920-10928.

${ }^{76}$ Chen, P.; Gu, J.; Brandin, E.; Kim, Y.; Wang, Q.; Branton, D. Probing Single DNA Molecule Transport Using Fabricated Nanopores. Nanoletters. 2004, 4, 2293-2298.

77 Mohanty, P.; Lee, J.; Glover, K.; Landskron, K. Discoid Bicelles as Efficient Templates for Pillared Lamellar Periodic Mesoporous Silicas at $\mathrm{pH} 7$ and Ultrafast Reaction Times. Nanoscale Research Letters. 2011, 6, 61-65.

${ }^{78}$ Tabard-Cossa, V.; Trivedi, D.; Wiggin, M.; Jetha, N.; Marziali, A. Noise Analysis and Reduction in Solid-State Nanopores. Nanotechnology. 2007, 18, 305505.

${ }^{79}$ Nakane, J.; Wiggin, M.; Marziali, A. A Nanosensor for Transmembrane Capture and Idenification of Single Nucleic Acid Molecules. Biophysical Journal. 2004, 87, $615-621$.

${ }^{80}$ Tabard-Cossa, V.; Wiggin, M.; Trivedi, D.; Jetha, N.; Dwyer, J.; Marziali, A. Single-Molecule Bonds Characterized by Solid-State Nanopore Force Spectroscopy. ACS Nano. 2009, 3, 3009-3014. 


\section{CHAPTER 5}

\section{CONCLUSION}

In this thesis work, different methods for surface functionalization were tried to control the interaction between solution-phase molecules and silicon nitride nanopore surfaces, advances necessary to deliver the full potential of nanopores as robust, lowcost tools for single-molecule sensing. Solid-state nanopores can be used in a technique called nanopore force spectroscopy (NFS) to probe the energy landscape between molecules for the possibility of molecular recognition. ${ }^{81,82}$ This technique can eventually allow for a label-free, robust, and easy-to-use single molecular sensor with little maintenance or replacement of parts. The challenges in working with a solid-state nanopore, especially due to its confined size and charged surface, have led to the need for optimized methods to cope with nanopore surface chemistry for the improvement of NFS performance. This thesis work has highlighted some of the technical issues that must be solved.

Research grade nanopores, which are frequently bare silicon nitride in contact with solution, can be used to sense a wide variety of molecules but typically require a great deal of user intervention, such as cleaning, or frequent replacement of the nanopore. A number of methods exist to clean nanopores. Piranha solution is the most historically used approach, but the work in this thesis found that both Nanostrip and oxygen plasma produced very good results with less risk and hazard. The solution based nature of Nanostrip requires extensive washing steps, and this necessitated used 
of a Teflon holder to prevent mechanical damage to the nanopore during cleaning and rinsing. Oxygen plasma also used a holder to secure the nanopore, but the gas-phase nature of the process required much less handling and device cleanup. Plasma cleaning was especially useful for rendering nanopores hydrophilic for mounting in the fluid holder.

While the literature ${ }^{83}$ contains a report of the use of silane chemistry to coat a nanopore with methoxyethoxyundecyltrichlorosilane (1), in practice this method remains incredibly challenging to reproduce and to implement in controllable fashion. The results in this thesis suggest that rather than uniformly coating surface of the pore, 1 likely readily polymerizes in the bulk of the pore, so that while still permeable to small ions, larger analyte molecules could not enter the pore and could not, therefore, be detected.

Use of non-covalent lipid bilayers to coat the nanopore surface was more successful, allowing for detection of DNA, whose slow translocation dynamics were consistent with literature reports for molecular transloation ${ }^{84}$ through such fluid lipid bilayer coated pores. Yet, the reproducibility of bilayer coating of the nanopore was low, motivating the need for improvement to the nanopore setup, such as the ability to apply a pressure differential to deliver greater control over the bilayer coating process. These modifications are currently underway.

The use of a glass micropore allowed lipid bilayer pore interactions to be studied without extreme challenges accompanying typical nanopore experiments. The ability to apply a pressure differential across pores allowed for bilayers to be quickly formed across the pore opening, supporting the addition of pressure differential 
capability in the nanopore experiments. Initial investigations using this micropore platform underscore the complexity of lipid bilayer coating of much smaller pores and show the need to carefully control lipid and electrolyte composition.

Throughout this thesis work a major limitation to achieving the full potential of nanopore methods has been prevalence of unwanted interactions between the charged molecules and charged nanopore surfaces. While this thesis work has provided insight into improved methods for nanopore surface passivation, surface functionalizing a highly constrained nanopore surface remains incredibly challenging. Suppressing unwanted interactions between molecule and pore by decorating the surface of the molecule, which is freely accessible in bulk solution, offers compelling possibilities. While we used non-specific self-assembly approaches, it is possible to imagine using sophisticated molecular recognition techniques to decorate the molecule and, thereby, simultaneously suppressing unwanted interactions and conferring sensing selectivity.

In this thesis work, we used surfactant self-assembly on the DNA backbone to both change net macromolecule charge and its effective cross-section. This tuning of charge allowed us to adjust at the molecular level the interaction between the applied voltage and the DNA complex, an interaction dependent on the net charge of the DNA. By charge neutralizing a fraction of the DNA oligmer's charges we demonstrated through the NFS measurement of the avidin-biotin rupture time that this molecular tuning was indeed effective. Thus, this decoration of the analyte molecule holds promise for improving NFS performance and allows for performance enhancements that can be delivered by tuning the effective analyte surface by using the powerful tools of molecular design. Once the surface chemistry is optimized, NFS 
will be a useful technique for molecular recognition that is low maintenance, robust, easy-to-use, and label-free.

${ }^{81}$ Nakane, J.; Wiggin, M.; Marziali, A. A Nanosensor for Transmembrane Capture and Identification of Single Nucleic Acid Molecules. Biophysical Journal. 2004, 87, 615-621.

${ }^{82}$ Tabard-Cossa, V.; Wiggin, M.; Trivedi, D.; Jetha, N.; Dwyer, J.; Marziali, A. Single-Molecule Bonds Characterized by Solid-State Nanopore Force Spectroscopy. ACS Nano. 2009, 3, 3009-3014.

${ }^{83}$ Wanunu, M.; Meller, A. Chemically Modified Solid-State Nanopores. Nanoletters. 2007, 7, 1580-1585.

${ }^{84}$ Yusko, E.; Johnson, J., Majd, S.; Prangkio, P.; Rollings, R.; Li, J.; Yang, J.; Mayer, M. Controlling Protein Translocation Through Nanopores with Bio-Inspired Fluid Walls. Nature Nanotechnology. 2011, 6, 253-260. 


\section{BIBLIOGRAPHY}

Adkins, J.; Varnum, S.; Auberry, K.; Moore, R.; Angell, N.; Smith, R.; Springer, D.; Pounds, J. Toward a Human Blood Serum Proteome: Analysis by Multidimensional Separation Coupled with Mass Spectrometry. Molecular \& Cellular Proteomics. 2002, 1, 947-955.

Akeson, M.; Branton, D.; Kasianowicz, J.; Brandin, E.; Deamer, D. Microsecond Time-Scale Discrimination Among Polycytidylic Acid, Polyadenylic Acid, and Polyuridylic Acid as Homopolymers or as Segments Within Single RNA Molecules. Biophysical Journal. 1999, 77, 3227-3233.

Ashkenasy, N.; Sanchez-Quesada, J.; Bayley, H.; Ghadiri, M.R. Recognizing a Single Base in an Individual DNA Strand: A Step Toward DNA Sequencing in Nanopores. Angewandte Chemie. 2005, 44, 1401-1404.

Avanti Polar Lipids. The Mini-Extruder, Instruction Manual. (Obtained Apr. 20, 2011).

Bayley, H.; Martin, C. Resistive-Pulse Sensing- From Microbes to Molecules. Chem. Rev. 2000, 100, 2575-2594.

Benner, S.; Chen, R.; Wilson, N.; Abu-Shumays, R.; Hurt, N.; Lieberman, K.; Deamer, D.; Dunbar, W.; Akeson, M. Sequences-Specific Detection of Individual DNA Polymerase Complexes in Real Time Using a Nanopore. Nature Nanotechnology. 2007, 2, 718-724.

Braha, O.; Gu, L.; Zhou, L.; Lu, X.; Cheley, S.; Bayley, H. Simultaneous Stochastic Sensing of Divalent Metal Ions. Nature Biotechnology. 2000, 18, 1005-1007. 
Campbell, V.W.; Jackson, D.A. The Effect of Divalent Cations on the Mode of Action of DNase I: The Initial Reaction Products Produced from Covalently Closed Circular DNA. Journal of Biological Chemistry. 1980, 255, 3726-3735.

Chen, P.; Gu, J.; Brandin, E.; Kim, Y.; Wang, Q.; Branton, D. Probing Single DNA Molecule Transport Using Fabricated Nanopores. Nanoletters. 2004, 4, 2293 2298.

Citartan, M.; Gopinath, S.; Tominaga, J.; Tan, S.; Tang, T. Assays for Aptamer-Based Platforms. Biosensors and Bioelectronics. 2012, 34, 1-11.

Cockroft, S.; Chu, J.; Amorin, M.; Ghadiri, M.R. A Single-Molecule Nanopore Device Detects DNA Polymerase Activity with Single-Nucleotide Resolution. Journal of the American Chemical Society. 2008, 130, 818-820.

Cornelius, T.W.; Apel, P.Yu.; Schiedt, B.; Trautmann, C.; Toimil-Molares, M.E.; Karim, S.; Neumann, R. Investigation of Nanopore Evolution in Ion trackEtched Polycarbonate Membranes. Nuclear Instruments and Methods in Physics Research B. 2007, 265, 553-557.

CRC: Handbook of Chemistry and Physics. Lide, D.R. Ed.; Taylor \& Francis: Boca Raton, 2005-2006; Vol 86.

David Guinot from Nanion, personal communication (Dec. 13, 2012).

Firnkes, M.; Pedone, D.; Knezevic, J.; Doblinger, M.; Rant, U. Electrically Facilitated Translocations of Proteins through Silicon Nitride Nanopores: Conjoint and Competitive Action of Diffusion, Electrophoresis, and Electroosmosis. Nanoletters. 2010, 10, 2162-2167. 
Fologea, D.; Gershow, M.; Ledden, B.; McNabb, D.; Golovchenko, J.; Li, J. Detecting Single Stranded DNA with Solid State Nanopore. Nanoletters. 2005, 5, 19051909.

Frament, C.; Dwyer, J.R. Conductance-Based Determination of Solid-State Nanopore Size and Shape: An Exploration of Performance Limits. Journal of Physical Chemistry C. 2012, 116, 23315-23321.

Georganopoulou, D.; Chang, L.; Nam, J.; Thaxton, C.S.; Mufson, E.J.; Klein, W.L.; Mirkin, C.A. Nanoparticle-Based Detection in Cerebral Spinal Fluid of a Soluble Pathogenic Biomarker for Alzheimer's Disease. PNAS. 2005, 102, 2273-2276.

Goertz, M.; Goyal, N.; Montano, G.; Bunker, B. Lipid Bilater Reorganization under Extreme pH Conditions. Langmuir. 2011, 27, 5481-5491.

Gu, L.; Braha, O.; Conlan, S.; Cheley, S.; Bayley, H. Strochastic Sensing of Organic Analytes by a Pore-Forming Protein Containing a Molecular Adapter. Nature. 1999, 398, 686-690.

Gyurcsanyi, R. Chemically-Modified Nanopores for Sensing. Trends in Analytical Chemistry. 2008, 27, 627-639.

Harris, D. Quantitative Chemical Analysis, $7^{\text {th }}$ ed.; Freeman: New York, 2007.

He, Y.; Tsutsui, M.; Fan, C.; Taniguchi, M.; Kawai, T. Controlling DNA Translocation through Gate Modulation of Nanopore Wall Surface Charges. ACS Nano. 2011, 5, 5509-5518.

Janeway, C.A. Jr.; Travers, P.; Walport, M. Immunobiology: The Immune System in Health and Disease, $5^{\text {th }}$ ed; Garland Science: New York, 2001. 
Jetha, N.; Wiggin, M.; Marziali, A. Forming an $\alpha$-Hemolysin Nanopore for SingleMolecule Analysis. In Micro and Nano Technologies in Bioanalysis: Methods in Molecular Biology; Lee, J.W. and Foote, R.S., Ed.; Humana Press: New York, 2009; Vol. 544; p113.

Kasianowicz, J.; Brandin, E.; Branton, D.; Deamer, D. Characterization of Individual Polynucleotide Molecules Using a Membrane Channel. PNAS. 1996, 93, 13770-13773.

Liebes, Y.; Drozdov, M.; Avital, Y., Kauffmann, Y.; Rapaport, H.; Kaplan, W.; Ashkenasy, N. Reconstructing Solid State Nanopore Shape from Electrical Measurements. Applied Physics Letters. 2010, 97, 223105.

Liu, C.; Qu, Y.; Luo, Y.; Fang, N. Recent Advances in Single-Molecule Detection on Micro- and Nano-Fluidic Devices. Electrophoresis. 2011, 32, 3308-3318.

Lu, H.; Campbell, C.; Castner, D. Attachment of Functionalized Poly(ethylene glycol) Films to Gold Surfaces. Langmuir. 2000, 16, 1711-1718.

M. Wanunu, personal communication (2012).

Ma, L.; Cockroft, S. Biological Nanopores for Single-Molecules Biophysics. ChemBioChem. 2010, 11, 25-34.

Maitra, R.; Kim, J.; Dunbar, W. Recent Advances in Nanopore Sequencing. Electrophoresis. 2012, 33, 3418-3428.

McIntire, T.M.; Smalley, S.R.; Newberg, J.T.; Lea, A.S.; Hemminger, J.C.; FinlaysonPitts, B.J. Substrate Changes Associated with the Chemistry of Self-Assembled Monolayers on Silicon. Langmuir. 2006, 22, 5617-5624. 
Melgar, E.; Goldthwait, D.A. Deoxyribonucleic Acid Nucleases: The Use of a New Method to Observe the Kinetics of Deoxyribonucleic Acid Degradation by Deoxyribonucleases I, Deoxyribonuclease II, and Escherichia Coli Endonuclease I. Journal of Biological Chemistry. 1968, 243, 4401-4408.

Miles, B.; Ivanov, A.; Wilson, K.; Dogan, F.; Japrung, D.; Edel, J. Single Molecule Sensing with Solid-State Nanopores: Novel Materials, Methods, and Applications. Chemical Society Reviews. 2013, 42, 15-28.

Mitchell, N.; Howorka, S. Chemical Tags Facilitate the Sensing of Individual DNA Strands with Nanopores. Angewandte Chemie. 2008, 47, 5565-5568.

Mohanty, P.; Lee, J.; Glover, K.; Landskron, K. Discoid Bicelles as Efficient Templates for Pillared Lamellar Periodic Mesoporous Silicas at $\mathrm{pH} 7$ and Ultrafast Reaction Times. Nanoscale Research Letters. 2011, 6, 61-65.

Nakane, J.; Wiggin, M.; Marziali, A. A Nanosensor for Transmembrane Capture and Idenification of Single Nucleic Acid Molecules. Biophysical Journal. 2004, 87, $615-621$.

Nanion Technologies. Smart Tools for Ion Channel Research, Instruction Manual. (Obtained Nov. 26, 2012).

Nanion Technologies. Vesticle Prep Pro: Smart Tools for Ion Channel Research, Instruction Manual. (Obtained Nov. 26, 2012).

Nanion. Port-a-Patch. http://nanion.de/products/port-a-patch.html (accessed Mar. 14, 2013).

Nanion. Vesticle Prep Pro. http://nanion.de/products/vesicle-prep-pro.html (accessed Mar. 14, 2013). 
New England BioLabs Inc. Lambda DNA. https://www.neb.com/products/n3011lambda-dna (accessed Jan. 18, 2013).

Okahata, Y.; Tanaka, K. Oriented Thin Films of a DNA-Lipid Complex. Thin Solid Films. 1996, 284-285, 6-8.

Rosso, M.; Nguyen, A.T.; de Jong, E.; Baggernan, J.; Paulusse, J.M.J.; Giesbers, M.; Fokkink, R.; Norde, W.; Schroen, K.; van Rijn, C.J.M.; Zuilhof, H. ProteinRepellent Silicon-Nitride Surfaces: UV-Induced Formation of Oligoethylene Oxide Monolayers. ACS Applied Materials and Interfaces. 2011, 3, 697-704.

Rotem, D.; Jayasinghe, L.; Salichou, M.; Bayley, H. Protein Detection by Nanopores Equipped with Aptamers. Journal of the American Chemical Society. 2012, $134,2781-2787$.

Schibel, A.; Heider, E.; Harris, J.; White, H. Fluorescence Microscopy of the PressureDependent Structure of Lipid Bilayers Suspended across Conical Nanopores. Journal of the American Chemical Society. 2011, 133, 7810-7815.

Spink, C.; Chaires, J. Thermodynamics of the Binding of a Cationic Lipid to DNA. Journal of the American Chemical Society. 1997, 119, 10920-10928.

Storm, A.J.; Chen, J.H.; Zandbergen, H.W.; Dekker, C. Translocation of DoubleStrand DNA Through a Silicon Oxide Nanopore. Physical Review E. 2005, 71, 051903-051912.

Tabard-Cossa, V.; Trivedi, D.; Wiggin, M.; Jetha, N.; Marziali, A. Noise Analysis and Reduction in Solid-State Nanopores. Nanotechnology. 2007, 18, 305505. 
Tabard-Cossa, V.; Wiggin, M.; Trivedi, D.; Jetha, N.; Dwyer, J.; Marziali, A. SingleMolecule Bonds Characterized by Solid-State Nanopore Force Spectroscopy. ACS Nano. 2009, 3, 3009-3014.

Thermo Scientific. DNase I. http://www.piercenet.com/browse.cfm?fldID=06010485 (accessed Jan. 19, 2013).

Thermo Scientific. NeutrAvidin Protein and Conjugates. http://www.piercenet.com/browse.cfm?fldID=01030702 (accessed Jan. 30, 2013).

Tropini, C.; Marziali, A. Multi-Nanopore Force Spectroscopy for DNA Analysis. Biophysical Journal. 2007, 92, 1632-1637.

van Gelder, W.; Hauser, V.E. The Etching of Silicon Nitride in Phosphoric Acid with Silicon Dioxide as a Mask. Journal of The Electrochemical Society. 1967, 114, $869-872$.

van Uitert, I.; Le Gac, S.; van den Berg, A. The Influence of the Different Membrane Components on the Electrical Stability of Bilayer Lipid Membranes. Biochimica et Biophysica Acta. 2010, 1798, 21-31.

Vlassiouk, I.; Apel, P.; Dmitriev, S.; Healy, K.; Siwy, Z. Versatile Ultrathin Nanoporous Silicon Nitride Membranes. PNAS. 2009, 106, 21039-21044.

Wanunu, M.; Meller, A. Chemically Modified Solid-State Nanopores. Nanoletters. 2007, 7, 1580-1585.

Wei, R.; Pedone, D.; Zurner, A.; Doblinger, M.; Rant, U. Fabrication of Metallized Nanopores in Silicon Nitride Membranes for Single-Molecule Sensing. Small. 2010, 6, 1406-1414, 
Yang, C.Y.; Yang, W.J.; Moses, D.; Morse, D.; Heeger, A.J. DNA Alignment and Characterization. 2003, 137, 1459-1460.

Yang, J.; Ferranti, D.; Stern, L.; Sanford, C.; Huang, J.; Ren, Z.; Qin, L.; Hall, A.R. Rapid and Precise Scanning Helium Ion Microscope Milling of Solid-State Nanopore for Biomolecule Detection. Nanotechnology. 2011, 22, 285310285316.

Yu, S.; Lee, S.; Kang, M.; Martin, C. Size-Based Protein Separations in Poly(ethylene glycol)-Derivatized Gold Nanotubule Membranes. Nanoletters. 2001, 1, 495498.

Yusko, E.; Johnson, J., Majd, S.; Prangkio, P.; Rollings, R.; Li, J.; Yang, J.; Mayer, M. Controlling Protein Translocation Through Nanopores with Bio-Inspired Fluid Walls. Nature Nanotechnology. 2011, 6, 253-260. 